\title{
Identifikation und immunologische Charakterisierung von MHC-Klasse-II- Peptidepitopen in humanen Leukämie- und Lymphom-assoziierten Antigenen
}

\author{
Dissertation \\ zur Erlangung des Doktorgrades \\ der Mathematisch-Naturwissenschaftlichen Fakultäten \\ der Georg-August-Universität zu Göttingen
}

vorgelegt von

Matthias Piesche

aus Bautzen

Mai 2006 
D7

Referent: Prof. Dr. R. Hardeland

Koreferent: Prof. Dr. med. K. von Figura

Tag der mündlichen Prüfung: 


\section{Abstract:}

CD4+ $\mathrm{T}$ cells play important roles in antitumor responses through several different mechanisms. Ultimately, they provide crucial help in the induction and maintenance of CTL responses. Experiments in animal models have demonstrated the importance of antigen-specific CD4+ $T$ cells in the elimination of tumors. Peptide vaccination to elicit antitumor immunity remains an attractive way to treat cancer patients. Because the main effort has been to induce CTL responses, a logical way to enhance the potency of these tumor vaccines is to include CD4+ T cell epitopes for the same tumor antigen. The central goal of the work was to identify MHC class II peptide epitopes in such proteins, which exhibit a tumor-associated expression and which were already well-known target antigens of cytotoxic T-cell reactions. In this work, proteinase 3 (PR3) and survivin (SVN) were selected as candidate antigens associated with leukemia and lymphoma. MHC class II candidate epitopes from these proteins were computer-assisted predicted and used as synthetic peptides for in vitro stimulation by human CD4+ T-cells. Peptide specific CD4+ T-cells were examined regarding their immune reactivity with the corresponding tumor protein. Several class-II epitope candidates in SVN and PR3 were identified by examining human T-cell responses to synthetic peptides. Then, epitope candidates were characterized by establishing and analyzing peptide-specific T-cell clones. It was demonstrated that CD4+ T cells specific for the SVN10 epitope respond to naturally processed SVN proteins. This epitope was presented by several HLA-DR alleles, including DR3, DR4, DR7, and DR11. Furthermore, the SVN10-specific T cells recognized SVN antigen from various tumor cell lines. Moreover, the T-cell clones were examined for MHC restriction patterns, immunophenotypes and epitopeMHC avidity. It was further found that SVN10 was promiscuous and capable of inducing CD4+ $\mathrm{T}$ cell responses in cancer patients. Thus, the identification of the naturally processed SVN epitope, together with the previous finding of class I-restricted SVN epitopes, provide a basis for the combined application of 
class I- and II-restricted SVN epitopes to induce potent, long-term CD4+ and CD8+ T-cell responses against various tumors.

Lately, CD4+ T-regulatory (Treg) cells were recognized and became increasingly important in antitumor immunity. Increased proportions of CD4+ CD25+ Treg cells have been observed in patients with different types of cancers. Additional analyses of the $\mathrm{T}$ cell clones with Treg specific markers revealed that our $\mathrm{CD} 4+$ clones mainly represented regulatory T cells.

In summary, new strategies that simultaneously stimulate CD4+ effector T cells while inhibiting or depleting CD4+ Treg cells are, therefore, needed to shift the dynamic equilibrium toward effector T cells in the treatment of cancer patients. The opposite approach, favouring expansion of the CD4+ Treg population, might improve the treatment of autoimmune diseases. 


\section{Kurzreferat:}

CD4+ T-Zellen spielen durch verschiedene Mechanismen eine wichtige Rolle bei der Tumorbekämpfung. Vor allem helfen sie bei der Induktion und Aufrechterhaltung von CTL-Antworten. Tierexperimente haben gezeigt, dass Antigen-spezifische CD4+ T-Zellen wichtig für die Eliminierung von Tumoren sind. Ein interessanter Weg zur Bekämpfung von Tumoren bei Patienten liegt in der Peptid-Vakzinierung. Bisherige Anstrengungen zielten auf die Induktion von CTL-Antworten $a b$; um eine Verbesserung der TumorVakzinierung $\mathrm{zu}$ erzielen, sollten CD4+ T-Zellepitope aus demselben Tumorantigen miteinbezogen werden.

Das Hauptziel dieser Arbeit war es, MHC Klasse-II Peptidepitope in den Proteinen $\mathrm{zu}$ identifizieren, welche eine tumor-assoziierte Expression aufweisen und die bereits bekannte Zielantigene von zytotoxischen T-Zellreaktionen sind. In dieser Arbeit wurden die Proteine Proteinase 3 (PR3) und Survivin (SVN) - beide Proteine werden mit Leukämien und Lymphomen in Verbindung gebracht - ausgewählt. MHC Klasse-II Kandidatenepitope dieser Proteine wurden Computer-basierend vorhergesagt und als synthetische Peptide für in vitro Stimulationen mit humanen CD4+ T-Zellen eingesetzt. Peptid-spezifische CD4+ T-Zellen wurden hinsichtlich ihrer Immunreaktivität gegen das korrespondierende Tumorprotein untersucht. Mehrere Klasse-II Epitopkandidaten konnten durch Bestimmung der humanen T-Zellantwort gegen die synthetischen Peptide in SVN und PR3 identifiziert werden. Die Epitopkandidaten wurden anschließend durch die Etablierung und darauffolgende Analyse von peptid-spezifischen T-Zellklonen charakterisiert. CD4+ T-Zellen, die spezifisch für das SVN10Epitop waren, zeigten eine proliferative Antwort gegen natürlich prozessiertes SVN-Protein. Dabei wird das SVN10-Epitop von verschiedenen HLA-DR Allelen (DR3, DR4, DR7 und DR11) präsentiert. Weiterhin konnte eine 
proliferative Antwort von SVN10-spezifischen T-Zellen gegen das SVN Antigen von verschiedenen Tumorzellinien nachgewiesen werden. Die T-Zellklone wurden zudem auf ihr MHC-Restriktionsmuster, ihrem ImmunPhänotyp und ihrer Epitop-MHC-Affinität hin untersucht. Schließlich konnte auch eine CD4+ T-Zellantwort gegen SVN10 bei verschiedenen Tumorpatienten induziert werden. Somit bilden die Identifikation des natürlich prozessierten SVN-Epitops zusammen mit den bereits identifizierten Klasse-I-restringierten SVN-Epitopen die Basis für eine kombinierte Therapie, um eine wirksame und langanhaltende CD4+ und CD8+ T-Zellantwort gegen Klasse-I und -II-restringierte SVN-Epitope zu induzieren.

Vor kurzem wurde gezeigt, dass CD4+ regulatorische T-Zellen (Treg) eine bedeutende Rolle in der Anti-Tumor-Immunität spielen. Eine erhöhte Anzahl von CD4+ CD25+ Treg-Zellen wurde im Tumorgewebe bei Patienten mit verschiedenen Arten von Tumoren nachgewiesen. Die Untersuchungen der in dieser Arbeit generierten T-Zellklone auf spezifische T-regulatorische Marker zeigten, dass sämtliche T-Zellklone CD4+ Treg Zellen darstellen.

Zusammenfassend kann gesagt werden, dass neue Strategien, die einerseits CD4+ Effektor T-Zellen stimulieren, andererseits CD4+ Treg-Zellen inhibieren oder depletieren, erarbeitet werden müssen um das dynamische Gleichgewicht zugunsten der Effektor- T-Zellen bei der Bekämpfung von Tumoren zu verschieben. Auf der anderen Seite kann die Expansion von TregZellen die Bekämpfung von Autoimmunkrankheiten verbessern. 


\section{Inhaltsverzeichnis}

Inhaltsverzeichnis..................................................................................................... I

Abkürzungen ................................................................................................................ VI

1. Einleitung .................................................................................. 1

1.1 Identifikation von Tumorantigenen.................................................................

1.2 Immuntherapie von Tumoren mit zytotoxischen T-Lymphozyten ....................

1.3 ,tumor-escape“ Mechanismen ................................................................................. 4

1.4 Einbeziehung von CD4+ T-Lymphozyten in die zelluläre Immuntherapie

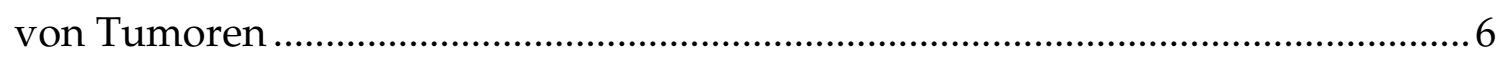

1.5 Peptidbeladung von MHC-II-Molekülen in Antigen-präsentierenden Zellen

1.6 Die Bedeutung der Präsentation von MHC-II-Selbstpeptiden auf DCs für die periphere Toleranz und die Regulation der T-Zell-Aktivität.............................9

1.7 Identifikation von MHC-Klasse-II-Peptidepitope …………………………......11

1.8 Das tumorassoziierte Protein Proteinase 3 …………………………………....13

1.9 Das tumorassoziierte Protein Survivin................................................................15

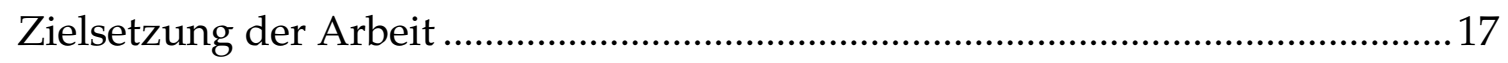

2. Material....................................................................... 19

2.1 Geräte ….............................................................................................................19

2.2 Chemikalien, Biochemikalien und Radiochemikalien .....................................20

2.3 Verbrauchsmaterialien ...........................................................................................23

2.4 Antikörper................................................................................................................24 


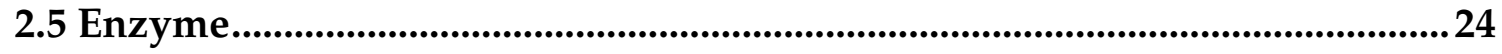

2.6 Zytokine......................................................................................................... 25

2.7 Oligonukleotide ........................................................................................................25

2.8 Peptide …….........................................................................................................26

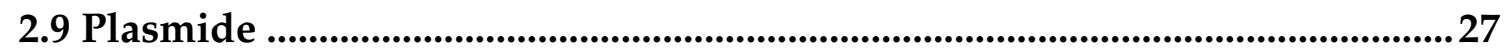

2.10 Lösungen und Puffer ..............................................................................................2

2.11 Medien ....................................................................................................... 29

2.12 Eukaryontische Zelllinien...................................................................................30

2.13 Bakterienstamm ........................................................................................................

2.14 Blutproben ...........................................................................................................

2.15 Computerprogramme..............................................................................................31

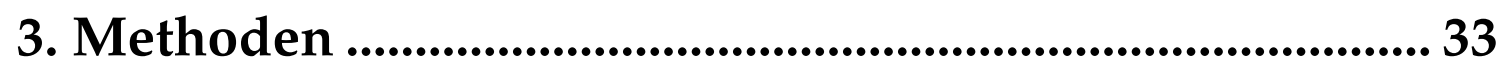

3.1 Zellbiologische Methoden ............................................................33

3.1.1 Allgemeine zellbiologische Methoden ..............................................................33

3.1.1.1 Bestimmung der Zellzahl ...........................................................................

3.1.1.2. Kultivierung von Zelllinien ........................................................................33

3.1.1.3 Kryokonservierung und Rekultivierung von Zellen.....................................34

3.1.2 Isolierung und Kultivierung verschiedener Zellpopulationen aus

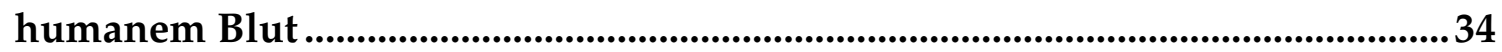

3.1.2.1 Isolierung mononukleärer Zellen (PBMCs) aus humanem Blut mittels

Dichtegradientenzentrifugation ...........................................................................

3.1.2.2 Isolierung von Monozyten und Differenzierung zu dendritischen

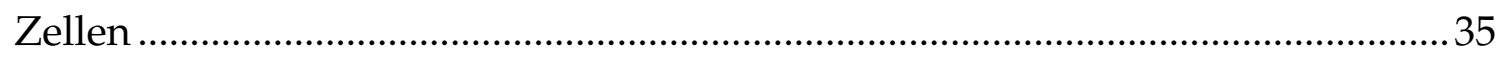

3.1.3 Generierung von Peptid-spezifischen CD4+-T-Zellklonen..........................36

3.1.3.1 Induktion von CD4+ T-Zellen........................................................................

3.1.3.2 T-Zellproliferationstest .........................................................................

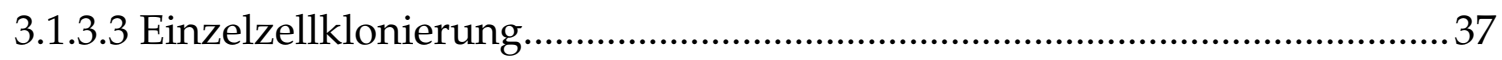

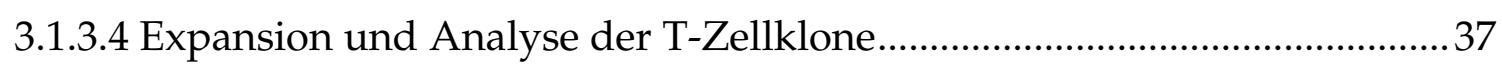

3.1.4 Durchflußzytometrie (FACS) ..............................................................................38 
3.1.5 Bestimmung der Zytokinproduktion mittels ELISA ..................................38

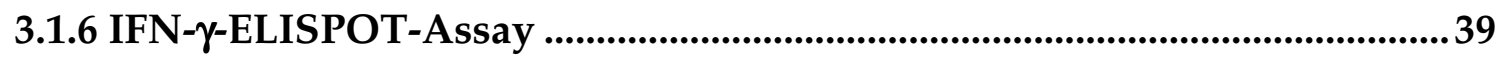

3.1.7 Herstellung von Zelllysaten für die Beladung von DC ................................41

3.1.8 Vermehrung und Aufreinigung rekombinanter Adenoviren .....................41

3.1.8.1 Vermehrung rekombinanter Adenoviren ................................................ 42

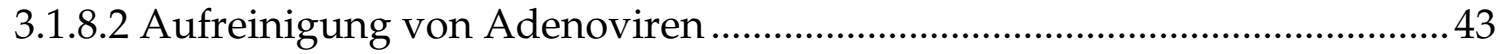

3.1.8.3 Photometrische Quantifizierung einer Adenovirus-Präparation.............. 43

3.1.8.4 Adenovirus Titration (Plaque-Test) ........................................................... 44

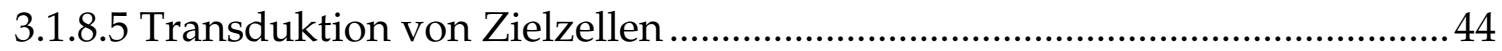

3.2 Molekularbiologische Methoden ........................................................45

3.2.1 Arbeiten mit Bakterien .............................................................................................. 45

3.2.1.1 Herstellung chemisch kompetenter Bakterien nach der

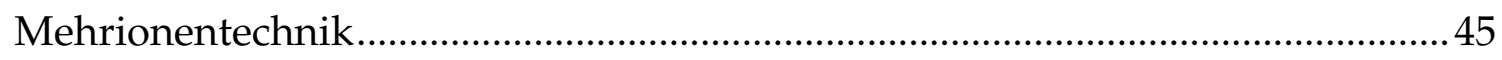

3.2.1.2 Transformation chemisch kompetenter Bakterien................................... 45

3.2.1.3 Präparation von Plasmid-DNA in kleinem Maßstab (Mini-Präp)............. 46

3.2.1.4 Präparation von Plasmid-DNA in quantitativem Maßstab........................46

3.2.2 DNA-analytische Methoden......................................................................47

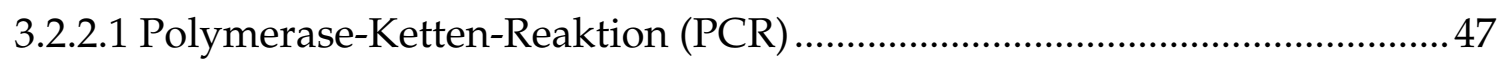

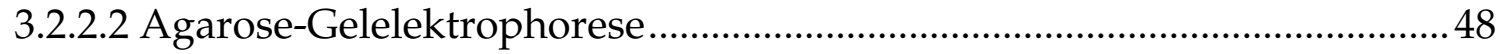

3.2.2.3 Elution von DNA-Fragmenten aus Agarosegelen .................................... 49

3.2.2.4 Spaltung von Plasmid-DNA durch Restriktions-Endonukleasen............. 49

3.2.2.5 Dephosphorylierung der Plasmide vor einer Ligation ...............................50

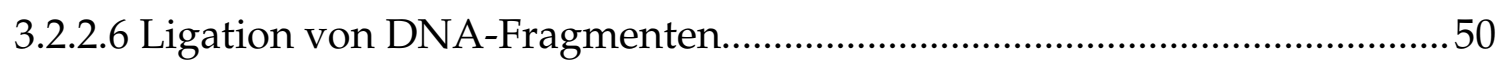

3.2.2.7 Konzentrationsbestimmung von DNA …................................................. 51

3.2.2.8 Abschätzung von DNA-Mengen im Agarosegel ...................................... 51

3.2.3 RNA-analytische Methoden ......................................................................51

3.2.3.1 Isolierung von mRNA und Quantifizierung ............................................ 51

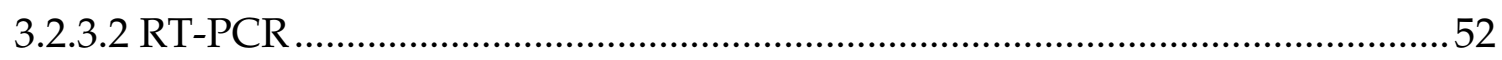


3.3 Proteinbiochemische Methoden ........................................................53

3.3.1 Quantifizierung der Proteinmenge nach Bradford .......................................53

3.3.2 SDS-Polyacrylamid-Gelelektrophorese (SDS-PAGE) ................................53

3.3.3 Transfer von Proteinen auf Nitrozellulosemembranen ...............................54

3.3.4 Färbung von Proteinen in Nitrozellulosemembranen mit Ponceau-Rot.54

4. Ergebnisse .......................................................................................... 56

4.1 Untersuchung der Expression von Survivin und Proteinase 3 in verschiedenen Tumorzelllinien .....................................................................................56

4.1.1 Nachweis der Expression auf mRNA-Ebene mittels RT-PCR ................... 56

4.1.2 Nachweis der Proteinexpression mittels Western Blot ..............................58

4.2 Konstruktion des adenoviralen Vektors .......................................................61

4.3 Identifikation und Charakterisierung von tumor-spezifischen HLA-IIPeptidepitopen ...........................................................................................................66

4.3.1 Analyse von Epitopkandidaten mittels TEPITOPE-Analyse.....................66

4.3.2 Generierung von peptid-spezifischen CD4+ T-Lypmphozyten ................68

4.3.3 Analyse peptidspezifischer CD4+ T-Lymphozyten ...................................... 71

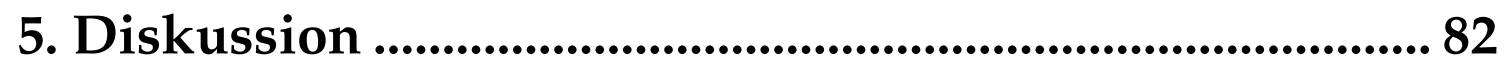

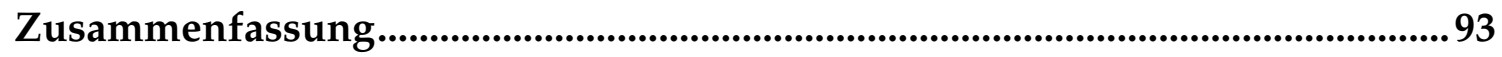

6. Literatur .......................................................................................... 95

7. Anhang............................................................................................. 127

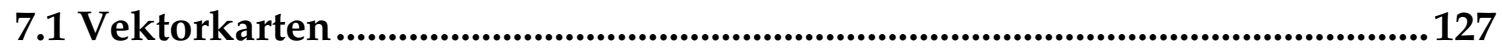


7.2 Abbildungsverzeichnis 131

7.3 Danksagungen.......................................................................................................... 134

7.4 Publikationsliste und wissenschaftliche Präsentationen .............................137

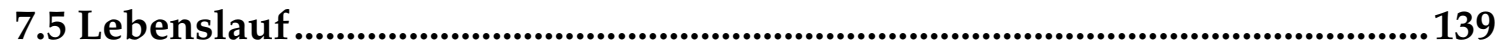




\section{$\underline{\text { Abkürzungsverzeichnis }}$}

A

ABTS

Ad

ALL

AML

Amp

APC

APS

AS

AT

ATP

BPB

BSA

bzw.

${ }^{\circ} \mathrm{C}$

C

C

cAMP

cANCA

CD

cDNA

$\mathrm{Ci}$

CLL

$\mathrm{cm}$

CML
Alanin

2,2’-Azino-bis(Ethylbenz-Thiazolin-6-sulfonsäure)

Adenovirus

akute lymphatische Leukämie

akute myeloische Leukämie

Ampicillin

antigen presenting cells, antigenpräsentierende Zellen

Ammoniumpersulfat

Aminosäuren

„annealing” Temperatur

Adenosintriphosphat

Bromphenolblau

Rinderserumalbumin

beziehungsweise

Grad Celsius

Carboxy

Cystein

zyklisches Adenosinmonophosphat

Antineutrophile-Antikörper

cluster of differentiation

komplementäre Desoxyribonukleinsäure

Curie

chronisch lymphatische Leukämie

Zentimeter

chronisch myeloische Leukämie 


\begin{tabular}{|c|c|}
\hline cpm & counts per minute \\
\hline CTLA4 & cytotoxic T-lymphocyte antigen 4 \\
\hline CTL & zytotoxische T-Lymphozyten \\
\hline $\mathrm{D}$ & Dalton \\
\hline $\mathrm{D}$ & Aspartat \\
\hline DAPI & 4',6-Diamidino-2-phenyl-indol \\
\hline dATP & Desoxyadenintriphosphat \\
\hline $\mathrm{DC}$ & dendritic cells, Dendritische Zellen \\
\hline $\mathrm{dCTP}$ & Desoxycytosintriphosphat \\
\hline ddNTP & Didesoxynukleotidtriphosphat \\
\hline DEPC & Diethylpyrocarbonat \\
\hline dGTP & Desoxyguanosintriphosphat \\
\hline d.h. & das heißt \\
\hline dNTP & Desoxynukleotidtriphosphat \\
\hline dTTP & Desoxythymidintriphosphat \\
\hline DMEM & 'Dulbecco’s Modified Eagle’s' Medium \\
\hline DMSO & Dimethylsulfoxid \\
\hline DNA & Desoxyribonukleinsäure \\
\hline E & Glutamat \\
\hline ECL & verstärkte Chemiluminiszenz \\
\hline E. coli & Escherichia coli \\
\hline EDTA & Ethylendiamin-N,N,N',N'- tetraessigsäure \\
\hline EGTA & $\begin{array}{l}\text { Ethylenglykol-bis2(2-aminoetyhlether)-N,N, } \mathrm{N}^{\prime}, \mathrm{N}^{\prime} \text { - } \\
\text { tetraessigsäure }\end{array}$ \\
\hline ELISA & enzyme-linked immunosorbent assay \\
\hline ER & Endoplasmatische Retikulum \\
\hline et al. & und andere \\
\hline $\mathrm{EtOH}$ & Ethanol \\
\hline $\mathrm{F}$ & Phenylalanin \\
\hline Fa. & Firma \\
\hline FACS & Fluorecense activated cells sorting \\
\hline
\end{tabular}




\begin{tabular}{|c|c|}
\hline FBS/FCS & fötales Kälberserum \\
\hline FITC & Fluoreszeinthiocyanat \\
\hline FoxP3 & Forkhead box P3 transcriptional factor \\
\hline $\mathrm{g}$ & Gramm \\
\hline G & Glyzin \\
\hline GDP & Guanosindiphosphat \\
\hline GFP & green fluorescent protein \\
\hline GITR & glucocorticoid-induced tumor necrosis factor receptor \\
\hline Gly & Glycin \\
\hline \multirow[t]{2}{*}{ GM-CSF } & Granulozyten-Makrophagen-koloniestimulierender \\
\hline & Faktor \\
\hline GTP & Guanosintriphosphat \\
\hline Gy & Gray \\
\hline $\mathrm{h}$ & Stunde \\
\hline $\mathrm{H}$ & Histidin \\
\hline $\mathrm{H}_{2} \mathrm{O}$ & Wasser \\
\hline $\mathrm{H}_{2} \mathrm{O}_{2}$ & Wasserstoffperoxid \\
\hline HEBS & HEPES buffered saline \\
\hline HEPES & [4-(2-Hydroxyethyl)-piperazino]-ethansulfonsäure) \\
\hline HLA & human leukocyte antigen \\
\hline HRP & Meerrettich-Peroxidase \\
\hline I & Isoleucin \\
\hline IAP & inhibitor of apoptosis \\
\hline iDC & unreife dendritische Zelle \\
\hline IFN & Interferon \\
\hline $\operatorname{IgG}$ & Immunglobulin G \\
\hline iI & invariante MHC-Klasse-II-Kette \\
\hline IL & Interleukin \\
\hline IPTG & Isopropyl- $\beta$-D-thiogalaktopyranosid \\
\hline IU & infektiöse Einheiten \\
\hline $\mathrm{J}$ & beliebige Aminosäure außer S und $\mathrm{T}$ \\
\hline
\end{tabular}




\begin{tabular}{|c|c|}
\hline $\mathrm{k}$ & Kilo \\
\hline K & Lysin \\
\hline KAc & Kalium-Acetat \\
\hline $\mathrm{kb}$ & Kilobasenpaare \\
\hline $\mathrm{kDa}$ & Kilodalton \\
\hline 1 & Liter \\
\hline $\mathrm{L}$ & Leucin \\
\hline LAMP-1 & lysosomal associated membrane protein 1 \\
\hline LB & Luria-Bertani-Medium \\
\hline $\mathrm{LRO}$ & lysosomal-related organell \\
\hline$\mu$ & mikro \\
\hline $\mathrm{m}$ & milli \\
\hline $\mathrm{m}$ & Meter \\
\hline M & Methionin \\
\hline M & molar $(\mathrm{mol} / \mathrm{l})$ \\
\hline MCL & Mantelzell-Lymphom \\
\hline $\mathrm{mDC}$ & mature dendritic cell, reife dendrititsche Zelle \\
\hline MHC & major histocompatibility complex \\
\hline $\min$ & Minute \\
\hline MOI & multiplicities of infection \\
\hline mRNA & 'messenger' Ribonukleinsäure \\
\hline MTOC & microtubule organization center \\
\hline MW & Molekulargewicht \\
\hline $\mathrm{n}$ & nano \\
\hline $\mathrm{N}-$ & Amino- \\
\hline $\mathrm{N}$ & Asparagin \\
\hline NF- $\kappa B$ & Nuklear Faktor-кB \\
\hline NHL & Non Hofgkin Lymphom \\
\hline NK & Natürliche Killerzellen \\
\hline NSCL & Non small cell lung cancer \\
\hline OD & optische Dichte \\
\hline
\end{tabular}


P

PAGE

PBS

PBMC

PCR

PE

$P_{\mathrm{E}} 2$

$\mathrm{PH}$

PHA

PIPES

PR3

Q

R

RNA

RNase

rpm

RT

RT-PCR

S

SCLC

SDS

sek

SI

ssDNA

SVN

$\mathrm{T}$

TA

TAA

TAE
Prolin

Polyacrylamid-Gelelektrophorese

Phosphat-gepufferte Salzlösung

peripheral blood mononuclear cells, mononukleäre

Zellen aus peripherem Blut

Polymerase-Ketten-Reaktion

Phycoerythrin

Prostaglandin E2

negativer dekadischer Logarithmus der

Wasserstoffionen-Konzentration

Phytohämaglutinin

Piperazin-N,N'-bis[2-ethansufonsäure]

Proteinase 3

Glutamin

Arginin

Ribonukleinsäure

Ribonuklease

Umdrehungen pro Minute

Raumtemperatur

Reverse Transkription- Polymerase-Ketten-Reaktion

Serin

Small cell lung cancer

Natriumdodecylsulfat

Sekunde

Stimulationsindex

,single stranded“-DNA

Survivin

Threonin

Tumorantigen

tumor-assoziiertes Antigen

Tris-Acetat-EDTA-Puffer 
TBS

Tris-gepufferte Salzlösung

TCR

$\mathrm{T}$ cell receptor, $\mathrm{T}-$ Zellrezeptor

TEMED

$\mathrm{N}, \mathrm{N}, \mathrm{N}^{\prime}, \mathrm{N}^{\prime}$-Tetramethylethylendiamin

TGF

transforming growth factor

$\mathrm{T}_{\mathrm{H}}$-Zelle

T-Helferzelle

$\mathrm{T}_{\mathrm{H}}$ 1-Lymphozyten

T-Helferlymphozyten vom Typ 1

$\mathrm{T}_{\mathrm{H}}$ 2-Lymphozyten

T-Helferlymphozyten vom Typ 2

TIL

tumorinfiltrierende Lymphozyten

TNF

Tumornekrosefaktor

Treg-Lymphozyten

regulatorische T-Lymphozyten

Tris

Tris(hydroxymethyl)-aminomethan

$\mathrm{U}$

unit

UTR

untranslatierte Region

$\mathrm{V}$

Volt

VEGF

vascular endothelial growth factor

Vol.

Volumenanteil

$\mathrm{v} / \mathrm{v}$

Volumen pro Volumen

W

Tryptophan

WB

Western Blot

Y

Tyrosin

$\mathrm{w} / \mathrm{v}$

Gewicht pro Volumen 


\section{Einleitung}

Tumorerkrankungen stellen nach den Herz-Kreislaufkrankheiten die zweithäufigste Todesursache in den westlichen Industrienationen dar. Obwohl die Standardbehandlungsverfahren, bestehend aus chirurgischen und zytostatischen Therapien sowie Bestrahlungsbehandlungen, innerhalb der letzten Jahrzehnte deutlich verbessert werden konnten, lassen sich viele Tumorarten bis heute vielfach nicht dauerhaft heilen. Die Weiterentwicklung neuer Modalitäten zur kurativen Behandlung von Tumoren ist demzufolge eine Herausforderung an die moderne medizinische Forschung. In diesem Zusammenhang ist die zelluläre Tumorimmuntherapie ein viel versprechender Ansatz. Diese Strategie beinhaltet die spezifische Aktivierung des zellulären Immunsystems mit dem Ziel der Erkennung und Elimination von Tumorzellen durch verschiedene Immuneffektorzellen.

\subsection{Identifikation von Tumorantigenen}

Eine wesentliche Grundlage für die Konzeption von spezifischen Tumorimmuntherapien ist die Kapazität des menschlichen Immunsystems, zwischen "Selbst" und "anomalem Selbst" zu unterscheiden. Mutationen in Tumorsuppressor-Genen, Proto-Oncogenen, Transkriptionsregulatoren und ähnlichen Genen führen zur Dysregulation der Zellproliferation und zur veränderten Expression zahlreicher zellulärer Proteine (Fearson and Vogelstein, 1990). Das Proteom einer Tumorzelle unterscheidet sich demnach 
von dem seiner nicht-neoplastischen Vorläuferzelle. Prinzipiell kann man zwischen tumorspezifischen und tumorassoziierten Proteinen unterscheiden. Tumorspezifische Proteine werden infolge Mutationen und/oder pathophysiologischer Prozesse nur von Tumorzellen exprimiert, nicht jedoch in normalen Zellen. Im Gegensatz hierzu können tumorassoziierte Proteine auch von nicht-transformierten Zellen auf niedrigem Niveau exprimiert werden. Tumorspezifische bzw. tumorassoziierte Proteine, welche immunogene Determinanten umfassen, die vom Immunsystem erkannt werden können, bezeichnet man als Tumorantigene (TA).

Fortschritte auf dem Gebiet der Immunologie, Molekulargenetik und -biologie haben in den vergangenen 20 Jahren die Identifikation einer stetig zunehmenden Zahl dieser TA ermöglicht. Fünf verschiedene Gruppen von TA kann man abhängig von ihrer Expressionsspezifität, Funktion und molekularen Entstehung unterscheiden:

- Zur ersten Klasse gehören Differenzierungsantigene, die nur in Tumorzellen sowie entsprechendem Normalgewebe exprimiert werden (Tyrosinase, Melan A).

- Die zweite Kategorie entspricht Proteinen, die in Tumoren überexprimiert vorliegen, gleichzeitig jedoch auch in gesunden Geweben zu finden sind (p53, Her-2/neu, PSMA, hTERT, Survivin, Proteinase 3).

- Antigene, die in gesunden Geweben mit Ausnahme der Hoden und der Placenta nicht vorkommen, aber in vielen Tumoren reaktiviert werden, bilden als dritte Gruppe die sogenannten „cancer-testis-Antigene“. Beispiele hierfür sind Proteine der MAGE-, GAGE- oder BAGE-Familie und NY-ESO-1.

- Die vierte Klasse besteht aus Antigenen, die auf spezifische Punktmutationen in normalen Genen basieren; gegen das mutierte Genprodukt können potentiell spezifische T-Zellreaktionen ausgelöst werden (Caspase-8, Cyklin-abhängige Kinase 4). 
- Zur letzten Kategorie werden verschiedene virale Proteine (z.B. E7/HPV) gezählt, für die ein Zusammenhang zwischen Virusinfektionen und Tumorentstehung belegt ist (Wölfel and Huber, 2001; Rosenberg, 1999).

\subsection{Immuntherapie von Tumoren mit zytotoxischen T-Lymphozyten}

Zahlreiche der heute charakterisierten TA sind Zielantigene zellulärer Immunreaktionen, die von antigenspezifischen T-Lymphozyten vermittelt werden (Renkvist et al., 2001; Livingston et al., 1979; Rouse et al., 1972; Zinkernagel and Doherty, 1979; Davis et al., 2003). In diesem Zusammenhang stellen CD8+ zytotoxische T-Lymphozyten (CTL) wesentliche Effektorzellen dar (Knuth et al., 1989; Knuth et al., 1984; Mukherji et al., 1983; Brunner et al., 1980). Nach Erkennung und Aktivierung polarisieren sich CD8+ T-Lymphozyten durch Umstrukturierung des Zytoskeletts, schütten nachfolgend zytotoxische Granula, die Perforin und Granzyme enthalten, aus und induzieren so die Apoptose der Zielzellen. Die spezifische Erkennung von TA durch T-Zellrezeptoren (TCR) auf CTLs erfolgt, wenn das Antigen in Form eines Peptidepitops gebunden an ein MHC-Klasse-I-Molekül auf der Tumorzelloberfläche präsentiert wird. Voraussetzung ist die Prozessierung von intrazellulären Proteinantigenen in Peptidepitope, die eine optimale Länge von 9 bis 10 Aminosäuren aufweisen und bei Vorliegen bestimmter Aminosäurekonstellationen mit hoher Affinität an MHC-Klasse-I-Moleküle binden (Bjorkman et al., 1987; Goldberg and Rock, 1992; Monaco, 1992; Falk et al., 1991 ; Seliger et al., 2000). In den vergangenen Jahren hat man von vielen TA ein oder mehrere Peptidepitope identifiziert, die von verschiedenen MHC- 
Klasse-I-Allelen präsentiert und vom TCR zytotoxischer CD8+ T-Zellen erkannt werden (Renkvist et al., 2001; Davis et al., 2003; Novellino et al., 2005).

Die Identifikation des ersten tumorpezifischen T-Zellepitops aus dem "cancertestis"-Tumorantigen MAGE Anfang der 90iger Jahre (van der Bruggen et al., 1991) machte den Weg frei für die Entwicklung von Krebsvakzinen. Seither sind MHC-Klasse-I-abhängige Peptidepitope in einer Vielzahl von klinischen Studien bei unterschiedlichen Tumorentitäten untersucht worden (Celis et al., 1995; Jaeger et al., 1996; Nestle et al., 1998; Jäger et al., 2000; Rosenberg, 2001). Waren in vielen dieser Studien die anfänglichen Ergebnisse auch vielversprechend - CD8+ zelluläre Immunreaktionen und Tumorregressionen traten bei einem Teil der geimpften Patienten auf (Nestle et al., 1998; Melief et al., 1996; Rosenberg et al., 1998; Marchand et al., 1999; Mackensen et al., 2000), so führten sie in aller Regel jedoch nicht zur vollständigen und permanenten Elimination des Tumors (Lee et al., 1999b; Panelli et al., 2000a; Panelli et al., 2000 b).

\section{3 "tumor escape" Mechanismen}

Bis heute gelingt es nicht, klinisch wirksame T-Zellantworten durch alternative Impfstrategien und Vakzinierung mit neu identifizierten TA und MHCKlasse-I-Peptidepitopen zu stimulieren (Rosenberg et al., 2004; Blattmann and Greenberg, 2004). Eine Erklärung hierfür sind die über einen Selektionsdruck geförderten „escape“ Mechanismen von Tumorzellen, die ihrer Erkennung und Vernichtung durch das Immunsystem entgegenwirken (Anichini et al., 1999; Costello et al., 1999; Espinoza-Delgado, 2002; Gouttefangeas and Rammensee, 2000). 
Beispielsweise können Tumorzellen für das Immunsystem quasi unsichtbar bleiben, indem sie MHC-Klasse-I-Moleküle herunterregulieren oder in TAPund proteasomdefizienten Mutanten die Präsentation der TA verhindern (Costello et al., 1999; Gilboa, 2001; Ferrone and Marincola, 1995; Seliger et al., 1997). Weiterhin können Tumorzellen durch Koexpression T-zellinhibitorischer Moleküle (z.B. CTLA-4) oder durch fehlende Koexpression von kostimulatorischen Molekülen (CD28, CD40, oder B7), woraufhin das entscheidende zweite Signal zur Aktivierung der T-Zelle fehlt, eine effiziente antitumorale Immunantwort verhindern oder sogar eine Immuntoleranz induzieren (Alexandroff et al. 2000; Chambers et al., 2001; Fenton and Longo, 1997). Im Rahmen von Immunantworten gegen körpereigene Zellen kommt es nicht $\mathrm{zu}$ inflammatorischen Reaktionen, die bei bakteriellen oder viralen Entzündungsreaktionen gesehen werden (Gilboa 2001). Es fehlt die Bildung proinflammatorischer Zytokine und Chemokine, die die Expression von Adhäsionsmolekülen anregen bzw. professionell antigen-präsentierende Zellen anlocken und zur Reifung bringen. Naive T-Zellen können so letztlich nicht einwandern und aktiviert werden (Fenton and Longo, 1997; Piali et al., 1995). Manche Tumoren können die Produktion des T-Zell-Wachstumsfaktors IL-2 blockieren und die Signaltransduktion von Il-2-Rezeptoren auf den T-Zellen verhindern (Rayman et al., 2000). Tumorzellen bilden auch immunsuppressive Faktoren wie VEGF, TGF- $\beta$, Prostaglandine oder IL-10. Antigenpräsentierende Zellen und T-Zellen werden so in ihrer Reifung, Proliferation und Funktion gehemmt und das gesamte Immunsystem des Tumorpatienten supprimiert (Fenton and Longo, 1997; Gabrilovich et al., 1996; Gilboa, 2001, Kim et al., 1995; Radoja and Frey, 2000, Restifo. 2000).

Schließlich konnte auch eine Beteiligung regulatorischer T-Zellen an der Induktion der Toleranz gegen Tumore gezeigt werden (Sutmuller et al., 2001; van Elsas et al., 2001). 


\subsection{Einbeziehung von CD4+ T-Lymphozyten in die zelluläre Immuntherapie von Tumoren}

Aufgrund der Vielzahl immunsuppressiver Strategien der Tumoren ist die Entwicklung von immuntherapeutischen Strategien wünschenswert, die trotz dieser Mechanismen eine effiziente, dauerhafte Immunantwort gegen Tumoren induzieren können. Eine mögliche Verbesserung antitumoraler Immuntherapien kann sich aus der Einbeziehung tumorspezifischer CD4+ T-Helferlymphozyten in antitumorale CD8+ T-Zellreaktionen ergeben (Knutson et al., 2001; Wang, 2001; Schuler-Thurner, 2002; Yu and Restifo, 2002). Bisher sind tumorspezifische CD4+ T-Zellepitope erst in sehr wenigen klinischen Vakzinierungsversuchen eingesetzt worden (Slingluff et al., 2001; Brossart et al., 2000) und es sind nur wenige tumorspezifische MHC-Klasse-IIPeptide bekannt. Die zentrale Bedeutung von CD4+ T-Zellen bei der Induktion und Aufrechterhaltung von humoralen und zellulären Immunreaktionen bei Infektions- und Autoimmunerkrankungen ist unbestritten (Ahlers et al., 2001; Charlton and Lafferty, 1995; Kalams and Walker, 1998; O'Garra et al.,1997; Zajac et al.,1998). Umso erstaunlicher ist es, dass CD4+ T-Helferzellen im Bereich der Tumorvakzinierung bisher wenig Aufmerksamkeit geschenkt wurde. Ein Grund dafür ist, dass Tumorzellen im allgemeinen MHC-Klasse-I Moleküle exprimieren, nicht aber MHC-Klasse-II Moleküle (Altomonte et al., 2003). 


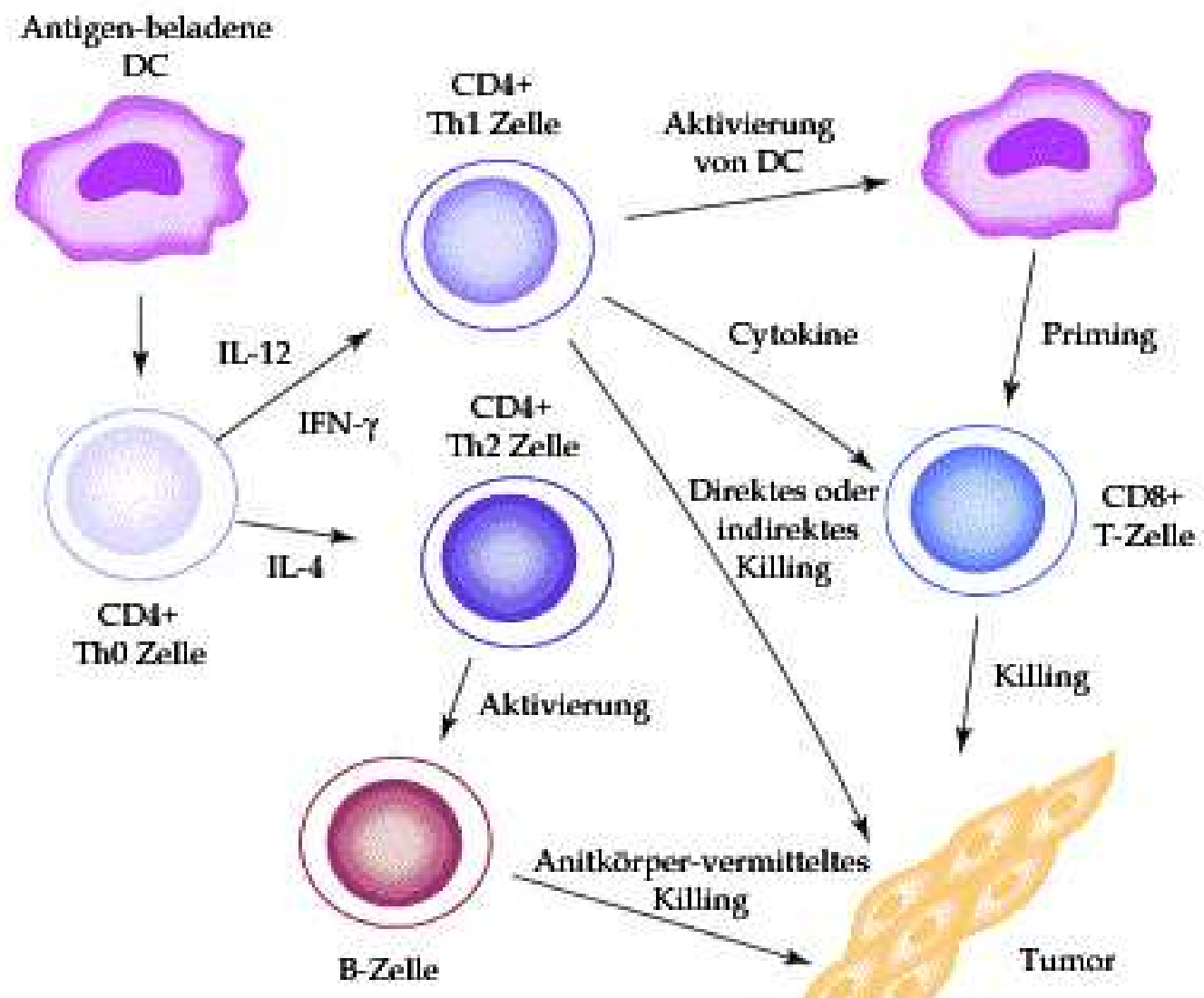

Abb. 1: CD4+ T-Zellen als Regulatoren der Anti-Tumor-Immunität. CD4+ T-Zellen sind an der Auslösung und Regulation zahlreicher Effektorwege beteiligt, die eine Anti-TumorAktivität entfalten können. Sie helfen beim Priming und der Proliferation von CD8+ T-Zellen, inhibieren das Tumorwachstum über direkte und indirekte Mechanismen und aktivieren B-Zellen. Die konzertierte Aktion dieser Effektoren führt dann zur Elimination des Tumors (modifiziert aus Wang, 2001).

Die essentielle Bedeutung von CD4+ T-Zellen für die Eliminierung auch von MHC-Klasse-II-negativen Tumoren konnte in den letzten Jahren durch verschiedene Studien gezeigt werden (Greenberg, 1991; Ossendorp et al., 1998; Hung et al., 1998; Toes et al., 1999; Mumberg et al., 1999). Sie sind an der Regulation vielfältiger Effektorwege beteiligt, die allesamt in der Beseitigung 
des Tumors resultieren können (siehe Abb. 1). So führen CD4+ T-Zellen vom Typ $1 \quad\left(\mathrm{~T}_{\mathrm{H}} 1\right) \quad \mathrm{zu}$ einer Proliferations- und Funktionsaktivierung von tumorreaktiven CD8+ zytotoxischen T-Lymphozyten. Dies geschieht durch sezerniertes Interleukin-2 und kostimulatorische Moleküle auf $\mathrm{T}_{\mathrm{H}} 1$-Zellen, sowie indirekt über die CD40-vermittelte Interaktion mit dendritischen Zellen (DC) (Lode et al., 2000; Giuntoli et al., 2002; Greenberg, 1991; Bennett et al., 1998; Schoenberger et al., 1998). Durch die Sezernierung von Interfon- $\gamma($ IFN- $\gamma)$ hemmen CD4+ T-Helferzellen die Tumorzellproliferation und die tumorvermittelte Angiogenese (Mumberg et al., 1999; Qin and Blankenstein, 2000). Weiterhin verstärken T-Helferlymphozyten die T-zelluläre Tumorabwehr durch das angeborene Immunsystem. Dies wird durch eine Rekrutierung und Aktivierung von Makrophagen, eosinophilen Granulozyten und NK-Zellen vermittelt (Hung et al., 1998; Greenberg, 1991; Tsung et al., 2002). Die Rolle von $\mathrm{T}_{\mathrm{H}} 2$-Zellen in der Anti-Tumor-Immunität liegt im wesentlichen in der Aktivierung von B-Lymphozyten, welche tumorspezifische Antikörper produzieren können, die den Tumor direkt oder indirekt schädigen (Old et al., 1996; Glennie and Johnson, 2000).

\subsection{Peptidbeladung von MHC-II-Molekülen in Antigen- präsentierenden Zellen}

Die Erkennung von Antigenen durch CD4+ T-Lymphozyten erfolgt in Form von Peptidepitopen, die auf MHC-Molekülen der Klasse II präsentiert werden. DC, B-Lymphozyten und Makrophagen nehmen extrazelluläre Antigene mittels Endozytose auf und spalten diese durch Proteasen in Peptide. Die nachfolgende Beladung von MHC-Klasse-II Molekülen mit antigenen Peptiden in einer variablen Länge von 12 bis 28 Aminosäuren findet in 
speziellen Zellkompartimenten, den MHC-II-Kompartimenten, statt (Pieters, 1997; Germain, 1994; Watts, 2004; Wang et al., 1999). Diese stellen lysosomenverwandte Organellen (LRO: lysosomal-related organell) dar, die zusätzlich über die notwendige Ausrüstung an HLA-DM-Molekülen verfügen. HLADM-Moleküle helfen bei der Beladung von Peptid auf die Bindungsfurche der MHC-II Moleküle. Für den Weitertransport von Peptid:MHC-II-Komplexen an die Zelloberfläche und die effektive Präsentation der MHC-II-Epitope an CD4+ T-Lymphozyten ist eine stabile - hochaffine - Bindung der Peptidfragmente mit geeigneten Aminosäurekonstellationen an MHC-IIMoleküle eine wichtige Voraussetzung.

\subsection{Die Bedeutung der Präsentation von MHC-II- Selbstpeptiden auf DCs für die periphere Toleranz und die Regulation der T-Zell-Aktivität}

Neben exogenen Fremdproteinen nehmen DC auch exogene Selbstproteine auf und präsentieren diese nach Prozessierung auf ihren MHC-II-Molekülen - die wichtigste Quelle potentieller Autoimmunreaktionen. T-Zellen, die auf solche Selbstpeptide antworten, müssen im Thymus eliminiert werden. Die zentrale Toleranzinduktion ist aber unvollständig. Einige T-Lymphozyten mit niedriger Affinität für Selbstantigene sind in der Lage der negativen Selektion im Thymus zu entgehen (Bouneaud et al., 2000). Zudem gibt es Selbstproteine, die erst in späteren Phasen des Lebens auftreten, wenn das LymphozytenRepertoire bereits gebildet ist (Matzinger, 1994). Alternativ handelt es sich um Selbstproteine, die nur in spezialisierten Geweben (z.B. Hoden) exprimiert werden, nicht jedoch im Thymus präsentiert werden (Lo et al., 1989; Anderson et al., 2002). Periphere Toleranzmechanismen ergänzen offensichtlich die 
thymusabhängige Toleranz, wobei verschiedene Mechanismen diskutiert werden (Rocha and von Boehmer, 1991; Jones et al., 1990; Powrie and Maloy, 2003).

Eine zentrale Rolle bei der Aufrechterhaltung der peripheren Toleranz wird den DC zugeschrieben (Steinman, 2003; Steinman and Nussenzweig, 2002). Unreifen DC fehlen kostimulatorische Moleküle. Die Präsentation von Selbstpeptiden-MHC-Komplexen ohne die kostimulatorischen Moleküle führt zur Anergie der erkennenden T-Zellen (Greenfield et al., 1998). Weiterhin gibt es Hinweise darauf, dass selbstreaktive T-Lymphozyten in der Peripherie auch deletiert werden können (Hawiger et al., 2001). Ein anderer Mechanismus könnte die indirekte Tolerisierung selbstreaktiver T-Zellen über regulatorische

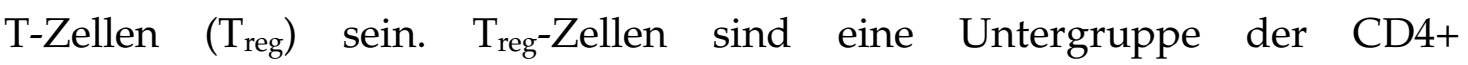
T-Lymphozyten, die die IL-2R- $\alpha$-Kette (CD25) und den Transkriptionsfaktor FOXP3 („forkhead-winged helix Transcription factor $3^{\prime \prime}$ ) exprimieren (Schubert et al., 2001; Khattri et al., 2003). Die Suppression selbstreaktiver T-Zellen erfolgt entweder direkt über Zell-Zellkontakt oder indirekt über die Sezernierung von anti-inflammatorischer Mediatoren wie IL-10 und TGF- $\beta$ (Roncarolo et al., 2001; Shevach et al., 2002). Neben natürlich auftretenden $\mathrm{T}_{\text {reg- }}$

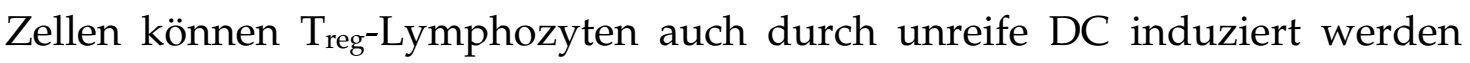
(Jonuleit et al., 2001; Menges et al., 2002). Interessanterweise ließen sich ebenso regulatorische $\mathrm{CD} 4+\mathrm{CD} 25+\mathrm{T}-$ Zellen durch reife DC stimulieren (Yamazaki et al., 2003). Zudem zeigten reife DC effizientere protektive Effekte bei Autoimmunreaktionen als unreife DC (Lenschow et al., 1996; Feili-Hariri et al., 1999; Salomon et al., 2000).

Selbstpeptid-MHC-II-Komplexe haben also sowohl eine Funktion als Liganden für die positive und negative Selektion von Thymozyten als auch für die Aufrechterhaltung der peripheren Toleranz. Auch für das Überleben naiver 
T-Lymphozyten scheinen Selbstpeptid-MHC-II-Komplexe essentiell zu sein (Brocker, 1997; Viret et al., 1999). Neueste Studien zeigen zudem eine bedeutende Rolle von Selbstpeptiden für die Antigenerkennung und Regulation der T-Zellaktivität gegenüber Fremdantigenen: Zum einen können sie als „akzessorische Liganden“ die Bildung der immunologischen Synapse unterstützen und zur T-Zell-Signaltransduktion beitragen (Wülfing et al., 2002), zum anderen könnten Selbstpeptide dem TCR das Auffinden seines passenden MHC-Peptid-Liganden erleichtern, indem sie schwache Wechselwirkungen mit dem TCR eingehen und ihn so zum FremdpeptidMHC-II-Komplex leiten (Wu et al., 2002). Der genaue Einfluss der MHC-IISelbstpeptid-Komplexe auf die T-Zellaktivierung ist zur Zeit allerdings noch umstritten. Bandhoola et al. (2002) zeigten in einer Studie, dass Selbstpeptide die T-Zellreaktion gegenüber Fremdpeptiden dämpfen, indem sie zum einen die Aktivierbarkeitsschwelle anheben und zum anderen regulatorische T-Zellen aktivieren. Im selben Jahr zeigten dagegen Stefanova et al. (2002), dass die Gegenwart, von Selbstpeptiden die Sensitivität des T-Zell-Rezeptors gegenüber Fremdpeptiden sogar steigert.

\subsection{Identifikation von MHC-Klasse-II-Peptidepitopen}

Bisher sind kaum tumorspezifische MHC-II-Peptidepitope bekannt. Ein Grund dafür liegt in methodisch-technischen Herausforderungen bei ihrer Identifikation. Zahlreiche Versuche sind in jüngster Zeit unternommen worden, um tumorassoziierte MHC-II-Epitope zu identifizieren. Ausgehend von cDNA-Bibliotheken aus Tumorzellen und tumorspezifischen T-Lymphozyten können zelluläre Tumorantigene mittels Expressionsklonierung identifiziert werden. Hierbei müssen die 
zellbiologischen Abläufe bei der MHC-II-abhängigen Antigenprozessierung und -präsentation berücksichtigt werden.

Eine relativ erfolgreiche und systematische Strategie bestand in einem 1999 von Wang vorgestellten genetischen Verfahren. Hierbei wurden aus Tumorzellen generierte cDNAs an die invariante MHC-II-Kette-Gen (Ii) fusioniert (Wang et al., 1999a; Wang et al., 1999b). Die sekretorischen als auch die zytoplasmatischen Proteine werden so in den exogenen Pfad der Antigenprozessierung geleitet und potenziell $\mathrm{zu}$ MHC-II-restringierten Helferepitopen verarbeitet. Der Ii-TA-Fusionsvektor wird anschließend in antigenpräsentierende HEK293IMDR-Zellen, die zusätzlich wichtige Komponenten des MHC-II-Pfades (HLA-DM, -DRa, DRb) überexprimieren, transfiziert. Die Detektion antigenspezifischer Immunreaktionen erfolgt schließlich durch Kokultivierung dieser Zellen mit patienteneigenen, tumorspezifischen CD4+ T-Zellen (Wang et al., 1999b).

Eine biochemische Strategie zur Auffindung von T-Helferzellantigenen basiert auf der Peptidelution von MHC-II-positiven Tumorzellen (Li et al., 1998b). Auch Proteinfraktionierungen aus Tumorzelllysaten mit anschließender Proteinidentifikation mittels Massenspektrometrie führte zur Identifikation neuer Tumorantigene (Pieper et al., 1999). Die immunologische Antigendetektion erfolgt bei diesen Strategien über tumorspezifische CD4+ T-Zellen. Patienteneigene CD4+ T-Lymphozyten mit ausreichender Tumorspezifität sind allerdings nur bei wenigen Tumorentitäten - z.B. bei MHC-II-exprimierenden Melanomen aus tumorinfiltrierenden Lymphozyten (TIL) - kultivierbar. So können für die Identifikation von tumorassoziierten Helferzellantigenen sowohl das genetische als auch das biochemische Verfahren bei der Mehrzahl der Tumorarten a priori nicht genutzt werden. 
Die Identifikation mittels „reverser Immunologie“ oder „Epitopdeduktion“ (Schultze and Vonderheide, 2001) erfolgt hingegen zuerst ohne Einsatz von patienteneigenen tumorspezifischen T-Zellen. Proteine, die in Tumorzellen im Vergleich zu entsprechenden Normalzellen überexprimiert vorliegen, werden über genomweite Expressionsanalysen und ihrer möglichen funktionellen Bedeutung in der Kanzerogenese identifiziert. Anschließend werden mit Hilfe von inzwischen sehr zuverlässigen computergestützten Epitop-Algorithmen die T-Zell-Epitope vorhergesagt, die eine potentiell hohe Bindungsaffinität zwischen allelen MHC-Molekülen und Peptidsequenzen in der Aminosäuresequenz des Kandidatenantigens besitzen. Diese Kandidatenepitope finden als synthetische Peptide Anwendung bei der in vitro-Stimulation von spezifischen T-Zellen und werden hinsichtlich ihrer Antigenität und immunologischen Eigenschaften untersucht. Bei Vorliegen eines „genuinen“ T-Zellantigens werden die entsprechenden Peptidepitope für immunologische Untersuchungen aus dem Blut von Tumorpatienten und schließlich für klinische Vakzinierungen genutzt. In der hier vorgestellten Arbeit wurden die tumorassoziierten Proteine Survivin und Proteinase 3 untersucht.

\subsection{Das tumorassoziierte Protein Proteinase 3}

Proteinase 3 (PR3), auch als Myeloblastin bekannt, gehört zur Gruppe der neutralen Serinproteasen und kommt in der azurophilen Granula von neutrophilen Granulozyten und in der Granula von Monozyten vor (Campanelli et al., 1990; Borregaard and Cowland, 1997). Unter physiologischen Bedingungen lässt sich das PR3-Protein nur in Zellen der Myelopoese nachweisen. PR3 besitzt eine mikrobizide Wirkung gegen Bakterien sowie Pilze, die unabhängig von der enzymatischen Aktivität durch 
eine Hemmung der Synthese von Makromolekülen sowie Inhibition des Sauerstoffmetabolismus und energieabhängigen Membrantransports erklärt wird (Janoff, 1985). Über einen enzymatischen Abbau verschiedener Strukturproteine, wie Elastin, Fibronektin, Proteoglykanen und Typ IV Kollagen, bahnt PR3 die Migration von neutrophilen Granulozyten durch die extrazelluläre Matrix und durch Basalmembranen (Owen and Campell, 1999; Borregaard and Cowland, 1997; Rao et al., 1996). Überdies ist eine physiologische Rolle von PR3 im Rahmen der myeloischen Differenzierung hämatopoetischer Stammzellen experimentell belegt. So konnte unter anderem gezeigt werden, dass eine konstitutive Überexpression von PR3 in CD34+ hämatopoetischen Stammzellen einen unabhängigen Proliferationsstimulus darstellt (Lutz et al., 2000). Im Stadium der Promyelozyten reguliert PR3 die Differenzierung durch eine enzymatische Spaltung von NF-אB (Franzoso et al., 1994), Hsp28 (Spector et al., 1995) und Sp1 (Rao et al., 1998).

Pathologisch ist PR3 in eine Vielzahl von Krankheiten involviert. So spielt es eine Rolle bei der zystischen Fibrose (Just et al., 1999), der Vaskulitis und rheumatoiden Arthritis (Witko-Sarsat et al., 1999) und der cANCA-positiven Wegener Granulomatose (Hagen et al., 1993). Darüber hinaus ist PR3 in den malignen Zellen von akuten und chronischen myeloischen Leukämien überexprimiert und spielt bei der Erhaltung der Lebensfähigkeit maligner Zellen eine wichtige Rolle (Bories et al., 1989; Lutz et al., 2001).

Mitte der 90iger Jahre konnten PR3-spezifische CTL aus dem Blut von Tumorpatienten isoliert werden (Molldrem et al., 1996). Myeloische Zellen mit einer physiologischen PR3-Expression werden von diesen reaktiven CTL nicht lysiert oder in ihrer Proliferation und Differenzierung beeinträchtigt (Molldrem et al., 2000).

Als wichtigster Beleg für eine T-Helferzellantwort gegen PR3 ist das Phänomen des Immunglobulin-Klassen-Switch mit den vorherrschenden IgGSubklassen $\operatorname{IgG}_{1}$ und $\mathrm{IgG}_{4}$ bei der Wegenerschen Erkrankung $\mathrm{zu}$ werten 
(Brouewer et al., 1991). MHC-Klasse-II-Epitope als Ziele einer CD4+ T-Helferreaktion gegen PR3 waren zu Beginn der hier vorgestellten Arbeiten nicht beschrieben.

\subsection{Das tumorassoziierte Protein Survivin}

Survivin (SVN) gehört zur Familie der „Inhibitor of apoptosis protein“ (IAP), die an der Regulation der Zellteilung und der Suppression der Apoptose beteiligt sind. SVN wird Zellzyklus-abhängig gebildet und bindet während der Mitose die Pro-Caspase-9, wodurch es die Aktivierung der Caspase durch Apaf1s/cytochrome $c$ verhindert. Desweiteren ist SVN mit der MTOC („microtubule organization center“) während der Interphase, und an der mitotischen Spindel und den Zentrosomen während der Metaphase assoziiert (Giodini et al., 2002). Eine dominant-negativ mutierte Form von SVN führt zu einem Zellteilungsdefekt, dessen Auswirkung sich in der ZentrosomenDeregulation, einer multipolaren, mitotischen Spindel und von multinucleated, polyploiden Zellen widerspiegelt.

Mit Ausnahme von Thymozyten (Ambrosini et al., 1997), Placenta, CD34+ Stammzellen (Carter et al., 2001; Fukuda and Pelus, 2002a) und Basalzellen des Kolonepithels (Gianani et al., 2001; Zhang et al., 2001) wird SVN normalerweise nur in embryonalem und fötalem Gewebe exprimiert (Adida et al., 1998; Kobayashi et al., 2002). In vielen Tumoren liegt SVN dagegen überexprimiert vor (Altieri, 2003); die tumorale SVN-Überexpression ist mit einer erhöhten Tumorrezidivquote (Swana et al., 1999), einer höheren Therapieresistenz (Ikeguchi and Kaibara, 2001; Tran et al., 2002) sowie einer kürzeren Überlebenszeit der betroffenen Patienten assoziiert (Adida et al., 2000a). Dies wurde neben Neuroblastomen (Islam et al., 2000), Harnblasen-Karzinomen (Swana et al., 1999) und Melanomen (Lee et al., 1998) auch für Leukämien 
(Adida et al., 2000b) und Lymphome (Ambrosini et al., 1997; Adida et al., 2000a) gezeigt. Die Transkription des SVN-Gens in Tumorzellen ist global dereguliert; so wurde eine Zellzyklus-unabhängige Expression nachgewiesen (Grossmann et al., 1999b). Bei der Erhaltung der Lebensfähigkeit entarteter Zellen spielt der SVN-Pathway der Apoptose-Regulation eine wichtige Rolle (Ambrosini et al., 1998; Chen et al., 2000; Grossmann et al., 1999a; Li et al., 1998a; Olie et al., 2000). Die Überexpression von SVN in Tumorzellen führte zu der Annahme, dass es sich möglicherweise um ein tumorassoziiertes Antigen handelte (Andersen et al., 2002). Kürzlich konnten aus dem peripheren Blut von Patienten mit malignem Melanom und chronischer lymphatischer Leukämie (CLL) reaktive CTL isoliert werden, die allogene, HLA-identische Tumorzellen lysierten (Altieri, 2001; Andersen et al., 2001; Mahotka et al., 1999; Schmitz et al., 2000; Tamm et al., 1998). Zudem konnten Antikörper gegen SVN bei verschiedenen Tumoren nachgewiesen werden (Chang et al., 2004; Rohayem et al., 2000), was auf die Existenz von T-Helferzellantworten gegen SVN hinweist. Damit ist eine der Voraussetzungen für den Einsatz dieses Proteins in der spezifischen Immuntherapie von Tumoren gegeben. 


\section{Zielsetzung der Arbeit}

Das Kernziel der Arbeit bestand in der Identifikation von MHC-IIrestringierten Peptidepitopen in solchen Proteinen, die ein tumorassoziiertes Expressionsverhalten aufwiesen und die bereits bekannte Zielantigene zytotoxischer T-Zellreaktionen waren. Als entsprechende Kandidatenantigene wurden Proteinase 3 und Survivin ausgewählt. Ein erster Arbeitsschritt bestand in der computergestützten Vorhersage von potentiellen MHC-IIPeptidepitopen innerhalb der Aminosäuresequenzen von PR3 und SVN. Epitopkandidaten können mit Hilfe von datenbankgestützten Algorithmen, die Bindungs-Aviditäten zwischen beliebigen Peptiden und bestimmten MHC-Allelen der Klassen I und II vorhersagen, identifiziert werden. Im vorliegenden Fall wurde mit Hilfe des Computerprogramms TEPITOPE ${ }^{\circledR}$ sowie der von H. G. Rammensee über das Internet verfügbaren Prädiktionssoftware in der Primärstruktur von PR3 und SVN nach Aminosäuresequenzen, die mit hoher Wahrscheinlichkeit an die wichtigsten allelen MHC-II-Moleküle binden, gesucht. Die Epitope wurden in Form von synthetischen Peptiden zur in vitro-Stimulation von humanen CD4+ T-Lymphozyten eingesetzt. In diesem Zusammenhang waren die Kulturbedingungen für CD4+ TA-spezifische T-Helferzelllinien und -klone zu etablieren. Peptidspezifische CD4+ T-Zellen wurden hinsichtlich ihrer MHCRestriktion, ihrem Phänotyp und ihrer Epitop-MHC-Affinität untersucht. Mit ihrer Immunreaktivität gegen korrespondierendes Tumorprotein bzw. Tumorzelllysate, die das entsprechende Antigen exprimieren, sollte der Nachweis erbracht werden, dass die entsprechenden Peptidsequenzen im 
endozytotischen Pfad der Antigenprozessierung zu MHC-II-gebundenen Peptidepitopen für eine Präsentation an CD4+ Helferzellen verarbeitet wurden. Bei Vorliegen eines „genuinen“ Peptidepitops sollte die Frage geklärt werden, ob sich Peptid-spezifische CD4+ T-Lymphozyten aus dem Blut von Krebspatienten stimulieren lassen - eine wichtige Voraussetzung für eine adoptive T-Zelltherapie bzw. für nachfolgende Analysen hinsichtlich einer möglicherweise induzierten T-Zellanergie. 


\section{Material}

\subsection{Geräte}

ÄKTApurifier

Analysenwaage H54AR

Blotkammer Mini-Trans Blot

Cell Harverster IH-110-96

$\mathrm{CO}_{2}$-Inkubator HeraCell

Epifluoreszenzmikroskop IX 70

FACScan

Feinwaage

Geldokumentationsapparatur

Gelkammer Modell AE-6450

Gelkammer für Agarosegele

Heizblock Techne Dry-block DB2A

IKA KS 260 Schüttler

ImmunoSpot Analyzer LLC

Megafuge 2.0R

Microbeta Triflux 1450

Microplate Reader 680

Mini-Trans Blot Kammer

Multifuge 3 L-R

pH-Meter PHM 82

Power Supply Consort E734
AmershamPharmacia, UK

Mettler, Gießen

Biorad, München

Inotech, Schweiz

Heraeus, Hamburg

Olympus

Becton Dickinson, Heidelberg

Sartorius, Göttingen

INTAS, Göttingen

Atto, Japan

Renner, Dannstadt

Thermo-Dux, Wertheim

IKA, Staufen

CTL-Europe, Reutlingen

Heraeus, Hamburg

Wallac, PerkinElmer

Biorad, München

Biorad, München

Heraeaus, Hamburg

Radiometer, Dänemark

Schütt Labortechnik, Göttingen 
Power-Supply EPS 500/400

Protec Optimax X-Ray Film Processor

PTC 100 DNA

Reax2 Rotorschüttler

Schweißer Cordless tube topper

Spektralphotometer

Sterilwerkbank MicroFlow

Televal 31 Inverses Durchlichtmikroskop

Thermocycler 60

Thermocycler Trio

Trockenschrank

Ultraschallbad Sononrex RK 31

Ultrazentrifuge L-70

Vortex Genie 2

Wasserbad

Zentrifuge Sorvall Evolution RC
Pharmacia Fine Chemicals

Maco, Heidelberg

Biozyme, Hessisch Oldendorf

Heidolph, Schwabach

Beckmann Coulter

Eppendorf, Hamburg

Astec, UK

Zeiss, Jena

Biomed, Theres, Deutschland

Biometra, Göttingen

Heraeaus, Hamburg

Rottberg, Göttingen

Beckmann Coulter. Krefeld

Schütt Labortechnik, Göttingen

Kottermann

Kendro Laboratory,

Langenselbold

\subsection{Chemikalien, Biochemikalien und Radiochemikalien}

Sämtliche in dieser Arbeit verwendeten Chemikalien wurden in Analysequalität von den angegebenen Firmen bezogen.

[3 $\mathrm{H}]$-methyl-Thymidin

AIM-V

Agarose
Amersham,UK

Gibco-Invitrogen, Karlsruhe

Sigma-Aldrich, München 
$\beta_{2} \mathrm{~m}$, human

$\beta$-Mercaptoethanol

Ampicillin

Bacto Trypton

Bacto Yeast-Extract

BSA

Coomassie Brillant Blue R-250

DAPI

DC Medium

Dimethylsulfoxid

DNA-Marker

DTT

DMEM

ECL

Ethidiumbromid

$\mathrm{EtOH}$

FBS

Geniticin (G418)

Größenstandards

DNA-Marker 50-1000 Bp

1 kB Ladder DNA-Marker

Proteinmarker Nu PAGE MES

Proteinmarker

Page Ruler ${ }^{\mathrm{TM}}$, "prestained"

$\mathrm{H}_{2} \mathrm{O}_{2}$

Harnstoff

HEPES
Sigma-Aldrich, München

Serva, Heidelberg

Sigma-Aldrich, München

Difco Laboratories, USA

Difco Laboratories, USA

New England Biolabs, USA

Serva, Heidelberg

Serva, Heidelberg

Cell Genix Freiburg

Sigma, München

Sigma, München

Serva, Heidelberg

Gibco-Invitrogen, Eggenstein

Amersham Bioscience

Roche, Mannheim

JT Baker

Fluka (Sigma)

Gibco BRL Life Technologies,

Karlsruhe

Biozym, Hessisch Oldendorf:

Gibco BRL Life Technologies,

Karlsruhe

Invitrogen

Fermentas

Fluka, Neu-Ulm

Merck, Darmstadt

Fluka, Buchs, Schweiz 
HeringSperm DNA

IPTG

Isopropanol

Kanamycin

L-Glutamin

Leupeptin

Lymphoprep/Ficoll

Magermilchpulver

Nonidet P40

dNTP-Mix

PBS-Tabletten

Penicillin/Streptomycin

Pepstatin A

PHA-P

$\mathrm{PPO}$

Protein A-Sepharose

Protogel (30\% Acrylamid/

0,8\%Bisacrylamid)

RNasin ${ }^{\circledR}$

RPMI 1640 (1x) mit L-Glutamin

steriles Wasser für Injektionszwecke

Sucrose

TEMED

Trasylol (Aprotinin)

Tris- $\mathrm{HCl}$

Triton X-100

Trypsin-EDTA-Lösung

Tween-20
Roche, Mannheim, Deutschland

Biomol, Hamburg

Fluka, Neu-Ulm

Amersham, UK

Gibco Technologies, Eggenstein

Boehringer, Mannheim

Gibco Technologies, Eggenstein

Neuform, Herrenberg

Fluka, Neu-Ulm

Invitrogen

Gibco Technologies, Eggenstein

Gibco Technologies, Eggenstein

Biomol, Hamburg

Sigma-Aldrich, München

Fluka, Neu-Ulm

Pharmacia, Freiburg

National Diagnostics, England

Promega, Madison, USA

Gibco-Invitrogen, Eggenstein

Baxter, Belgien

Sigma, München

Serva, Heidelberg

Bayer, Leverkusen

Serva, Heidelberg

Fluka, Neu-Ulm

Invitrogen

Fluka, Neu-Ulm 


\subsection{Verbrauchsmaterialien}

Cryoröhrchen 2,0 ml

Dialyseschläuche Visking 8/32

FACS-Röhrchen

Filtermatten für MicroBeta

Filterpapier Whatman 3MM

Gewebekulturschalen

Hybond-C Super

(Nitrozellulose) Membran

hIFN- $\gamma$ ELISA-KIT

hIL-2 ELISA-KIT

hIL-4 ELISA-KIT

hIL-10 ELISA-KIT

hTGF- $\beta 1$ ELISA-Kit

Mini-Q-Anionenaustauschersäule

Pipetten $(5,10,25 \mathrm{ml})$

Prefusorspritzen $50 \mathrm{ml}$

Protein Assay-Kit (Bradford)

QIAfilter Plasmid Maxi Kit

QIAshredder

RNeasy Mini Kit

Röntgenfilm Kodak X-OMAT AR

Röntgenfilm Kodak X-OMAT BMR

Sample Bags für MicroBeta

Superfect Reagent

TC-96-Loch-Rundbodenplatten

TC-Flaschen (T-25, T-75,T-175)

TC-Kulturschalen $(15 \mathrm{~cm})$
Sigma, München

Serva, Heidelberg

Sarstedt, Nürnbrecht

Amersham

Schleicher und Schüll, Dassel

Nunc, Roskilde, Dänemark

Amersham, UK

Mabtech, Hamburg

Mabtech, Hamburg

Mabtech, Hamburg

Mabtech, Hamburg

Diaclone

Biorad, München

Sarstedt

Braun

Biorad, München

Qiagen, Hilden

Qiagen, Hilden

Qiagen, Hilden

Kodak, USA

Kodak, USA

Perkin Elmer

Qiagen, Hilden

Sarstedt, Nürnbrecht

Sarstedt, Nürnbrecht

Greiner 
Titan One Tube RT-PCR System

Zellsiebe $70 \mu \mathrm{m}$

Zentrifugenröhrchen (15 bzw. $30 \mathrm{ml})$
Roche Diagnostics, Mannheim

Falcon

Sarstedt, Nürnbrecht

\subsection{Antikörper}

$\alpha$-hCD3-PE
$\alpha$-hCD4-FITC
$\alpha$-hCD8-PE
$\alpha$-hCD25-FITC
$\alpha$-hCTLA-4
$\alpha$-hGITR-PE
$\alpha$-hIgG-FITC
$\alpha$-hIgG-PE
$\alpha$-Kaninchen-IgG-HRP
$\alpha$-Maus-IgG-HRP
$\alpha$-hPR3
$\alpha$-hSurvin

\subsection{Enzyme}

Endonukleasen

Reverse Transkriptase

RNaseA

T4-DNA-Ligase
R\&D

R\&D

R\&D

R\&D

BD Bioscience

R\&D

R\&D

R\&D

Santa Cruz Biotechnology

Santa Cruz Biotechnology

Neo Markers B

Santa Cruz Biotechnology
EcoRI, HindIII, I-CeuI, KpnI, MluI, NheI PacI, PI-SceI: New England Biolabs, Frankfurt Invitrogen Sigma, Deisenhofen

Invitrogen 
Taq-Polymerase Invitrogen

Die Reaktionsansätze der jeweiligen Enzyme wurden nach Angaben des Herstellers eingesetzt.

\subsection{Zytokine}

$\begin{array}{ll}\text { hIL-1b } & \text { Biosource } \\ \text { rhIL-2 } & \text { Roche } \\ \text { hIL-4 } & \text { Roche } \\ \text { hIL-6 } & \text { Roche } \\ \text { hGM-CSF } & \text { Biosource } \\ \text { PGE2 } & \text { Biosource } \\ \text { hTNF-a } & \text { Biosource }\end{array}$

\subsection{Oligonukleotide}

Sämtliche Oligonukleotide wurden von der Fa. IBA, Göttingen, bezogen.

Für Klonierungen:

Proteinase 3

F: 5'-ATTAAGCTTGCTAGCCGCCACCATGGCTCACCGGCCCCCCAGCCCT-3'

R: 5'-TATAACGCGTGGGGCGGCCCTTGGCCTCCACAC-3' 

LAMP-1
F: 5'-TATAACGCGTGGTAACAACATGCTGATCC-3
R: 5'-TATAGAATTCGGTACCTCAGATGGTCTGATAGCCCGCGT-3

Für RT-PCR:

$\beta$-Actin

F: 5'-GGGTCAGAAGGATTCCTATG-3'

R: 5'-GGTCTCAAACATGATCTGGG-3'

FoxP3

F: 5'-TTCTGTCAGTCCACTTCACCAAGC-3'

R: 5'-GTTGAGAGCTGGTGCATGAAATGTGG-3'

Proteinase 3

F: 5'- -ACAACTACGACGCGGAGAAC-3'

R: 5'- GTGACCACGGTGACATTGAG-3'

Survivin

F: 5'-CTCAAGGACCACCGCATCTC-3'

R: 5'-AGCGCAACCGGACGAATGCT-3'

\subsection{Peptide}

Peptide mit einer Länge zwischen 15 und 25 AS (AS-Sequenzen der einzelnen Peptide siehe Tab. 4.3, S. 68) wurden in der "Peptide Synthesis Core Facility" des MD Anderson Cancer Center (Houston, Texas) von Dr. M. Campbell synthetisiert und mittels HPLC aufgereinigt (>95\%). 


\subsection{Plasmide}

pAd5/F35 Clontech

pcDNA3.1(+) ZEO Invitrogen, Karlsruhe

pLAMP1 freundlicherweise von G. Wulf, Uniklinik Göttingen

pPRTN3 h freundlicherweise von U. Specks, Mayo Klinik, Rochester, USA

pShuttle Clontech

\subsection{Lösungen und Puffer}

Die Lösungen und Puffer wurden mit $4 \mathrm{x}$ demineralisiertem Wasser angesetzt. Lösungen, die in der Zellkultur eingesetzt worden sind, wurden mit sterilem Wasser für Injektionszwecke angesetzt.

Agarose-Gele $\quad 0,8-1,5 \%$ Agarose in TAE-Puffer, $1 \mu \mathrm{g} / \mathrm{ml}$ Ethidiumbromid

Agarplatten $\quad 1,5 \%$ Bacto-Agar in LB-Medium, $50 \mu \mathrm{gg} / \mathrm{ml}$ Ampicillin, Platten steril gießen (ca. 5 mm dick)

Wirkstoff Aprotinin

(Trasylol 1000x) $5 \mathrm{mg} / \mathrm{ml}$ in PBS

Blockpuffer $\quad 5 \%$ Milchpulver in Waschpuffer

Coomassie-Entfärber $\quad 10 \%$ Isopropanol; $10 \%$ Essigsäure in $\mathrm{H}_{2} \mathrm{O}$

Coomassie-

Färbelösung 1,5 g Coomassie Brilliant Blue R-250 in 11 Methanol/ $\mathrm{H}_{2} \mathrm{O} /$ Eisessig (5:5:1) 
DNA-Probenpuffer

100 mM EDTA pH 8,0; 50\% Glycerin; 1\% SDS; 0,25\% BPB; 0,25\% Xylencyanol

dNTP-Mix (50x) $10 \mathrm{mM} \mathrm{dATP;} 10 \mathrm{mM} \mathrm{dCTP;} 10 \mathrm{mM}$ dGTP; $10 \mathrm{mM}$ dTTP

ECL-Lösung 1 2,5 mM Luminol; $400 \mu \mathrm{M}$ p-Coumarinsäure;

$100 \mathrm{mM}$ Tris- $\mathrm{HCl} \mathrm{pH} 8,5$

ECL-Lösung $2 \quad 13 \mathrm{mM} \mathrm{H}_{2} \mathrm{O}_{2} ; 100 \mathrm{mM}$ Tris- $\mathrm{HCl} \mathrm{pH} \mathrm{8,5}$

Elutionspuffer $\quad 50 \mathrm{mM}$ Tris- $\mathrm{HCl} \mathrm{pH}$ 7,5; $10 \%$ Glycerol; $5 \mathrm{mM}$ reduziertes Glutathion

Ethidiumbromidlösung $100 \mathrm{mg} / \mathrm{ml}$ Aqua bidest.; lichtgeschützt lagern

FACS-Puffer $1 \times$ PBS, $0,5 \%$ BSA

HEBS

$20 \mathrm{mM}$ HEPES, $140 \mathrm{mM} \mathrm{NaCl}, 5 \mathrm{mM} \mathrm{KCl}, 0,75 \mathrm{mM}$ Na2HPO4, 7,6 mM Glukose, $\mathrm{pH}=7,05$

Ligasepuffer (10x) 660 mM Tris- $\mathrm{HCl}$ pH 7,6; $50 \mathrm{mM} \mathrm{MgCl}$; 50 mM DTT; $10 \mathrm{mM}$ ATP

Mounting-Medium 5\% Polyvinylalkohol 25/140 (Merck); 10\% Glycerin in PBS

PCR-Puffer (10x) 100 mM Tris- $\mathrm{HCl}$ pH 8,3; 500 mM KCl; 15 mM MgCl ; $0,1 \%$ Gelatine

PBS $140 \mathrm{mM} \mathrm{NaCl} ; 3 \mathrm{mM} \mathrm{KCl} ; 8 \mathrm{mM} \mathrm{Na} 2 \mathrm{HPO}_{4} ; 1,5 \mathrm{mM}$ $\mathrm{KH}_{2} \mathrm{PO}_{4}$

Plasmidisolierung

S1 RNase A $(100 \mu \mathrm{g} / \mathrm{ml}) ; 50 \mathrm{mM}$ Tris-HCl pH 8,0; 10 mM EDTA

S2 $0,2 \mathrm{M} \mathrm{NaOH} ; 1 \% \mathrm{SDS}$

S3 2,55 M KAc pH 4,8

SDS-PAGE-Laufpuffer 250 mM Tris-HCl; 1,9 M Glycin; 1\% SDS 
6x SDS-Probenpuffer 130 mM Tris- $\mathrm{HCl}$ pH 6,8; 10\% $\beta$-Mercapto-Ethanol (frisch zusetzen); 20\% Glycerin; 4,6\% SDS; 0,2\% Bromphenolblau

SDS-Sammelgelpuffer 0,1 \% SDS; 4 \% Acrylamid; 130 mM Tris- $\mathrm{HCl}$ (pH 6,8); erst unmittelbar vor dem Gießen der Gele zugeben: $0,09 \%$ APS und 0,3\% TEMED

SDS-Trenngelpuffer $\quad 0,1 \%$ SDS; 10-15 \% Acrylamid; 130 mM Tris- $\mathrm{HCl}(\mathrm{pH}$ 8,8); erst unmittelbar vor dem Gießen der Gele zugeben: 0,05 \% APS und 0,12\% TEMED

TAE 40 mM Tris-Acetat pH 8,0; 1 mM EDTA

TBE-Puffer $90 \mathrm{mM}$ Tris-HCl; $90 \mathrm{mM}$ Borsäure; 2 mM EDTA $(\mathrm{pH} 8,0)$

TBS $10 \mathrm{mM}$ Tris- $\mathrm{HCl} \mathrm{pH} 8,0 ; 150 \mathrm{mM} \mathrm{NaCl}$

TE-Puffer $10 \mathrm{mM}$ Tris- $\mathrm{HCl}$ pH 7,5; 1 mM EDTA

TfB1 $100 \mathrm{mM} \mathrm{RbCl}, 50 \mathrm{mM} \mathrm{MnCl}$, $10 \mathrm{mM} \mathrm{CaCl}_{2}, 30 \mathrm{mM}$ KAc, 15\% Glycerin, pH 5,8 mit 0,2 M Essigsäure

TfB2 $10 \mathrm{mM}$ MOPS, $10 \mathrm{mM} \mathrm{RbCl}, 75 \mathrm{mM} \mathrm{CaCl} 2$ 15\% Glycerin, $\mathrm{pH}$ 7,0 mit $\mathrm{NaOH}$

Transferpuffer (WB) 192 mM Glycin; 50 mM Tris-HCl pH 8,3 Trypsin 2\% Trypsin; 1x PBS; 0,5 mM EDTA pH 8,0

Waschpuffer 0,05\% Tween-20 in TBS

\subsection{Medien}

DMEM

$\mathrm{DMEM}+10 \%$ FCS; 20 mM L-Glutamin, $100 \mathrm{mM}$ HEPES; $100 \mathrm{U} / \mathrm{ml}$ Penicillin; 100 \%g/ml Streptomycin, Antimykotikum

Einfriermedium 50 \% FCS; 3,7 g/L NaHCO 3 ; 12 \% DMSO in RPMI 
LB-Medium

10 g Bacto-Trypton; 5 g Hefeextrakt; 10 g NaCl; mit $\mathrm{H}_{2} \mathrm{O}$ auf $1 \mathrm{~L}$ auffüllen; $\mathrm{pH} 7,4$

RPMI 1640

RPMI + $10 \%$ FCS; 20 mM L-Glutamin, $100 \mathrm{mM}$

HEPES; $100 \mathrm{U} / \mathrm{ml}$ Penicillin; 100 g/ml Streptomycin

\subsection{Eukaryontische Zelllinien}

697

Granta-519

HEK 293a

HL-60

Jurkat

Jeko-1

K-562

Karpas -422

Mino

OCI

PM-1

Ramos

SP53

THP-1 humane B-Zellvorläufer Leukämie

humane MCL

humane embryonale Nierenzelllinie

epithelialen Ursprungs, welche die adenovirale

E1-Region des Ad5 stabil exprimieren

humane AML

humane T-Zell-Leukämie-Linie

humane MCL

humane Erythroleukämie

humanes B-Zelllymphom

humane MCL

humane AML

humane T-NHL

humane non-Hodgkin B-Zelllinie

humane MCL

humane AML 


\subsection{Bakterienstamm}

E.coli $\mathrm{DH} 5 \alpha \quad \mathrm{F}^{-} ;$endA1, hsdR17 $\left(\mathrm{r}_{\mathrm{k}^{-}}, \mathrm{m}_{\mathrm{k}}^{+}\right)$; supE44; thi-1; $\lambda^{-}$; recA1; gyrA96; relA1; $\Delta$ [argF-lacZYA]U169; [Ф80dlacZM15] (Hanahan, 1983)

\subsection{Blutproben}

Nach Zustimmung der Ethik-Kommission der Medizinischen Fakultät (Universität Göttingen) wurden mononukleäre periphere Blutzellen aus „buffy coats“ gesunder Blutspender (Transfusionsmedizin Universitätsklinikum Göttingen) und aus überschüssigem Blutmaterial aus der Routinediagnostik von Tumorpatienten (Abteilung Hämatologie und Onkologie) isoliert. Die HLA-Typisierungen erfolgten in der Abteilung Transfusionsmedizin, Universität Göttingen.

\subsection{Computerprogramme}

Text und Abbildungen: Microsoft Office 2000

Bildverarbeitung: Photoshop 5.0

Bilddokumetation: DM-RA: Spot

IX-70: Tillvision

ELISA: $\quad$ Microplate Manager 5.2, Biorad, München

ELISPOT: $\quad$ Immunspot Software 1.7e, CTL-Europe, Reutlingen 
FACS-Analyse: $\quad$ CELLquest ${ }^{\circledR}$ Software, Beckton Dickinson, Heidelberg

FlowJo, Treestar, USA

Internet Recherche: Internet Explorer

Literaturverwaltung: EndNote 3

Peptidanalyse:

TEPITOPE, Jürgen Hammer, Duke University, NC 


\section{Methoden}

\subsection{Zellbiologische Methoden}

\subsubsection{Allgemeine zellbiologische Methoden}

\subsubsection{Bestimmung der Zellzahl}

Zur Ermittlung der Zellzahl und Überprüfung der Vitalität der Zellen wurden diese mit Trypanblau (nur tote Zellen nehmen den Farbstoff auf) 1:10 verdünnt und in einer Neubauer-Zählkammer aufgetragen. Durch ein Invertmikroskop wurden die ungefärbten Zellen in den vier Feldern der Kammer gezählt und der Durchschnittswert ermittelt. Dieser Wert, multipliziert mit dem Verdünnungs- und Kammerfaktor, ergab wiederum die Zellkonzentration pro ml.

\subsubsection{Kultivierung von Zelllinien}

Die Kultivierung aller Zelllinien erfolgte in beschichteten Falcon ${ }^{-}$ Zellkulturflaschen $\left(75 \mathrm{~cm}^{2}\right.$ oder $150 \mathrm{~cm}^{2}$ in einem Brutschrank bei $37^{\circ} \mathrm{C}$ unter $\mathrm{CO}_{2}$-Atmosphäre $(5 \% \mathrm{v} / \mathrm{v})$. Das Splitten der in Suspensionskultur wachsenden Zellen erfolgte bei einer Dichte von ca. $1-2{ }^{*} 10^{6}$ Zellen/ml in einem Verhältnis von 1:2 bis 1:10 durch Austauschen des entsprechenden Volumens an Zellsuspension gegen frisches Medium. Adhärente Zellen wurden bis zu einer Konfluenz von 80-100 \% vermehrt und dann in einem Verhältnis von 1:2 bis 1:10 gesplittet. Dazu wurden die adhärenten Zellen 
zunächst in der Zellkulturflasche mit PBS gewaschen und anschließend mit Trypsin/0,5 mM EDTA bedeckt. Der Ablöseprozess konnte mikroskopisch verfolgt werden. Die abgelösten Zellen wurden in Komplettmedium (zur Inaktivierung des Trypsins) aufgenommen und entsprechend verdünnt wieder ausgesät werden.

\subsubsection{Kryokonservierung und Rekultivierung von Zellen}

Zur Kryokonservierung wurden die Zellen zentrifugiert (380 g, $5 \mathrm{~min}$ ) und anschließend in eiskaltem, sterilfiltriertem Einfriermedium (50\% FCS, $40 \%$ RPMI-1640, $10 \%$ DMSO) so resuspendiert, dass eine Zelldichte von $4^{*} 10^{6}$ bis $1^{*} 10^{7}$ Zellen $/ \mathrm{ml}$ resultierte. Die Zellen wurden in Kryoröhrchen überführt und in einer Einfrierbox bei $-70^{\circ} \mathrm{C}$ eingefroren. Nach einem Tag wurden die Röhrchen in flüssigen Stickstoff überführt.

Die Rekultivierung der Zellen erfolgte durch rasches Auftauen in einem $37^{\circ} \mathrm{C}$ Wasserbad. Die aufgetaute Zellsuspension wurde sodann in ein $15 \mathrm{ml}$ FalconRöhrchen mit PBS überführt, die Zellen zentrifugiert und der DMSO-haltige Überstand abgesaugt. Die Zellen wurden anschließend in vorgewärmten Komplettmedium aufgenommen und in einen Zellinkubator überführt.

\subsubsection{Isolierung und Kultivierung humaner Blutzellpopulationen}

\subsubsection{Isolierung mononukleärer Blutzellen (PBMC) mittels Dichtegradientenzentrifugation}

Mononukleäre Zellen des peripheren Blutes können aufgrund ihrer Dichte von den anderen Bestandteilen des Blutes getrennt werden. Heparinisiertes Blut wurde 1:1 mit PBS verdünnt und über Ficoll-Hypaque in Zentrifugenröhrchen geschichtet. Nach Zentrifugation (bei 450 x g für 35 Minuten ohne Bremse) 
wurden die mononukleären Zellen aus der Interphase zwischen dem Ficoll und dem Plasma mit einer Pasteurpipette abgezogen. Nach dreimaligem Waschen mit PBS, bei 380 x g für jeweils 5 Minuten, wurden die Zellen anschließend in komplettem AIM-V-Medium aufgenommen und ausgezählt (siehe 3.1.1.1).

\subsubsection{Isolierung von Monozyten und Differenzierung $\mathrm{zu}$ dendritischen Zellen}

Dendritische Zellen (DC) wurden aus der monozytären Blutzellfraktion generiert. PBMC wurden wie unter 3.1.2.1 beschrieben über einen FicollDichtegradienten isoliert und $5 \times 10^{7}$ Zellen in $75 \mathrm{~cm}^{2}$ Zellkulturflaschen mit $10 \mathrm{ml}$ DC-Medium für 2 Stunden bei $37^{\circ} \mathrm{C}$ inkubiert. In dieser Zeit adhärierten die Monozyten an die Plastikoberfläche der Zellkulturflasche. Die nichtadhärenten Zellen (NAC) wurden entfernt und die verbleibende Zellfraktion in DC-Medium, welches rhGM-CSF (1000 U/ml) und IL-4 (1000 U/ml) enthielt, für sechs Tage kultiviert. An den Tagen drei und fünf wurden die entsprechenden Zytokine erneut hinzugefügt. Nach sechs Tagen in Kultur wurden die noch unreifen DC geerntet, gezählt und 2x106 Zellen in $1 \mathrm{ml}$ DCMedium in eine 24-Lochplatte überführt. Für die Reifung der DC wurde ein zweiter Zytokincocktail, bestehend aus TNFa (10 ng/ml), IL-1 $\beta$ (10 ng/ml), IL-6 (10 ng/ml) und PGE2 $(1 \mu \mathrm{g} / \mathrm{ml})$, zugefügt. Nach 24 Stunden wurden die reifen $\mathrm{DC}(\mathrm{mDC})$ geerntet und in anschließenden Experimenten verwendet. 


\subsubsection{Generierung von Peptid-spezifischen CD4+-T-Zellklonen}

\subsubsection{Stimulation von CD4+ T-Zellen}

PBMC (3x105 Zellen /Loch) wurden in einer 96-Lochplatte ausplattiert. Zur T-Zellstimulation wurden $50 \mu \mathrm{l}$ Peptid (Konzentration $20 \mathrm{ng} / \mu \mathrm{l}$ ) zu den PBMC pipettiert. Pro Peptid wurden 48 Löcher präpariert. Um eine Stimulation durch im fetalen Kälberserum enthaltene Fremdantigene zu vermeiden, wurden die PBMC in serumfreiem AIM-V-Medium kultiviert. Nach sieben Tagen wurde das Medium gegen frisches AIM-V-Medium ausgetauscht. In einem Proliferationstest (3.1.3.2) wurden die Zellen mit dem entsprechenden Peptid und bestrahlten (30 Gy), autologen PBMC (1x105 Zellen/Loch) auf ihre spezifische Proliferationsantwort getestet.

\subsubsection{T-Zellproliferationstest}

In T-Zellproliferationstests wurden die Zellen an Tag 3 nach Peptidstimulation mit $1 \mu \mathrm{Ci}\left[{ }^{3} \mathrm{H}\right]$-Thymidin pro Loch inkubiert. Nach einer Inkubationszeit von 16 Stunden bei $37^{\circ} \mathrm{C}$ und $5 \% \mathrm{CO}_{2}$ erfolgte der Einbau des $\left[{ }^{3} \mathrm{H}\right]$-Thymidins in die T-Lymphozyten-DNA. Dieser Vorgang wurde durch Ernten der Mikrotiterplatte beendet. Die Zellansätze wurden mit einem Zellernter (IH-110-96, Inotech) auf Glasfaserfilter übertragen. Nach dem Trocknen der Filter wurden sie in Szintillationsflüssigkeit überführt. Die Proliferation der T-Zellen wurde anhand der Radioaktivität auf den Glasfaserfiltern mit einem Beta-Counter (1450 MicroBeta liquid scintillation counter, Wallac) als „counts per minute (cpm)“ quantifiziert. Die Ergebnisse wurden als Stimulationsindex (SI) ausgedrückt, (cpm der Zellen gepulst mit Peptid/cpm der Zellen ohne Peptid). Bei einem SI > 3 und einem Absolutwert von cpm > 1000 wurde das Ergebnis als positive T-Zell-Proliferation gewertet. 


\subsubsection{Einzelzellklonierung}

Peptidspezifische T-Zelllinien wurden durch limitierende Verdünnung (je nach Wachstumsverhalten der T-Linien 0,3-3 Zellen/Loch) in Anwesenheit von $1 \times 10^{5}$ radioaktiv bestrahlten (90 Gy), allogenen PBMC als Stimulatorzellen, $5 \mathrm{\mu g} / \mathrm{ml}$ Phytohämaglutinin (PHA) und $10 \mathrm{IU} / \mathrm{ml} \mathrm{rhIL}-2$ kloniert. Alle 3-4 Tage wurde das Medium gegen frisches, $10 \mathrm{IU} / \mathrm{ml} \mathrm{rhIL}-2$ enthaltendes, RPMI 1640 ausgetauscht. Nach durchschnittlich 12-14 Tagen wurden die proliferativen Zellen sichtbar und erneut in Proliferationstests auf ihre Peptid-Spezifität hin getestet.

\subsubsection{Expansion und Analyse der T-Zellklone}

Die peptid-spezifischen T-Zellklone wurden wöchentlich mit autologen, radioaktiv-bestrahlten (30 Gy) PBMC in Anwesenheit des spezifischen Peptids $(20 \mathrm{mg} / \mathrm{ml})$ in $10 \mathrm{IU} / \mathrm{ml}$ rhIL-2 enthaltendes, RPMI 1640 restimuliert. Alle 3-4 Tage wurde frisches RPMI 1640 mit 10 IU/ml rhIL-2 zugefügt.

Zur Analyse wurden die T-Zellklone (3x104 Zellen/Loch) in eine 96-Lochplatte überführt. Die T-Zellen wurden in Anwesenheit verschiedener Konzentrationen des Antigens (Peptid, rekombinantes Protein bzw. Tumorzelllysate) mit radioaktiv-bestrahlten (30 Gy), autologen dendritischen Zellen (DC) in RPMI 1640-Medium kokultiviert. In einigen Fällen wurden zusätzlich verschiedene Antikörper gegen die MHC I- bzw. MHC-II-Moleküle (20 $\mathrm{\mu g} / \mathrm{ml}$ ) hinzugegeben. Antigen-spezifische T-Zellantworten wurden wiederum in Proliferationstests gemessen. 


\subsubsection{Durchflußzytometrie (FACS)}

Vor der durchflußzytometrischen Färbung wurden die Zellen zunächst in FACS-Puffer (2 \% FCS + 0,02\% $\mathrm{NaN}_{3}$ in PBS) gewaschen und anschließend bei $4^{\circ} \mathrm{C}$ für $30 \mathrm{~min}$ mit $5 \mu \mathrm{g} / \mathrm{ml}$ des jeweiligen direkt markierten Antikörpers in FACS-Puffer inkubiert. Nach zwei finalen Waschschritten wurden die Zellen auf einem FACSCalibur® Durchflußzytometer unter Verwendung der CELLquest ${ }^{\circledR}$ Software (Beckton Dickinson, Heidelberg) analysiert. Die Kalibrierung des Gerätes erfolgte über eine nichtgefärbte Probe (Autofluoreszenz), die Bestimmung der unspezifischen Färbung der Zellen über einen irrelevanten Antikörper gleichen Isotyps (Isotyp-Kontrolle). Um den Anteil an toten Zellen in den Proben zu bestimmen, wurden die Ansätze mit $1 \mu$ l Propidiumiodid (0,2 \%) versetzt. Die Proben wurden direkt im Anschluss an die Färbung gemessen.

\subsubsection{Bestimmung der Zytokinproduktion mittels ELISA}

Die Bestimmung der Zytokine in den Zellkulturüberständen von peptidstimulierten CD4+ T-Zellklonen erfolgte mittels ELISA („enzyme linked immunosorbent assay"). Hierzu wurde einer 96-Loch-Maxisorpplatte $100 \mu \mathrm{l}$ Primärantikörper pro Vertiefung (2 $\mathrm{mg} / \mathrm{ml}$ in Natriumphosphatpuffer, $\mathrm{pH}$ 9) zugegeben und über Nacht bei $4^{\circ} \mathrm{C}$ inkubiert. Am nächsten Tag wurde die Platte zweimal mit PBS gewaschen und anschließend $100 \mu \mathrm{l}$ PBS 1\% BSA in jede Vertiefung für zwei Stunden bei $37^{\circ} \mathrm{C}$ gegeben. Daraufhin wurde zweimal mit PBS gewaschen, und dann die Kulturüberstände und die, in einer 1:2 Verdünnung titrierten Standards und reines Medium als Leerwert auf die Platte gegeben (100 $\mu \mathrm{l} /$ Vertiefung). Es folgte eine Inkubation von zwei Stunden bei Raumtemperatur und danach vier Waschschritte. Daraufhin wurden $100 \mu \mathrm{l}$ des biotinylierten Sekundärantikörpers $(1 \mu \mathrm{g} / \mathrm{ml}$ in PBS $0.1 \%$ BSA) zugegeben und die Platte für eine Stunde bei $37^{\circ} \mathrm{C}$ inkubiert. Nach sechs 
Waschschritten und der Zugabe von $100 \mu \mathrm{\mu l}$ Peroxidase-gekoppeltem Streptavidin $(0.5 \mathrm{mg} / \mathrm{ml})$ folgte eine $30 \mathrm{~min}$ Inkubation und sechs Waschschritte. Anschließend wurden $100 \mu 1$ der Substratlösung (BCIP-NBT) pro Vertiefung zugegeben. Nach 3 bis 10 Minuten wurde die Farbreaktion durch Zugabe von $100 \mu$ Stopplösung (TMB) gestoppt und die Extinktion bei $450 \mathrm{~nm}$ gemessen, wobei die maximale Extinktion den Wert von $2.6 \mathrm{nicht}$ überschreiten durfte. Von den gemessenen Werten wurde die Extinktion des Leerwertes abgezogen. Mit Hilfe der „Microplate Manager” Software wurde eine Eichgerade erstellt und die Konzentration der Kulturüberstände bestimmt. Das Detektionslimit lag je nach Zytokin bei 0,5-7 pg/ml.

\subsubsection{IFN- $\gamma$-ELISPOT-Assay}

Eine Nitrocellulose-Platte mit 96 Vertiefungen wurde unter sterilen Bedingungen für einige Minuten mit $100 \mu \mathrm{l}$ PBS/Vertiefung benetzt. Anschließend wurden $100 \mu \mathrm{l}$ des Maus-anti-human- IFN- $\gamma$-Antikörpers pro Vertiefung in einer Konzentration von $5 \mu \mathrm{g} / \mathrm{ml}$ dazugegeben und die Platte über Nacht bei $4^{\circ} \mathrm{C}$ inkubiert.

Nach Dekantieren des Antikörpers von der Platte wurde den Vertiefungen je $100 \mu \mathrm{PBS}+0.05 \%$ Tween $20+0.1 \%$ BSA zugegeben und für eine Stunde bei $37^{\circ} \mathrm{C}$ und $5 \% \mathrm{CO}_{2}$ inkubiert. Die aus Heparin-Vollblut isolierten und über Nacht im Brutschrank inkubierten PBMC wurden nun bei einer Konzentration von $2 \times 10^{6} / \mathrm{ml}$ mit je $50 \mu \mathrm{l}$ Zelllösung pro Vertiefung auf die ELISPOT-Platte pipettiert. Dies entspricht $1 \times 10^{5}$ Zellen pro Vertiefung. Anschließend wurden die Peptide (P2, P11, P12b und P13) hinzugegeben. Bei einer Peptidkonzentration von $10 \mathrm{ng} / \mu \mathrm{l}$ wurden $50 \mu \mathrm{l}$ in jede Vertiefung pipettiert. Desweiteren wurde als Negativkontrolle in je sechs Vertiefungen kein Antigen hinzugefügt. Die Platte wurde dann $24-48 \mathrm{~h}$ bei $37^{\circ} \mathrm{C}$, unter gesättigter Luftfeuchtigkeit und $5 \% \mathrm{CO}_{2}$ im Brutschrank inkubiert. Die Platte wurde anschließend sechsmal mit $200 \mu \mathrm{l} /$ Vertiefung PBS + 0,05 \% Tween-20 
gewaschen. Danach erfolgte eine 2-stündige Inkubation bei $37^{\circ} \mathrm{C}$ mit $100 \mu \mathrm{l} /$ Vertiefung eines biotinylierten Maus-anti-human-IFN- $\gamma$-Antikörpers in einer Konzentration von $0,5 \mu \mathrm{g} / \mathrm{ml}$ in PBS + 0.5\% BSA.

Nach viermaligem Waschen der Platte mit $200 \mu \mathrm{l}$ PBS/Vertiefung wurden $100 \mu \mathrm{l}$ /Vertiefung Streptavidin-Alkaline-Phosphatase (1:1000 in PBS verdünnt) hinzugegeben und für zwei Stunden bei Raumtemperatur inkubiert. Nach viermaligem Waschen der Platte mit PBS wurden ihr $100 \mu l$ /Vertiefung des farblosen BCIP/NBT-Substrats (5-bromo-4-chloro-3-indolyl-phosphate/ nitroblue-tetrazolium) hinzugefügt. Die eintretende Farbreaktion wurde nach ca. sieben Minuten durch waschen mit Leitungswasser gestoppt.

Nach Trocknung der Platte über Nacht bei Raumtemperatur und unter Lichtabschluß wurde die Anzahl der farbigen Spots mithilfe des automatisierten, computergesteuerten Lesegeräts "ELISPOT-Reader" (AID) gezählt. Die Summe der ermittelten Anzahl von Spots (ein Peptid) spiegelt den

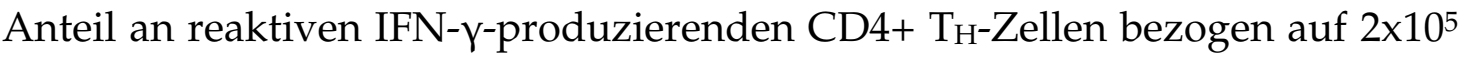
eingesetzte PBMC wider. Die gemessene spontane IFN- $\gamma$-Freisetzung (Negativkontrollen) wird als Hintergrund von der Gesamtzahl an Spots abgezogen.

Eine T-Zell-Antwort wurde dann als positiv betrachtet, wenn nach Subtraktion der Negativkontrolle mindestens 5 T-Zellen pro 2x105 PBMC (entsprechend 2 Plattenvertiefungen) als Reaktion auf den Antigenkontakt IFN-ץ sezernierten. Außerdem musste dieser Wert im Vergleich zur Negativkontrolle im einseitigen „student's t-Test" signifikant erhöht sein. Bei einem Testergebnis von $\mathrm{p}<0.05$ wurde dies als positive T-Zell-Antwort gegen das entsprechende Epitop gewertet. Aufgrund der wiederholten Testungen sind diese Ergebnisse als deskriptiv zu betrachten. 


\subsubsection{Herstellung von Zelllysaten für die Beladung von DC}

Von verschiedenen Zelllinien wurden $5 \times 10^{6}$ Zellen geerntet und in 2ml RPMI 1640 in ein 1,5 ml Eppendorf-Reagiergefäß überführt. Die Zellsuspension wurde fünfmal in flüssigem Stickstoff schockgefroren und im $37^{\circ} \mathrm{C}$ warmen Wasserbad wieder aufgetaut. Anschließend wurde die Zellsuspension $10 \mathrm{sec}$ im Ultraschallbad behandelt. Vor der weiteren Verwendung der Zelllysate wurden diese bei $-80^{\circ} \mathrm{C}$ gelagert.

\subsubsection{Vermehrung und Aufreinigung rekombinanter Adenoviren}

Das Adeno-XTM System wurde von der Fa. Clontech (Heidelberg, Deutschland) bezogen. Dieses System besteht aus einem "shuttle" Plasmid (pShuttle, siehe Anhang) und einem adenoviralen „backbone“ Plasmid (pAdeno-x, siehe Anhang). Das Plasmid pShuttle enthält eine MCS zwischen einem humanen CMV Promotor und dem BGH-Polyadenylierungssignal. Zudem enthält es eine Kanamycin-Resistenz zur Selektion transformierter E. coli. 5' des Promotors befinden sich eine I-CeuI Schnittstelle, 3' des BGHpolyA befindet sich eine PISceI Schnittstelle. Diese beiden Schnittstellen dienen der Einklonierung der Transgenkassette in die entsprechende Stelle des adenoviralen Genoms.

Das Plasmid pAdeno-X besitzt zwischen den beiden Schnittstellen I-CeuI und PI-SceI eine SwaI Schnittstelle. Zudem enthält es eine Ampicillin-Resistenz zur Selektion transformierter E. coli. Im Anschluss an die Ligation von pAdeno-X und Transgen-Kassette wurden die Ligationsansätze mit SwaI geschnitten. Das fertige Konstrukt wurde mit PacI geschnitten und in HEK293a Zellen transfiziert (=Virusvorkultur). 


\subsubsection{Vermehrung rekombinanter Adenoviren}

Für die Transfektion wurden HEK 293a-Zellen in $20 \times 6 \mathrm{~cm}$ Schalen $(5 \mathrm{ml}$ DMEM/Schale, ungefähr $60 \%$ Konfluenz) ausgelegt. Anschließend wurden pro Schale $500 \mu \mathrm{l}$ HEBS und $5 \mu \mathrm{l}$ HeringSperm-DNA-Lösung $(0,2 \%$ (w/v) HeringSperm DNA, $15 \mathrm{mM} \mathrm{NaCl}$, 1,5 mM Na-Citrat, pH=7,0, als Träger-DNA) in ein $15 \mathrm{ml}$ Röhrchen gegeben und dieses mittels eines Vortexers für $1 \mathrm{~min}$ gründlich gemischt. Anschließend wurde dem Gemisch die zu transfizierende Virusvorkultur, die das Gen für PR3/LAMP-1 bzw. GFP enthält, (5 $\mu$ g) und tropfenweise $25 \mu \mathrm{l}$ 2,5 M Kalziumchlorid-Lösung zugegeben. Nach $30 \mathrm{~min}$ Inkubation bei Raumtemperatur wurden die Transfektionsansätze auf je eine 6 cm Schale getropft und diese 8-16 h im Brutschrank inkubiert. Im Anschluss an die Inkubation wurde das Medium abgesaugt und frisches Kulturmedium zugegeben. Nach Eintreten des zytopathischen Effektes (3-4 Tage) runden und lösen sich die Zellen ab. Die abgelösten Zellen und der Überstand wurden in ein $15 \mathrm{ml}$ Reaktionsgefäß überführt und zentrifugiert (5 min, $1500 \mathrm{~g}$, Raumtemperatur). Der Überstand wurde verworfen und das Pellet in $500 \mu \mathrm{l}$ PBS aufgenommen. Anschließend wurden die Zellen durch dreimaliges einfrieren (mit Trockeneis) und wiederauftauen ( $37^{\circ} \mathrm{C}$ Wasserbad) lysiert, damit die Viruspartikel freigesetzt werden. Nun wurden in zehn $15 \mathrm{~cm}$ Kulturschalen HEK293a-Zellen ausgesät und bis zur Konfluenz im Brutschrank inkubiert. Das Medium wurde abgesaugt und die Zellen mit $2 \mathrm{ml}$ des vorher gewonnenen Überstandes, der Viruspartikel enthält, tranzduziert. Die Schalen wurden 30 min im Brutschrank inkubiert, wobei die Schalen nach 15 min geschwenkt wurden, um ein Austrocknen der Zellen zu vermeiden. Anschließend wurden die Schalen mit frischem Medium aufgefüllt. Nach Eintreten des zytopathischen Effektes wurde das Medium und die Zellen in ein $15 \mathrm{ml}$ Reaktionsgefäß überführt und der Virus wie oben beschrieben isoliert. Bis zur Aufreinigung wurde die Viruslösung bei $-80^{\circ} \mathrm{C}$ eingefroren. 


\subsubsection{Aufreinigung von Adenoviren}

Ein Ultraschallzentrifugenröhrchen wurde mit $3 \mathrm{ml}$ „schwerer" CsCl-Lösung ( $\mathrm{d}=1,34 \mathrm{~g} / \mathrm{ml})$ befüllt und mit $3 \mathrm{ml}$,leichter" CsCl-Lösung ( $\mathrm{d}=1,32 \mathrm{~g} / \mathrm{ml})$ überschichtet. Der CsCl-Gradient wurde mit $5 \mathrm{ml}$ Virusüberstand überschichtet und über Nacht bei $16^{\circ} \mathrm{C}$ und $40000 \mathrm{rpm}$ (ohne Bremse) in der Ultrazentrifuge zentrifugiert. Das aufgereinigte Virus erscheint als hellgraublaue Bande im CsCl-Gradienten. Das Zentrifugenröhrchen wurde in ein Laborstativ gespannt, mit einer $2 \mathrm{ml}$ Spritze mit Kanüle unterhalb der Virusbande angestochen und die Virusbande in die Spritze gesaugt. Das Virus wurde nun in einen Dialyseschlauch, der vorher für 15 min. in 1 mM EDTA, $2 \%$ Natriumcarbonat gekocht wurde und daraufhin in Wasser mit $5 \mathrm{mM}$ EDTA gewaschen wurde, überführt. Nach verschließen des Dialyseschlauchs wurde dieser zweimal in 51 Succroselösung $\left(\mathrm{H}_{2} \mathrm{O}\right.$ :Succrose $\left.=1: 10\right)$ bei $4^{\circ} \mathrm{C}$ dialysiert (1. Dialyseschritt 5 h, 2. Dialyseschritt 12 h). Das Virus wurde anschließend in ein 1,5 ml Röhrchen überführt und photometrisch quantifiziert (siehe 3.1.8.3).

\subsubsection{Photometrische Quantifizierung einer Adenovirus-Präparation}

$2 \mu l$ der Viruspräparation wurden mit Aqua dest. zu einem Volumen von $100 \mu \mathrm{l}$ (1:50) in einer Küvette verdünnt. Am Photometer wurde nun der Nullwert mit Aqua dest. bei 260 nm eingestellt, daraufhin die Probe gemessen und nach folgender Formel die pfu (plaque forming unit) berechnet: OD $260 \mathrm{x}$ Verdünnungsfaktor x $1.1 \times 10^{12}=\mathrm{pfu} / \mathrm{ml}$. Die Reinheit wurde durch das Verhältnis $\mathrm{OD}_{260}: \mathrm{OD}_{280}$ bestimmt. Sie sollte zwischen 1,2 und 1,3 liegen. 


\subsubsection{Adenovirus Titration (Plaque-Test)}

Die Titration der Adenovektoren wurde nach Hitt et al. (1995) durchgeführt. Am Vortag der Titration wurden pro Titration 12-16 Schalen HEK293a Zellen zugegeben. Für die Erstellung einer Verdünnungsreihe wurde für den ersten Verdünnungsschritt $90 \mu \mathrm{l}$ PBS mit $10 \mu \mathrm{l}$ des zu titrierenden Ad5/F35 gemischt. Die nachfolgenden Verdünnungsschritte erfolgten mit je $540 \mu 1$ PBS und $60 \mu 1$ Ad5/F35-Lösung der vorangegangenen Verdünnung. Es wurden stets zwei unabhängige Verdünnungsreihen erstellt und die Transduktionen jeder Verdünnungsreihe erfolgten in Doppelansätzen. Die Transduktionen wurden mit je $200 \mu \mathrm{l}$ der entsprechenden Verdünnung (in der Regel 10-5 - 10-10 pfu) 30 min im Brutschrank durchgeführt Nach der Transduktion wurde den Zellen frisches DMEM plus aufgekochter und 30 min bei $42^{\circ} \mathrm{C}$ abgekühlter $1 \%$ (w/v) Zellkultur-Agarose (Verhältnis 1:1; $10 \mathrm{ml} /$ Schale) zugegeben. Diese wurden bei Raumtemperatur inkubiert bis das Gemisch erstarrt war. Anschließend wurden die Zellen im Brutschrank inkubiert und die Plaques (durch Zelllyse entstandene Löcher im Zellrasen) nach sieben bis zehn Tagen ausgezählt und der Titer berechnet (Bestimmung des biologischen Titers: Titer $[\mathrm{pfu} / \mathrm{ml}]=$ Mittelwert der Plaques pro Schale/ [Verdünnungsfaktor $\mathrm{x}$ Volumen des zugefügten verdünnten Virus zu den Zellen]).

\subsubsection{Transduktion von Zielzellen}

Zielzellen (DC oder 293a) wurden mit unterschiedlicher MOI transduziert. Hierfür wurden die Zellen in einer 24-Loch-Platte ausgesät (1x106 Zellen/Loch in DMEM) und 24 Stunden inkubiert $\left(37^{\circ} \mathrm{C}, 5 \% \mathrm{CO}_{2}\right)$. Nach Dekantieren des Überstandes wurden die Zellen mit unterschiedlicher MOI in einem Volumen von $300 \mu \mathrm{l}$ transduziert. Nach zwei Stunden Inkubation wurde den Zellen $700 \mu \mathrm{l}$ frisches Medium hinzugegeben. 24 bzw. 48 Stunden später konnten die transduzierten Zellen für weitere Versuche verwendet werden. 


\subsection{Molekularbiologische Methoden}

\subsubsection{Arbeiten mit Bakterien}

\subsubsection{Herstellung chemisch kompetenter Bakterien nach der Mehrionen- Technik}

$100 \mathrm{ml}$ LB-Medium mit $10 \mathrm{mM} \mathrm{MgCl} 2$ und $10 \mathrm{mM} \mathrm{MgSO}_{4}$ wurden mit 0,5 ml einer Bakterienkultur angeimpft und bei $37{ }^{\circ} \mathrm{C}$ unter schütteln inkubiert, bis eine optische Dichte von etwa 0,5 bei $595 \mathrm{~nm}$ Wellenlänge erreicht war. Die Bakterien wurden dann in $50 \mathrm{ml}$ Falcon-Röhrchen überführt und auf Eis 2 Minuten abgekühlt. Nach dem Zentrifugieren (5000 x g, 10 Minuten, $4{ }^{\circ} \mathrm{C}$ ) wurde das Bakteriensediment in $30 \mathrm{ml}$ eiskaltem TfB1 resuspendiert, 3060 Minuten auf Eis inkubiert, wieder abzentrifugiert, in $5 \mathrm{ml}$ TfB2 aufgenommen und weitere 15 Minuten auf Eis belassen. Die kompetenten Bakterien wurden anschließend portionsweise in flüssigem Stickstoff schockgefroren und bei $-80^{\circ} \mathrm{C}$ gelagert.

\subsubsection{Transformation chemisch kompetenter Bakterien}

Kompetente Bakterien wurden auf Eis aufgetaut und jeweils $50 \mu l$ mit 100500 ng Plasmid-DNA für 30 Minuten auf Eis inkubiert. Danach erfolgte eine Inkubation bei $37{ }^{\circ} \mathrm{C}$ für 5 Minuten und auf Eis für weitere 2 Minuten. Nach Zugabe von 0,5 ml LB-Medium mit $10 \mathrm{mM} \mathrm{MgCl}_{2}$ und $10 \mathrm{mM} \mathrm{MgSO}_{4}$ wurde die Bakteriensuspension für 1 Stunde bei $37^{\circ} \mathrm{C}$ geschüttelt und anschließend auf Agarplatten mit dem entsprechenden für die Selektion verwendeten Antibiotikum (Ampicillin, Kanamycin) ausplattiert. 


\subsubsection{Präparation von Plasmid-DNA in kleinem Maßstab (Mini-Präp)}

$3 \mathrm{ml}$ LB-Medium mit Kanamycin oder Ampicillin wurden mit jeweils einer Bakterienkolonie von der Agarplatte angeimpft und über Nacht bei $37{ }^{\circ} \mathrm{C}$ unter schütteln inkubiert. $2 \mathrm{ml}$ der Bakterienkulturen wurden zentrifugiert (14.000 x g, 2 Minuten, RT), das Sediment in $200 \mu \mathrm{l}$ S1 resuspendiert und nach Zugabe von $200 \mu \mathrm{l}$ S2 für 5 Minuten bei RT inkubiert. Anschließend wurden $200 \mu \mathrm{l} \mathrm{S3}$ zugegeben und weitere 5-10 Minuten auf Eis inkubiert. Unlösliche Bakterienbestandteile wurden nach der Zentrifugation (14.000 x g, 10 Minuten, $4^{\circ} \mathrm{C}$ ) verworfen. Der Überstand wurde mit $600 \mu \mathrm{l}$ Isopropanol gemischt. Nach dem Zentrifugieren (14.000 x g, 10 Minuten, RT) der Plasmid-DNA wurde diese mit 70\% Ethanol gewaschen, getrocknet und in $50 \mu \mathrm{l} \mathrm{H}_{2} \mathrm{O}$ aufgenommen. Zur Stammkulturhaltung wurden die Bakteriensuspensionen mit $25 \%$ (v/v) Glyzerin versetzt und bei $-80^{\circ} \mathrm{C}$ eingefroren.

\subsubsection{Präparation von Plasmid-DNA in quantitativem Maßstab}

Für die Aufreinigung von Plasmid-DNA wurde der "QIAfilter Plasmid Maxi“Kit der Firma Qiagen verwendet. Um Plasmid-DNA in größeren Mengen zu gewinnen, wurden $500 \mathrm{ml}$ LB-Medium mit Kanamycin oder Ampicillin mit der entsprechenden Bakterienkultur angeimpft und bei $37^{\circ} \mathrm{C}$ unter schütteln inkubiert. Die Bakterien wurden zentrifugiert (5000 x g, 10 Minuten, $\left.4{ }^{\circ} \mathrm{C}\right)$, und in $10 \mathrm{ml} \mathrm{P1} \mathrm{Puffer} \mathrm{resuspendiert.} \mathrm{Durch} \mathrm{Zugabe} \mathrm{von} 10 \mathrm{ml}$ Puffer P2 und Inkubation für 5 min wurden die Zellen lysiert. Die alkalische Lösung wurde durch Zugabe von $10 \mathrm{ml}$ Puffer P3 neutralisiert und auf eine Filterkartusche überführt. Nach 10 min Inkubation wurde das Lysat filtriert und mit 2,5 ml ER-Puffer vermischt. Nach 30 min Inkubation wurde das Filtrat über eine QBT-Puffer äquilibierte Qiagen-tip 500 Säule gegeben und die Säule anschließend 3x mit 30 ml QC-Puffer gewaschen. Die an die Säule gebundene 
Plasmid-DNA wurde dann mit $20 \mathrm{ml}$ Puffer QN eluiert und durch eine Fällung mit Isopropanol gewonnen. Die präzipitierte DNA wurde in endotoxin-freiem Wasser aufgenommen und die Konzentration bestimmt.

\subsubsection{DNA-analytische Methoden}

\subsubsection{Polymerase-Ketten-Reaktion (PCR)}

Die PCR ermöglichte die in vitro Amplifikation definierter DNA-Fragmente und wurde in dieser Arbeit zur Einführung von Schnittstellen in DNAFragmente und zur Vervielfältigung von zu klonierenden DNA-Fragmenten eingesetzt. Die eingeführten Schnittstellen erlaubten nach einer Restriktion die gerichtete Klonierung der PCR-Produkte in ein Plasmid. Um eine spezifische Sequenz für einen weiteren Klonierungsschritt mit bestimmten Restriktionsschnittstellen zu amplifizieren, wurde ein Standard PCR-Protokoll durchgeführt In Abhängigkeit von den verwendeten Primern variierte die Annealingtemperatur zwischen $52{ }^{\circ} \mathrm{C}$ und maximal $60{ }^{\circ} \mathrm{C}$.

Die Kettenreaktion lässt sich in drei Schritte unterteilen: Im ersten Schritt wird die $\mathrm{zu}$ amplifizierende dsDNA thermisch (94 bis $\left.100{ }^{\circ} \mathrm{C}\right)$ denaturiert, so dass zwei Einzelstränge vorliegen. Im nächsten Schritt erfolgt bei einer geringeren Temperatur (45 bis $72{ }^{\circ} \mathrm{C}$ ) die Hybridisierung („,annealing“) der Primer an die ssDNA. Die Primer werden im dritten Schritt, der bei einer Temperatur von $72{ }^{\circ} \mathrm{C}$ abläuft, durch eine thermostabile DNA-Polymerase (Taq-Polymerase) verlängert. Diese drei Schritte werden zyklisch wiederholt, und durch eine 25bis 35-fache Wiederholung dieses Zyklus lässt sich eine Amplifikation der DNA um den Faktor $10^{9}$ erreichen.

PCR-Reaktionen wurden in einem Volumen von $50 \mu$ d durchgeführt. Die Ausgangsmenge an Template-DNA betrug 500 ng. Ein PCR-Ansatz enthielt neben der zu amplifizierenden DNA: 
$5 \mu$ PCR-Puffer (10x)

$250 \mu \mathrm{M}$ jedes dNTP

5 pmol jedes Primers

$2,5 \mathrm{mM} \mathrm{MgCl}_{2}$

1 U Taq-Polymerase

ad $50 \mu \mathrm{l} \mathrm{H}_{2} \mathrm{O}$

Für ein bis zu 1500 bp langes DNA-Fragment fand die Amplifikation in einem DNA-Thermo-Cycler nach folgendem Programm statt (x: je nach Primer zwischen 52 und $60^{\circ} \mathrm{C}$ ):

1. $\quad 5$ Minuten $94^{\circ} \mathrm{C}$ (einmalige Denaturierung)

2. 1 Minute $94^{\circ} \mathrm{C}$

1 Minute $\quad x{ }^{\circ} \mathrm{C}$

1,5 Minuten $72{ }^{\circ} \mathrm{C}$

35 Zyklen

3. $\quad 10$ Minuten $72{ }^{\circ} \mathrm{C}$ (abschließende Polymerisationsreaktion)

Im Anschluss an die PCR wurden die amplifizierten Produkte im Agarosegel analysiert.

\subsubsection{Agarose-Gelelektrophorese}

Plasmide und DNA-Fragmente wurden auf 0,8-1,2 \% Agarose-Gelen $(0,1$ mg/ml Ethidiumbromid) der Abmessung 80x90x7 mm bei $100 \mathrm{~V}$ aufgetrennt. Als Elektrophoresepuffer wurde TAE-Puffer verwendet. Vor dem Auftrag der DNA-Proben auf das Gel wurden die Proben mit DNA-Probenpuffer versetzt. Parallel zu den Proben wurde ein DNA-Größenstandard aufgetrennt. Die Detektion der DNA erfolgte unter UV-Licht (254 nm). 


\subsubsection{Elution von DNA-Fragmenten aus Agarosegelen}

Die durch Agarosegelelektrophorese aufgetrennten DNA-Fragmente wurden unter UV-Licht aus dem Agarosegel als kleiner Block ausgeschnitten; ein Arbeitsschritt, der sehr rasch erfolgen musste, um Strangbrüche und Mutationen der DNA durch das UV-Licht zu verhindern. Die in der wäßrigen Phase des Gels enthaltene DNA wurde durch Zentrifugation über ein Glaswolle-Filter für 5 Minuten bei 14000 x g von der festen Agarosematrix getrennt. $\mathrm{Zu}$ dem Durchfluss wurde das 2,5-fache Volumen EtOH und 1/10 Volumen KAc gegeben. Die DNA wurde für 1 Stunde auf Trockeneis oder bei $-20{ }^{\circ} \mathrm{C}$ über Nacht gefällt und dann für $1 / 2$ Stunde bei $14000 \times \mathrm{g}$ ( $\left.4^{\circ} \mathrm{C}\right)$ pelletiert. Abschließend wurde die DNA mit $70 \%$ EtOH gewaschen und nach dem Trocknen in $50 \mu \mathrm{lddH_{2 }} \mathrm{O}$ resuspendiert.

\subsubsection{Spaltung von Plasmid-DNA durch Restriktions-Endonukleasen}

Restriktionsendonukleasen sind in der Lage, doppelsträngige DNA an für sie spezifische, meist palindrome Erkennungssequenzen $\mathrm{zu}$ schneiden. Für eine vollständige Restriktion benötigen die Restriktionsenzyme spezielle Puffer, die optimale Ionenstärke und den adäquaten $\mathrm{pH}$-Wert liefern. Die für eine Restriktion benötigte Menge Enzym richtet sich nach der zu schneidenden DNA-Menge. Zur groben Abschätzung kann man davon ausgehen, dass $1 \mathrm{U}$ Restriktionsenzym ausreicht, um $1 \mu \mathrm{g}$ DNA in einem $50 \mu \mathrm{l}$ Ansatz innerhalb einer Stunde zu schneiden.

Sequenzielle Doppelrestriktionen wurden in zwei Schritten durchgeführt, jeder in Bezug auf die jeweilige Restriktionsendonuklease optimiert. Nach der ersten Restriktion wurde der Ansatz in einem Agarosegel aufgetrennt, die entsprechende DNA-Bande aus dem Gel eluiert und aufgereinigt. 
Anschließend wurde die DNA mit der zweiten Restriktionsendonuklease geschnitten.

Die Restriktionen wurden für 2 bis 4 Stunden bei der für das Restriktionsenzym optimalen Reaktionstemperatur (meist $37{ }^{\circ} \mathrm{C}$ ) inkubiert. Daraufhin erfolgte eine Überprüfung der Restriktion im Agarosegel und eine anschließende Reinigung der geschnittenen DNA vor der weiteren Verwendung.

\subsubsection{Dephosphorylierung der Plasmide vor einer Ligation}

Um bei der Ligation die Wahrscheinlichkeit einer Religation der Plasmide zu verringern, wurden die Plasmide nach der Restriktion dephosphoryliert. Dazu wurden die Restriktionsansätze 30 Minuten bei $37^{\circ} \mathrm{C}$ mit alkalischer ShrimpPhosphatase (SAP) inkubiert. Dabei wurden für 5'-überhängende Enden 0,1 Unit bei 1 pmol Termini benötigt. Dies entspricht ca. 2,5 $\mu \mathrm{g}$ eines $3 \mathrm{~kb}$ großen Plasmids. Um SAP zu inaktivieren, wurde der Ansatz für 15 Minuten bei $65^{\circ} \mathrm{C}$ inkubiert.

\subsubsection{Ligation von DNA-Fragmenten}

Ziel der Ligation ist es, glatte oder überhängende Enden von DNAFragmenten mit Hilfe der T4-DNA-Ligase kovalent über die endständige 5'Phosphatgruppe mit der freien 3'-OH Gruppe zu verknüpfen.

Vektoren und zu inserierende DNA-Fragmente wurden im molaren Verhältnis von 1:3 mit einer Gesamtmenge an DNA von maximal 200 ng eingesetzt. Die DNA wurde in $17 \mu \mathrm{l} \mathrm{ddH}_{2} \mathrm{O}$ aufgenommen und mit $2 \mu \mathrm{l} 10 \mathrm{x}$ T4-DNALigationspuffer versetzt. Der Reaktionsansatz wurde vermischt und nach Zugabe von $1 \mu \mathrm{l}$ T4-DNA-Ligase 5 Minuten bei Raumtemperatur inkubiert. 
Die ligierte DNA wurde ohne weitere Aufarbeitung in den Transformationen verwendet.

\subsubsection{Konzentrationsbestimmung von DNA}

Die Konzentration von DNA-Lösungen wurde spektralphotometrisch bei 260 $\mathrm{nm}$ bestimmt $\left(1 \mathrm{OD}_{260}=50 \mu \mathrm{g}\right.$ DNA/ml). Der Quotient $\mathrm{OD}_{260} / \mathrm{OD}_{280}$ diente dabei als Maß für die Reinheit der DNA und betrug im Idealfall 1,8.

\subsubsection{Abschätzung von DNA-Mengen im Agarosegel}

DNA-Mengen wurden im Agarosegel über einen Vergleich der Fluoreszenzintensität der $\mathrm{zu}$ untersuchenden DNA-Bande mit der Fluoreszenzintensität von DNA-Banden eines quantifizierten DNAGrößenstandards abgeschätzt. Mit Hilfe eines solchen DNA-Standards konnten DNA-Mengen bis zu 15 ng im Agarosegel quantifiziert werden.

\subsubsection{RNA-analytische Methoden}

\subsubsection{Isolierung von mRNA und Quantifizierung}

Die mRNA wurde aus Tumorzelllinien mit Hilfe des RNeasy Mini Kits nach mitgeliefertem Protokoll für tierische Zellen isoliert. Prinzip dieser Methode ist die Bindung von mRNA einer Größe von 200 Nukleotiden und mehr an eine Siliciumdioxid-Membran (Säulenchromatographie). Die DNA wird durch DNaseI degradiert und mit den anderen Zellbestandteilen abgewaschen; die RNA schließlich mit Wasser eluiert. Pro Säule können bis zu $100 \mu \mathrm{g}$ RNA isoliert werden. 
Die Bestimmung der Reinheit der Proben erfolgte durch spektrophotometrische Messung und Bildung des $\mathrm{OD}_{260} / \mathrm{OD}_{280}$ Verhältnisses (Ziel: zwischen 1,8 und 2,0). Zur Bestimmung der Konzentration wurde die $\mathrm{OD}_{260}$ gemessen. Die RNA wurde bei $-80^{\circ} \mathrm{C}$ gelagert.

\subsubsection{RT-PCR}

Die RT-PCR (Reverse Transkription/PCR) ermöglicht es, den kodierenden Bereich eines Gens ausgehend von der dazugehörigen mRNA in cDNA zu übersetzen und $\mathrm{zu}$ amplifizieren. Hierzu isoliert man zuerst die mRNA aus Zellen und übersetzt anschließend die Poly(A)-mRNA mit Hilfe der ReversenTranskription in einzelsträngige DNA (ssDNA). Im zweiten Schritt wird diese mit Hilfe zweier spezifischer Primer amplifiziert. Bei der ReversenTranskription wurden eingesetzt:

1-2 $\mu \mathrm{g}$ Gesamt-RNA

2,5 $\mu \mathrm{M}$ Oligo dT16 (16-mer bestehend aus Thymidin)

$1 \mathrm{mM}$ dNTPs

1U RNase-Inhibitor

$5 \mathrm{mM} \mathrm{MgCl} 2$

$2 \mu l$ 10fach PCR-Puffer

add $20 \mu \mathrm{d} \mathrm{H}_{2} \mathrm{O}$

Der Ansatz wurde für 5 min auf $65^{\circ} \mathrm{C}$ erhitzt, um vorhandene Sekundärstrukturen der RNA zu zerstören. Zum Ansatz wurden 1,5 $\mu$ (1U) MuLV-Reverse Transkriptase (Muriner Leukemia Virus-Reverse Transkriptase) hinzugegeben, für $45 \mathrm{~min}$ bei $42^{\circ} \mathrm{C}$ inkubiert und anschließend für 5 min auf $90^{\circ} \mathrm{C}$ erhitzt, um die Reverse Transkriptase zu inaktivieren. Der so erhaltene Ansatz konnte zur Amplifikation der ssDNA direkt in einer PCR verwendet werden. 


\subsection{Proteinbiochemische Methoden}

\subsubsection{Quantifizierung von Proteinmengen nach Bradford}

Zur Proteinbestimmung nach Bradford (Bradford, 1976; Spector, 1978) wurde der "Bio-Rad Protein Assay"-Kit verwendet. $10 \mu \mathrm{l}$ des zu analysierenden Zellextraktes wurden in $800 \mu \mathrm{H}_{2} \mathrm{O}$ aufgenommen und mit $200 \mu \mathrm{l}$ BradfordReagenz versetzt. Nach 10 Minuten Inkubation bei Raumtemperatur im

Dunkeln wurde die optische Dichte der Proteinlösung bei $595 \mathrm{~nm}$ im Spektralphotometer bestimmt. Zur Quantifizierung der Proteinmenge wurde bei jeder Messung eine BSA-Eichreihe erstellt.

\subsubsection{SDS-Polyacrylamid-Gelelektrophorese (SDS-PAGE)}

Die Auftrennung der Proteine erfolgte unter denaturierenden Bedingungen in einer diskontinuierlichen Gelelektrophorese nach der Methode von Laemmli (Laemmli, 1970). Es wurden Gele der Abmessung 90x80x1 mm und eine Elektrophorese-apparatur der Firma Atto verwendet. Als erstes wurde das Trenngel gegossen und vorsichtig mit $\mathrm{H}_{2} \mathrm{O}$ überschichtet. Nach der Polymerisation des Trenngels (ca. 20 Minuten) wurde das Wasser entfernt, das Sammelgel gegossen und ein Kamm für die Probentaschen eingesetzt. Die Proben wurden mit SDS-Probenpuffer versetzt, vor dem Auftragen auf das Gel 5 Minuten bei $95{ }^{\circ} \mathrm{C}$ denaturiert und auf Eis abgekühlt. Die Proteine wurden im Sammelgel bei einer Spannung von $80 \mathrm{~V}$ konzentriert und im Trenngel bei $180 \mathrm{~V}$ getrennt. 


\subsubsection{Transfer von Proteinen auf Nitrozellulosemembranen}

Nach der Gelelektrophorese wurden die Proteine für 2 Stunden bei 60 V oder für 1 Stunde bei $100 \mathrm{~V}$ in einer Naßblotapparatur aus dem Gel auf eine Nitrozellulosemembran transferiert. Dazu wurden drei Lagen WhatmanPapier in Tris-Glycin Puffer getränkt und das Gel vorsichtig daraufgelegt. Die angefeuchtete Nitrozellulosemembran wurde blasenfrei auf das Gel gelegt, darauf kamen wiederum drei Lagen Whatman-Papier. Die Proteine wurden in Richtung Anode auf die Nitrozellulosemembran transferiert.

\subsubsection{Färbung von Proteinen in Nitrozellulosemembranen mit Ponceau-Rot}

Zur Prüfung der Proteinbeladung und der Kontrolle des Western Blots wurde eine Proteinfärbung auf der Nitrozellulose-Membran mittels Ponceau-Rot durchgeführt. Hierzu wurde die Membran für 2-3 min in Ponceau-Lösung (2\% $(\mathrm{w} / \mathrm{v})$ Ponceau S, 3\% (v/v) Essigsäure) gelegt und danach die Hintergrundfärbung durch ddH2O entfernt. Eine vollständige Entfärbung erfolgte durch Inkubation mit TBS-T.

\subsubsection{Immundetektion (Western Blot Analyse)}

Durch Immundetektion wurden Proteine auf der Nitrozellulosemembran mit spezifischen Antikörpern sichtbar gemacht. Nach dem Transfer der Proteine auf die Membran wurden zunächst unspezifische Bindungsstellen der Antikörper auf der Membran mit Blockpuffer 1 Stunde bei RT oder über Nacht bei $4{ }^{\circ} \mathrm{C}$ abgesättigt. Die anschließenden Inkubationen der Membran mit 
Antikörpern sowie alle Waschschritte wurden in Blockpuffer durchgeführt. Die Inkubation mit dem jeweiligen primären Antikörper erfolgte für 45 Minuten bei RT. Nach 2maligem Waschen für 10 Minuten in Blockpuffer wurde die Membran mit dem Meerrettichperoxidase (HRP)-gekoppelten, Spezies-spezifischen sekundären Antikörper für 30 Minuten bei RT inkubiert. Abschließend wurde die Membran dreimal für je 10 Minuten in Waschpuffer gewaschen.

Die Detektion erfolgte mit dem ECL-Chemilumineszenzsystem, bei dem Luminol durch Wasserstoffperoxid oxidiert wird. Durch die Anregung des Luminolmoleküls wird Licht der Wellenlänge $\lambda=428 \mathrm{~nm}$ emittiert. Die Reaktion wird durch die Antikörper-gebundene Peroxidase HRP in alkalischer Lösung katalysiert. Je $10 \mathrm{ml}$ der ECL-Lösungen 1 und 2 wurden gemischt und die Membran für 1 bis 2 Minuten darin inkubiert. Im Dunkeln wurden dann Röntgenfilme in verschiedenen Zeitintervallen belichtet und anschließend entwickelt. 


\section{Ergebnisse}

\subsection{Untersuchung der Expression von Survivin und Proteinase 3 in verschiedenen Tumorzelllinien}

\subsubsection{Nachweis der Expression auf mRNA-Ebene mittels RT-PCR}

In der Literatur ist für eine Vielzahl von humanen Neoplasien eine Expression von SVN beschrieben worden. Beispiele hierfür sind das maligne Melanom, das Harnblasenkarzinom, das Mammakarzinom und orale Neoplasien (Lee et al., 1998; Swana et al., 1999; Tanaka et al., 2000; Tanaka et al., 2003). Die Expression von PR3 wurde in verschiedenen myeloischen Leukämien wie AML und CML nachgewiesen (Dengler et al., 1995). Zur Überprüfung der Expression in den hier verwendeten Tumorzellinien wurde zunächst das Vorkommen von SVN-mRNA (Abb. 4.1) bzw. PR3-mRNA (Abb. 4.2) mittels RT-PCR analysiert (Ergebnis aller untersuchter Zelllinien siehe Tab. 4.1). Zusätzlich wurde eine RT-PCR von SVNbzw. PR3-mRNA in PBMC und DC durchgeführt. Die Ergebnisse wurden in wiederholten Experimenten bestätigt.

A:

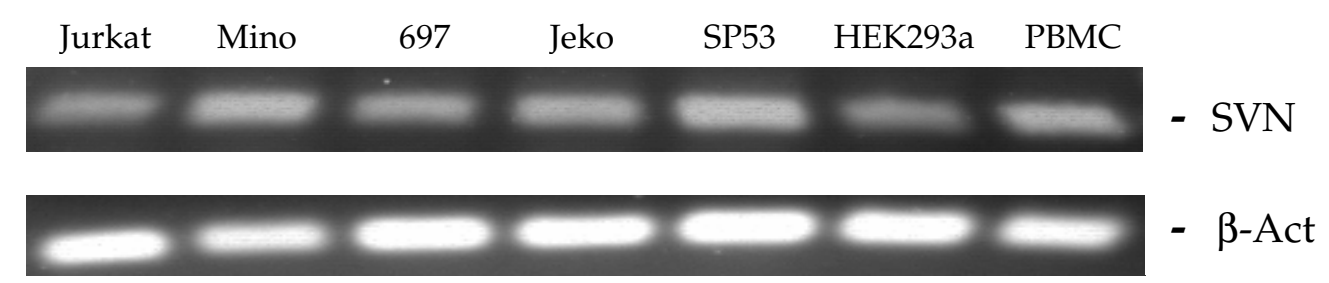


B:

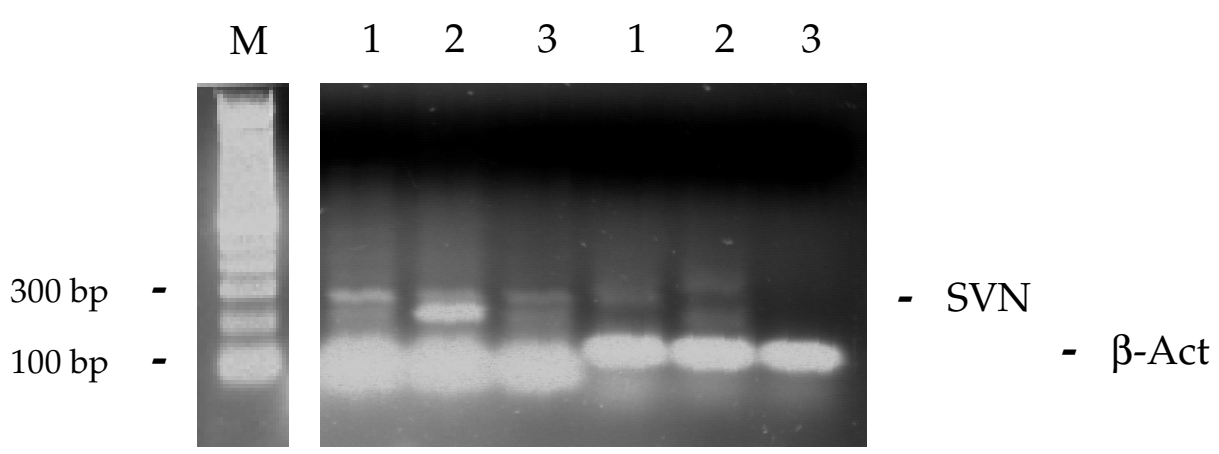

Abb. 4.1: Nachweis von SVN-mRNA mittels RT-PCR. A: Nachweis in verschiedenen Tumorzellinien, B: in PBMC und DC. Als Kontrolle wurde eine RT-PCR unter Verwendung von $\beta$-Actin-Primern ( $\beta$-Act) durchgeführt (Ergebnis aller getesteten Zelllinien ist in Tabelle 4.1 dargestellt) (M: Marker, 1: PBMC, 2: iDC, 3: mDC, bp: Basenpaare, SVN: Survivin).

A:
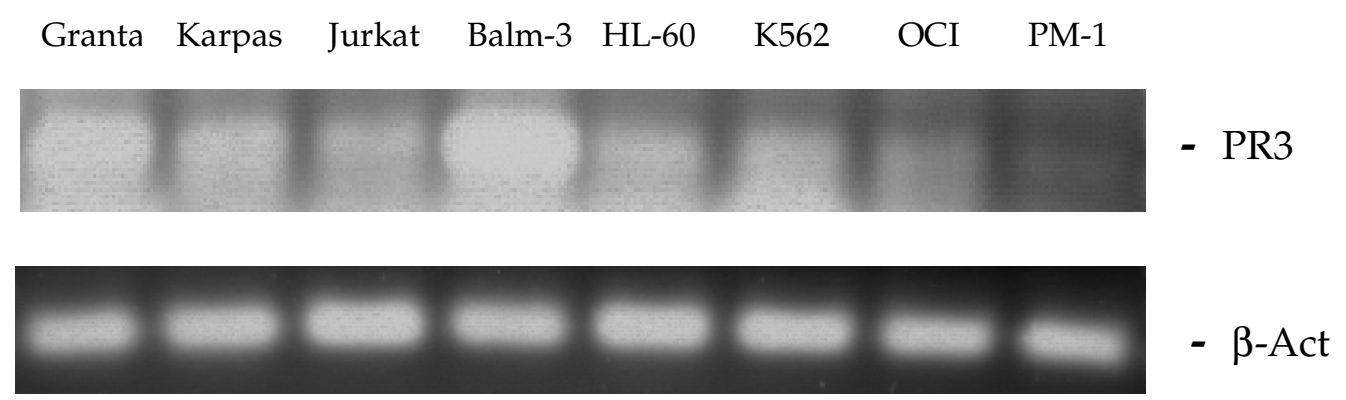

B:

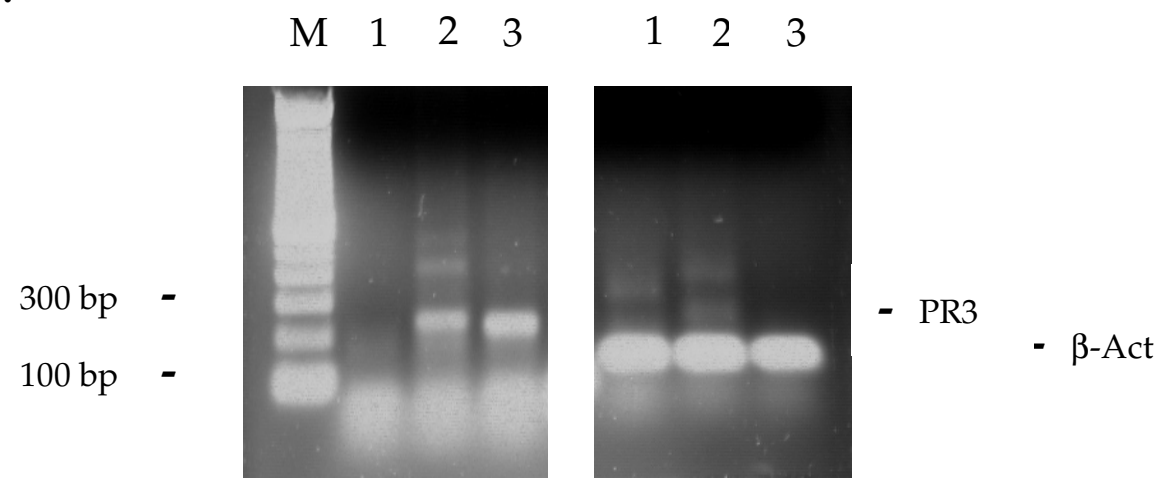

Abb. 4.2: Nachweis von PR3-mRNA mittels RT-PCR. A: Nachweis in verschiedenen Tumorzelllinien. B: in PBMC und DC. Als Kontrolle wurde eine RT-PCR unter Verwendung von $\beta$-Actin-Primern ( $\beta$-Act) durchgeführt (Ergebnis aller getesteten Zellinien ist in Tabelle 4.1 
dargestellt) (M: Marker, 1: PBMC, 2: iDC (unreife DC), 3: mDC (reife DC), bp: Basenpaare, PR3: Proteinase 3).

SVN-mRNA konnte abgesehen von PM-1 in allen untersuchten Tumorzelllinien detektiert werden. In PBMC, iDC und mDC war ebenfalls SVN-mRNA nachweisbar, wobei für iDC ein stärkeres Signal sichtbar war als für PBMC und $\mathrm{mDC}$.

PR3-mRNA konnte abgesehen von HEK293a und PM-1 in allen Zelllinien nachgewiesen werden. In PBMC war keine PR3-mRNA detektierbar. In iDC und mDC konnte dagegen gezeigt werden, dass sie PR3-mRNA exprimieren, wobei mDC ein stärkeres Signal aufwiesen als iDC. Als Kontrolle wurde jeweils eine RTPCR mit ß-Actin spezifischen Primern durchgeführt.

\subsubsection{Nachweis der Proteinexpression mittels Western Blot}

Der Nachweis einer Proteinexpression von SVN bzw. PR3 erfolgte im Western Blot für alle eingesetzten Zelllinien. In Abbildung 4.3 und 4.4 ist die Expression von SVN bzw. PR3 in den eingesetzten Tumorzelllinien sowie PBMC und DC dargestellt. Die Ergebnisse wurden in wiederholten Experimenten bestätigt.

A:

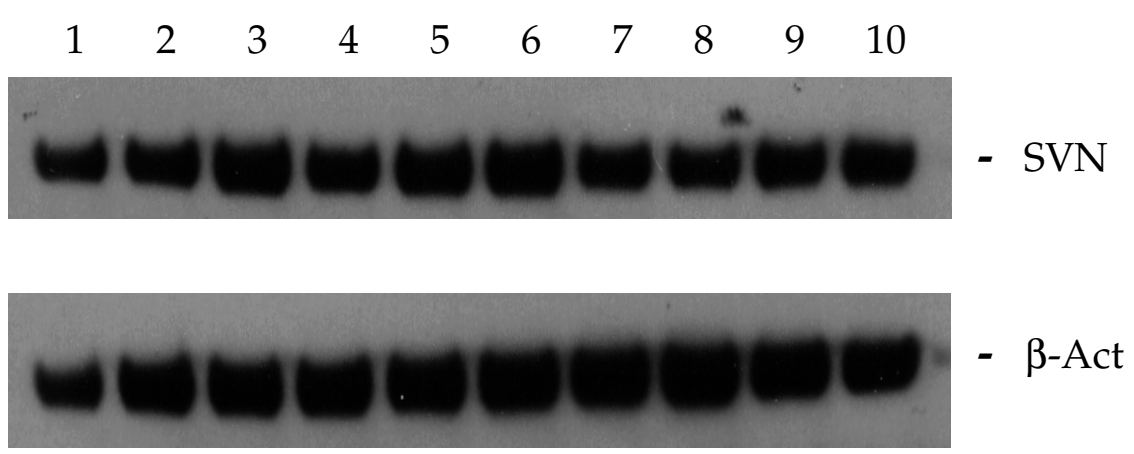


B:

$$
\begin{array}{cccc}
\mathrm{I} & \mathrm{I} & \mathrm{II} & \mathrm{II} \\
\mathrm{mDC} & \mathrm{iDC} & \mathrm{mDC} & \mathrm{iDC}
\end{array}
$$

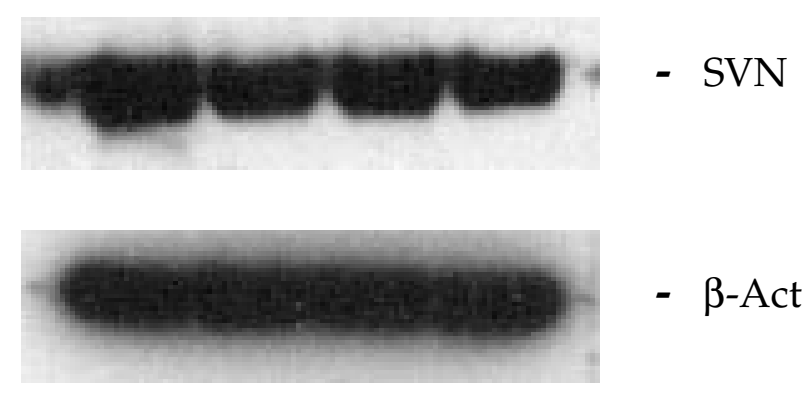

Abb. 4.3: Exemplarische Darstellung eines Western Blot durchgeführt mit einem monoklonalen SVN-Antikörper. A: Nachweis von SVN in verschiedenen Zelllinien. B: Nachweis von SVN in mDC und iDC. Als Kontrolle wurde ein Western Blot unter Verwendung von einem monoklonalen $\beta$-Actin-Antikörper ( $\beta$-Act) durchgeführt. 1: Granta-519, 2: HL-60, 3: K562, 4: Jurkat, 5: Mino, 6: 697, 7: Jeko-1, 8: SP53, 9: HEK293a, 10: PBMC, SVN: Survivin, $\beta$-Act: $\beta$-Actin (Ergebnis aller getesteten Zelllinien ist in Tabelle 4.1 dargestellt).

A:

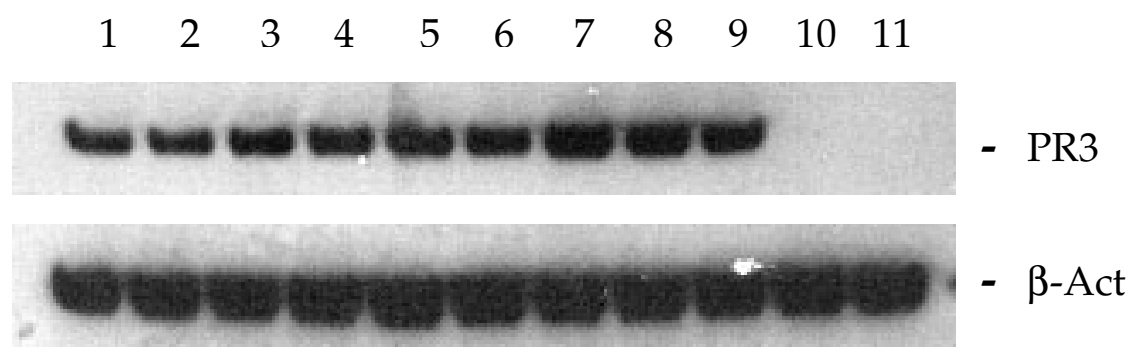

B:

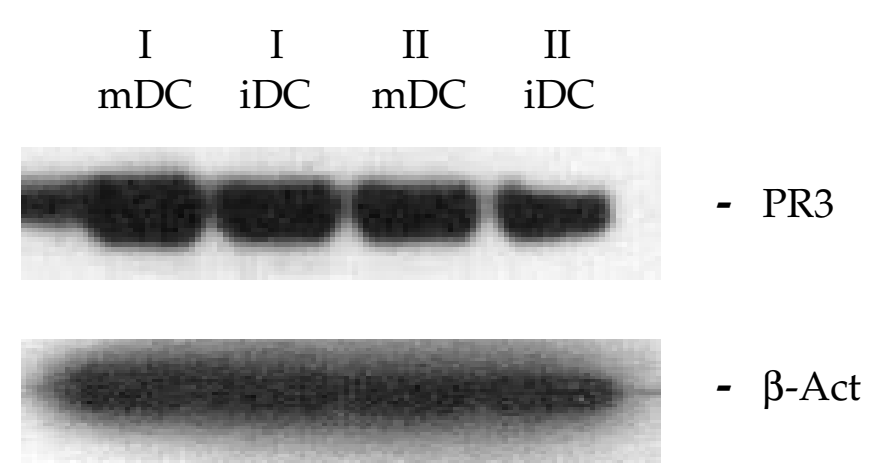

Abb. 4.4: Exemplarische Darstellung eines Western Blot durchgeführt mit einem monoklonalen PR3-Antikörper. A: Nachweis von PR3 in verschiedenen Zelllinien. B: Nachweis von PR3 in mDC 
und iDC, dargestellt für zwei verschiedene gesunde Spender. Als Kontrolle wurde ein Western Blot unter Verwendung von einem monoklonalen $\beta$-Actin-Antikörper ( $\beta$-Act) durchgeführt. 1: Granta-519, 2: Karpas-422, 3: HL-60, 4: K562, 5: Jurkat, 6: Mino, 7: 697, 8: Jeko-1, 9: SP53, 10: HEK293a, 11: PBMC, PR3: Proteinase 3, $\beta$-Act: $\beta$-Actin (Ergebnis aller getesteten Zelllinien ist in Tabelle 4.1 dargestellt).

Im Western Blot konnten die Ergebnisse der RT-PCR bestätigt werden. Die Resultate zur SVN- bzw. PR3-Transkription und -Expression sind in Tabelle 4.1 zusammengefasst.

\begin{tabular}{cccc} 
Tumorzellinien & Ursprung & PR3 & SVN \\
& & RT-PCR/WB & RT-PCR/WB \\
\hline
\end{tabular}

697

Granta-519

HEK293a

HL-60

Jurkat

Jeko-1

K-562

Karpas-422

Mino

OCI

PM-1 humane B-Zell-

\section{Vorläufer Leukämie}

humane MCL

humane embryonale

Nierenzelllinie

humane AML

humane T-ALL

humane MCL

humane Erythroleukämie $\quad+\quad+$

humanes B-Zelllymphom $+\quad+$

humane MCL

humane AML

humane T-NHL 
Ramos humane non-Hodgkin

$\begin{array}{lllll} & \text { B-Zellinie } & + & + & + \\ \text { SP-53 } & \text { humane MCL } & + & + & + \\ \text { THP-1 } & \text { humane AML } & + & + & +\end{array}$

Tabelle 4.1a: Expression von SVN bzw. PR3 in Tumorzelllinien (AML: Akute myeloische Leukämie; ALL: Akute lymphatische Leukämie; MCL: Mantelzell-Lymphom; T-NHL: T-Non Hodgkin Lymphom).

Zelltyp

PR3

SVN

RT-PCR/WB RT-PCR/WB

PBMC

iDC

$\mathrm{mDC}$

Tabelle 4.1b: Expression von SVN bzw. PR3 in PBMC und DC (PBMC: mononukleäre Zellen des peripheren Blutes, iDC: unreife Dendritische Zellen, mDC: reife Dendritische Zellen).

\subsection{Konstruktion des adenoviralen Vektors}

Der adenovirale Vektor, der für eine Analyse PR3-peptidspezifischer-T-Zellklone auf natürliches Antigen eingesetzt wurde, enthielt die kodierende Sequenz für ein chimäres Protein. Dieses setzt sich aus dem PR3-Gen und einem verkürzten LAMP-1-Gen zusammen. LAMP-1 als lysosomales Membranprotein wird durch sogenannte Sortierungssignale im cytoplasmatischen Anteil über das endosomale System zu den Lysosomen transportiert. Das MHC-II-Kompartiment ist ein 
lysosomal-verwandtes Organell (LRO), welches ebenfalls hohe Mengen an LAMP-1 enthält. Da dort die Antigenbeladung der MHC-Klasse-II-Moleküle stattfindet, sollte das Fusionsprotein über die zytoplasmatischen Sortierungssignale vermehrt auch in die MHC-II-Kompartimente entlang der biosynthetischen Route transportiert werden (Ruff et al., 1997). Die Transduktion des Virus in DC und die anschließende Expression des chimären Proteins diente als alternative Stimulationsmöglichkeit neben der Beladung der MHC-IIKompartimente über exogene Zufuhr und anschließender Endozytose.

Die Details der Klonierung sind unter Material und Methoden ausführlich dargelegt und die Plasmidkarten sind im Anhang zusammengestellt. Die wesentlichen Klonierungsschritte waren:

1) Ligation und Klonierung des PR3- und LAMP-1-Gens in das Plasmid pcDNA3.1

2) Ligation und Klonierung des PR3-LAMP-1-Konstrukts, bzw. für die Kontrolle das GFP-Gen, in das Plasmid pShuttle. Dieses Plasmid enthält den humanen CMV-Promoter und einen SV40 polyA.

3) Herstellung der adenoviralen Plasmide: Die Gene wurden aus pShuttle herausgeschnitten und in das Plasmid pAd5/F35 hineinkloniert.

4) Transfektion der adenoviralen Plasmide in HEK293a-Zellen: pAd5/F35PR3/LAMP-1 bzw. -GFP wurden nach Linearisierung in HEK293a-Zellen transfiziert, einzelne Virus-Plaques wurden isoliert und weiter analysiert.

Abb. 4.5 zeigt die entscheidenden Schritte: (a) Kontrolle der Klonierung des chimären Gens (PR3-LAMP-1) in pcDNA3.1, (b) Kontrolle der Klonierung des chimären Gens in pShuttle und (c) die Restriktionsanalyse der Vektor-DNA beispielhaft für Ad5/F35-PR3/LAMP-1. Die Analysen zeigen die in HEK293aZellen transfizierte virale DNA. 
Abb. 4.5 Wesentliche Schritte für die Herstellung eines Adenovirus (Ad5/F35).

$$
\begin{array}{llllllll}
1 & 2 & 3 & 4 & 5 & 6 & 7 & \mathrm{M}
\end{array}
$$

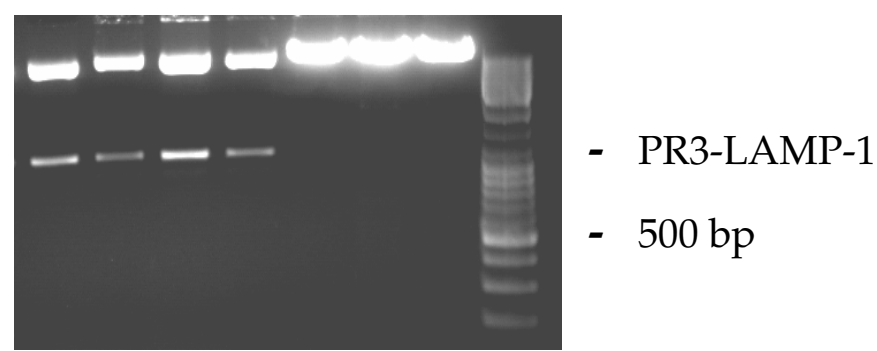

Abb. 4.5A: Nachweis der Ligation und Klonierung des chimären Gens in pcDNA3.1: Nach der Klonierung wurden die Plasmidpräparationen analysiert. Die Restriktion erfolgte mit den Enzymen NheI und KpnI. Spalten 1 bis 4 zeigen mögliche erfolgreiche Klonierungen. Die Spalten 5 bis 7 zeigen erfolglose Klonierungen (M: Marker, bp: Basenpaare).

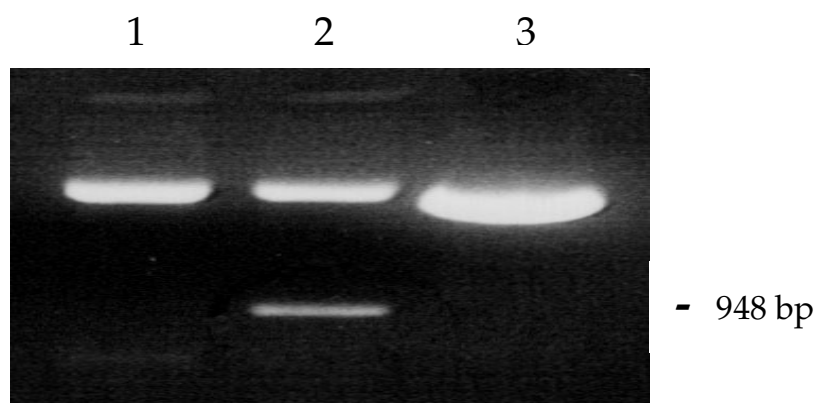

Abb. 4.5B: Nachweis der Ligation und Klonierung des chimären Gens in pShuttle: Nach der Klonierung wurden die Plasmidpräparationen analysiert. Bei erfolgreichen Konstrukten sollte nach Restriktion mit I-CeuI und PI-SceI ein Fragment von 948 bp erkennbar sein. Spalte 2 zeigt eine mögliche erfolgreiche Klonierung. Die Spalten 1 und 3 zeigen erfolglose Klonierungen (bp:-Basenpaare).

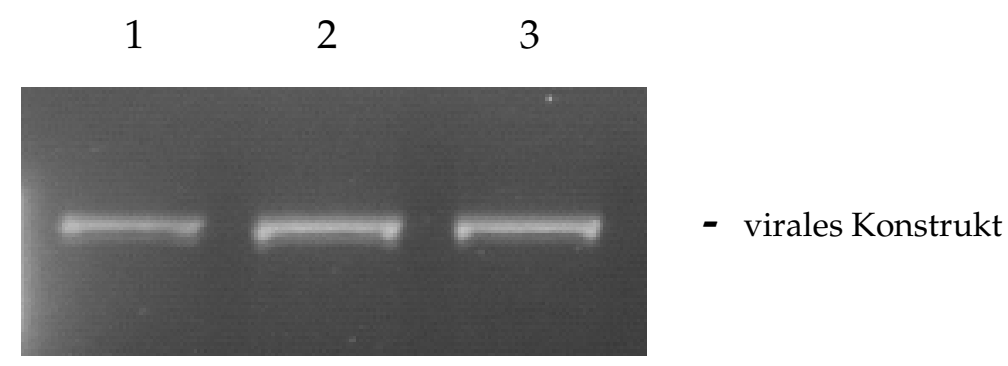

Abb. 4.5C: Restriktionsanalyse der viralen Vektor-DNA (Ad5/F35): Die Vektor-DNA wurde mit PacI geschnitten. In allen drei Spuren kann das gewünschte Fragment detektiert werden. 
Die Titration bzw. Konzentrationsbestimmung der infektiösen Viruspartikel erfolgte mit Hilfe eines Plaque-Tests und mittels optischer Dichte (OD). Tabelle 4.2 gibt einen Überblick über die Ergebnisse.

$\begin{array}{cccccc}\text { Bezeichnung } & \mathbf{O D}_{\mathbf{2 6 0}} & \mathbf{O D}_{\mathbf{2 8 0}} & \mathbf{O D}_{\mathbf{2 6 0}} / \mathbf{O D}_{\mathbf{2 8 0}} & \begin{array}{c}\text { Titer aus OD } \\ {\left[\times 10^{10} \mathrm{pfu} / \mathrm{ml}\right]}\end{array} & \begin{array}{c}\text { Biologischer } \\ \text { Titer }\left[\times 10^{10}\right. \\ \mathrm{pfu} / \mathrm{ml}]\end{array} \\ \text { PR3/LAMP-1 } & 0,267 & 0,217 & 1,23 & \mathbf{2 6 , 7} & \mathbf{1 9 , 1} \\ \text { GFP } & 0,119 & 0,094 & 1,27 & \mathbf{1 1 , 9} & \mathbf{1 5 , 4}\end{array}$

Tabelle 4.2: Titer der Viruspräparation

Die Titrationsbestimmung mit der OD erschien zuverlässiger, weil beim Zeitpunkt der Auszählung der Löcher im Zellrasen der HEK293a-Zellen, diese schon eine beträchtliche Größe aufwiesen - dies erschwerte die Auswertung. Ad5/F35-GFP ist der Kontrollvektor in den in vitro Studien. Er ist abgesehen vom Transgen mit dem anderen Konstrukt identisch. GFP steht für das „Green Fluorescent Protein".

Der Nachweis der Expression von PR3-Lamp-1 in den entsprechenden Zielzellen erfolgte $24 \mathrm{~h}$ bzw. 48 h nach Transduktion mittels Western Blot. Abb. 4.6 zeigt die erfolgreiche Transduktion und anschließende Expression von PR3-LAMP-1 in den Zielzellen HEK 293a und DC von verschiedenen Spendern; Abb. 4.7 die Expression von GFP in DC mittels Fluoreszenzmikroskopie und Durchflusszytometrie. 
A:

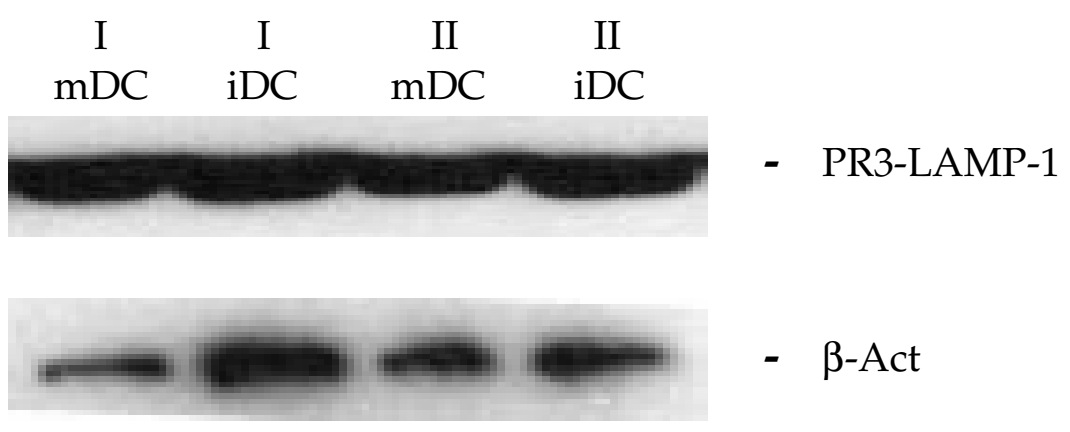

B:

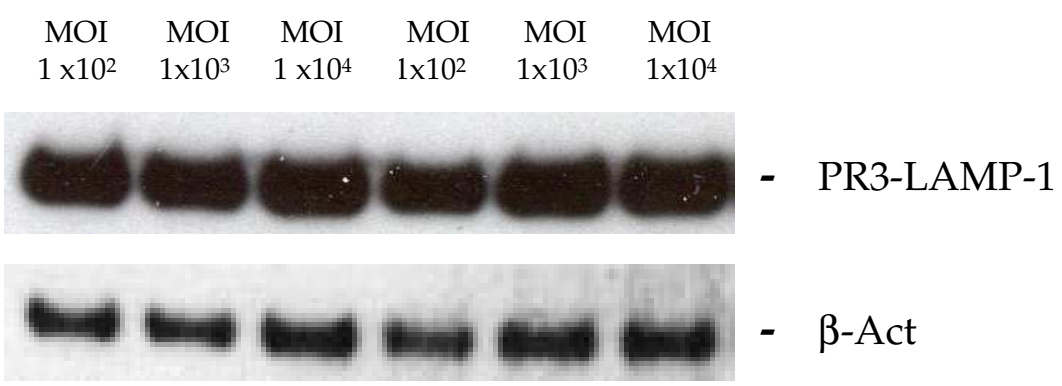

Abb. 4.6: Nachweis der PR3-LAMP-1-Expression nach Transduktion des Virus in verschiedene Zielzellen mittels Western Blot. Die Detektion erfolgte $48 \mathrm{~h}$ nach Transduktion mit einem monoklonalen PR3-Antikörper. A: in mDC und iDC mit einer MOI von 100 (dargestellt sind jeweils zwei verschiedene gesunde Spender), B: in HEK293a-Zellen mit verschiedener MOI. Als Kontrolle diente der Nachweis von $\beta$-Actin (MOI: multiplicities of infection). 


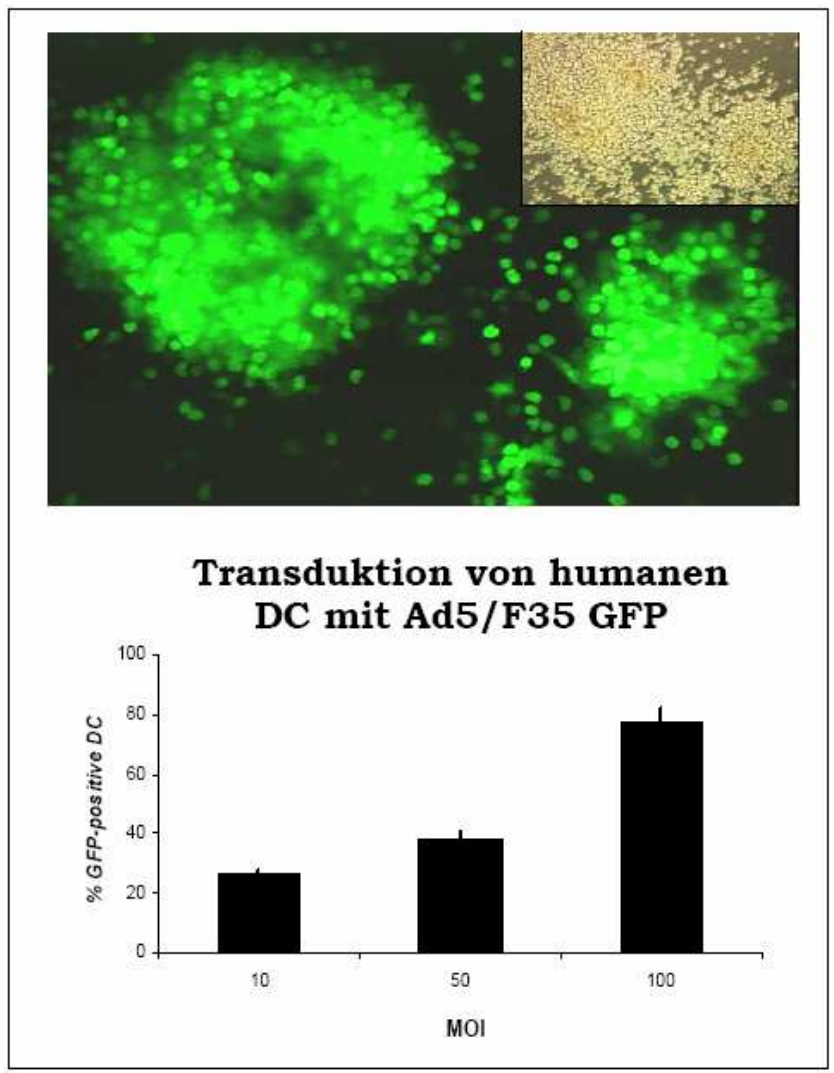

Abb 4.7: $\begin{array}{r}\text { Adenovirale } \\ \text { von }\end{array}$
Transduktion $r$ mit Ad5/F35
humanen DC
GFP. Chimäre Ad5/F35
GFP Adenovektoren
wurden in verschiedenen
Konzentrationen (bzw.
MOI, "multiplicity of
infections“, entsprechend
Adenovirionen pro
Zielzelle) zur Transduktion
von humanen DC aus
peripherem Blut eingesetzt.
24-48 Stunden nach der
Vektorexposition wurden
die Transduktionsraten
durch Detektion GFP-
positiver DC mittels
Durchflußzytometrie
ermittelt.

\subsection{Identifikation und Charakterisierung von tumor- spezifischen HLA-II-Peptidepitopen}

\subsubsection{Analyse von Epitopkandidaten mittels TEPITOPE}

Im Rahmen dieser Arbeit wurden MHC-II- bzw. HLA-II-restringierte Kandidatenepitope in Survivin (SVN) und in der Proteinase-3 (PR3) unter Anwendung des Computerprogramms TEPITOPE (Bian and Hammer, 2004) ermittelt. TEPITOPE erlaubte die Vorhersage von Peptidepitopen, die potenziell an Allele des wichtigsten HLA-Isotyps HLA-DR banden. Die TEPITOPE-Analyse ergab für SVN 6 Kandidatenepitope und für PR3 11 Kandidatenepitope mit 
hoher Bindungswahrscheinlichkeit für unterschiedliche HLA-DR-Allele. Diese insgesamt 17 Peptide wurden nach Synthese und chromatographischer Aufreinigung in T-zellimmunologischen Versuchen eingesetzt. Die variable Länge der Peptide resultierte aus überlappenden Epitopen, die gemeinsam in einem Peptid berücksichtigt wurden (Tab. 4.3).

Peptid Position Aminosäuresequenz T-Zellfrequenz

\section{$\underline{\text { SVN }}$}

$\mathrm{S}_{10}$

$\mathrm{S}_{22} \quad 22-36$

WQPFLKDHRISTFKN

$8,64^{*} 10^{-7}$

40-54

FKNWPFLEGAAATPE

$7,2 * 10^{-7}$

$\mathrm{S}_{40}$

58-72

EAGFIHAPTENEPDL

$8,64^{*} 10^{-7}$

$\mathrm{S}_{58}$

88-103

FFCFKELEGWEPDDD

$4,32^{*} 10^{-7}$

$\mathrm{S}_{88}$

110-124

LGEFLKLDRERAKNKI

$1,73^{*} 10^{-6}$

$\mathrm{S}_{110}$

KNKIAKETNNKKKEF

$8,64^{*} 10^{-7}$

$\underline{\text { PR3 }}$

$\mathrm{P}_{41}$

41-58

YMASLQMRGNPGSHFCGG

$5,76^{*} 10^{-7}$

$\mathrm{P}_{58} \quad 58-76$

GTLIHPSFVLTAAHCLRDI

$7,2 * 10^{-7}$

$\mathrm{P}_{67}$

67-84

PQRLVNVVLGAHNVRTQE

$1^{*} 10^{-6}$

$\mathrm{P}_{87}$

87-101

$\mathrm{P}_{117}$

117-133

AHNVRTQEPTQQHFS

$4,32^{*} 10^{-7}$

$\mathrm{P}_{166}{ }^{*}$

166-180

NDVLLIQLSSPANLSAS

$8,64^{*} 10^{-7}$

$\mathrm{P}_{166}$

166-188

PAQVLQELNVTVVTF

$\mathrm{P}_{187}$

187-201

$\mathrm{P}_{216}$

216-233

$\mathrm{P}_{235}$

235-262

$\mathrm{P}_{239}$

239-256

$7,2^{*} 10^{-7}$

$7,2^{*} 10^{-7}$

ICTFVPRRKAGICFG

$4,32 * 10^{-6}$

IDSFVIWGCATRLFPDFF

$5,76^{*} 10^{-7}$

$1,58^{*} 10^{-6}$

Tabelle 4.3: Bezeichnungen, AS-Positionen und AS-Sequenzen der synthetischen SVN- bzw. PR3-Peptide. Die Abschätzung der Frequenzen peptidspezifischer T-Lymphozyten in peripherem Blut von gesunden Kontrollprobanden erfolgte nach einwöchiger in vitro-Kultivierung von T-Zellen und nachfolgender Restimulation mit synthetischen Peptiden in 48 separaten 
Mikrokulturen (jeweils $2 \times 10^{5}$ Zellen). Mikrokulturen mit Peptid, die im Vergleich zu Kulturen ohne Peptid größer als dreifache Proliferationsraten aufwiesen, wurden als peptidspezifisch gewertet. Die Abschätzung peptidspezifischer T-Zellfrequenzen (f) erfolgte gemäß folgender Formel: $\mathrm{f}=\left([\right.$ Anzahl peptidspezifischer Mikrokulturen] $) /\left(48 \times 2 \times 10^{5}\right)$.

\subsubsection{Generierung von peptid-spezifischen CD4+ T-Lypmphozyten}

Humane T-Lymphozyten aus PBMC von gesunden Kontrollprobanden wurden in vitro mit den synthetischen Peptiden stimuliert. Als antigen/peptidpräsentierende Zellen fungierten zum einen Monozyten und B-Lymphozyten, die in der PBMC-Fraktion enthalten sind, und zum anderen reife dendritische Zellen (mDC). Eine vorherige Selektion von CD3+ T-bzw. CD4+ T-Lymphozyten wurde nicht durchgeführt. Nach einwöchiger Kultur wurden die Zellen hinsichtlich ihrer peptidspezifischen Proliferation mittels $\left[{ }^{3} \mathrm{H}\right]$-Thymidineinbau analysiert (Abb. 4.8).

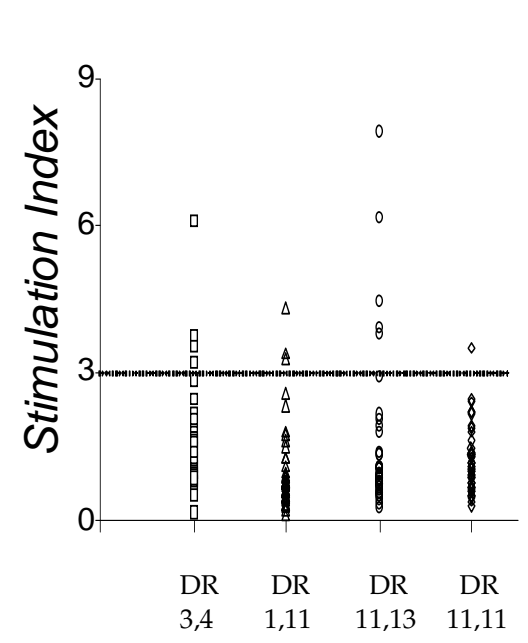

$\mathrm{S}_{10}$

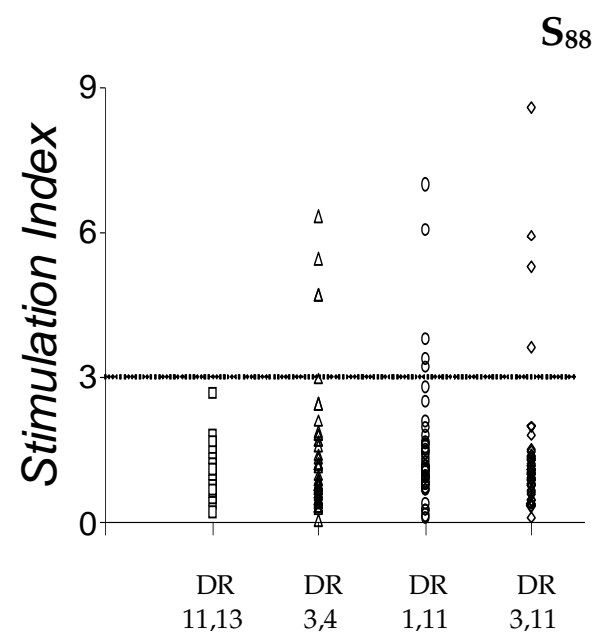




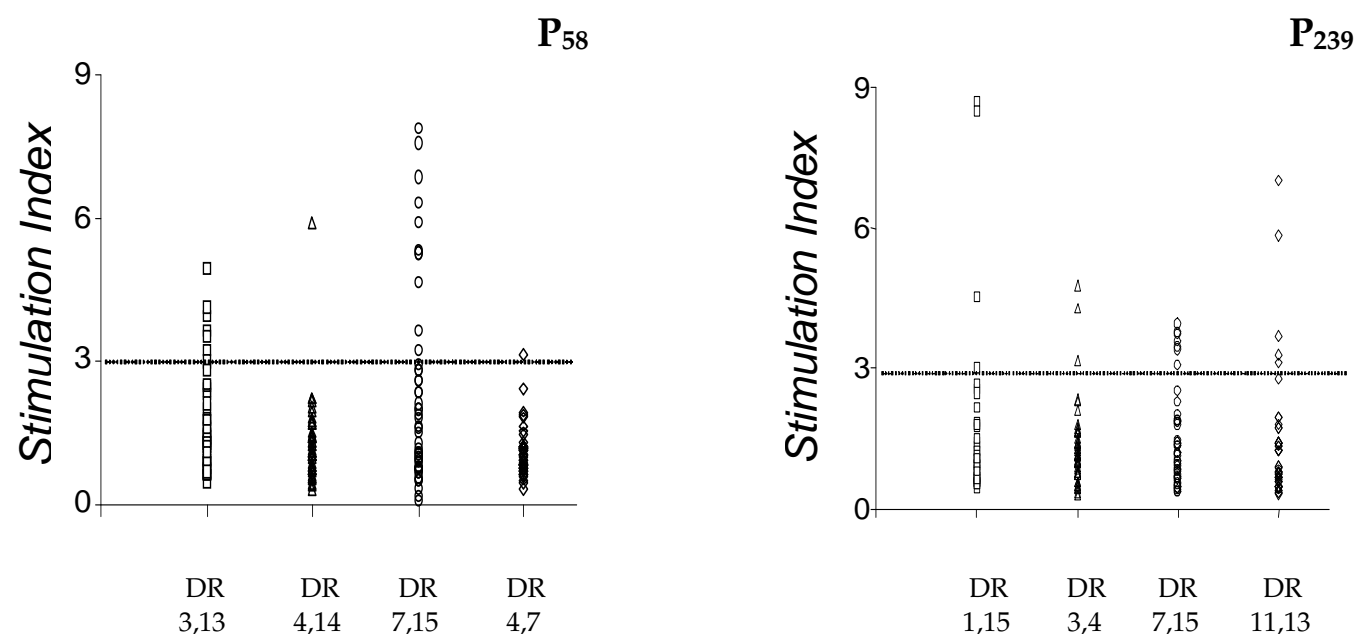

Abb. 4.8: Exemplarische Darstellung der proliferativen T-Zellantwort auf verschiedene Peptide. PBMC (2x105/Loch) von gesunden Kontrollprobanden verschiedenen HLA-DR-Typs wurden mit verschiedenen synthetischen Peptiden in 48 separaten Mikrokulturen (jeweils $2 \times 10^{5}$ Zellen) eine Woche kultiviert. Der proliferative Nachweis mittels $\left[{ }^{3} \mathrm{H}\right]$-Thymidin-Einbau erfolgte $72 \mathrm{~h}$ nach Restimulation mit den entsprechenden Peptiden. Mikrokulturen mit Peptid, die im Vergleich zu Kulturen ohne Peptid größer als dreifache Proliferationsraten aufwiesen, wurden als peptidspezifisch gewertet.

Für alle Peptide mit Ausnahme des Peptids $\mathrm{P}_{166^{*}}$ wurden peptidspezifische proliferierende Mikrokulturen nachgewiesen. Hieraus ließen sich die T-Zellfrequenzen der peptidspezifischen T-Lymphozyten unter Berücksichtigung der eingesetzten Zellzahlen und der Anzahl der proliferierenden Mikrokulturen ermitteln (Tab. 4.3). Diese waren vergleichbar mit publizierten T-Zellfrequenzen gegen körpereigene Antigene (Ford and Burger, 1983). Das Peptid $\mathrm{P}_{166^{*}}$ war unter allen getesteten nicht-toxischen Bedingungen unlöslich und konnte daher nicht für eine in vitro-T-Zellstimulation verwendet werden.

Die Selektion peptidspezifischer T-Zellen erfolgte mittels „limiting dilution“. Dies ermöglichte eine Expansion peptid-spezifischer T-Zellklone, die nachfolgend 
hinsichtlich ihrer Peptidspezifität, MHC-Restriktion und Proteinerkennung detailliert analysiert werden konnten. Spezifische T-Zellklone konnten für folgende Peptidepitope kultiviert werden: $\mathrm{P}_{58}, \mathrm{P}_{216}, \mathrm{P}_{235}, \mathrm{P}_{239}, \mathrm{~S}_{10}, \mathrm{~S}_{40}$ und $\mathrm{S}_{88}$. Trotz wiederholter Experimente mit PBMC von diversen, HLA-verschiedenen Blutspendern gelang es nicht, spezifische T-Zellklone gegen die Peptide $\mathrm{P}_{41}, \mathrm{P}_{67}$, $\mathrm{P}_{87}, \mathrm{P}_{117}, \mathrm{P}_{166}, \mathrm{P}_{187}, \mathrm{~S}_{22}, \mathrm{~S}_{58}$ und $\mathrm{S}_{110} \mathrm{zu}$ generieren.

\subsubsection{Analyse peptidspezifischer CD4+ T-Lymphozyten}

Die Antigenspezifität der T-Zellklone wurde durch Kokultivierung mit korrespondierenden Peptiden und unspezifischen Kontrollpeptiden belegt. Mit blockierenden Antikörpern gegen humanes HLA-A, B, C, -DR und -DQ wurde das HLA-Restriktionsmuster der Antigenpräsentation analysiert. Es konnte für alle peptidspezifischen T-Zellklone eine HLA-DR-abhängige Präsentation nachgewiesen werden (Abb. 4.9, exemplarisch: Klon Gö11-3/4-S10.3; Erklärung der Klonnamen: Gö11: Spender 11; 3/4: HLA-DR-Typ; S10.3: Peptid). 


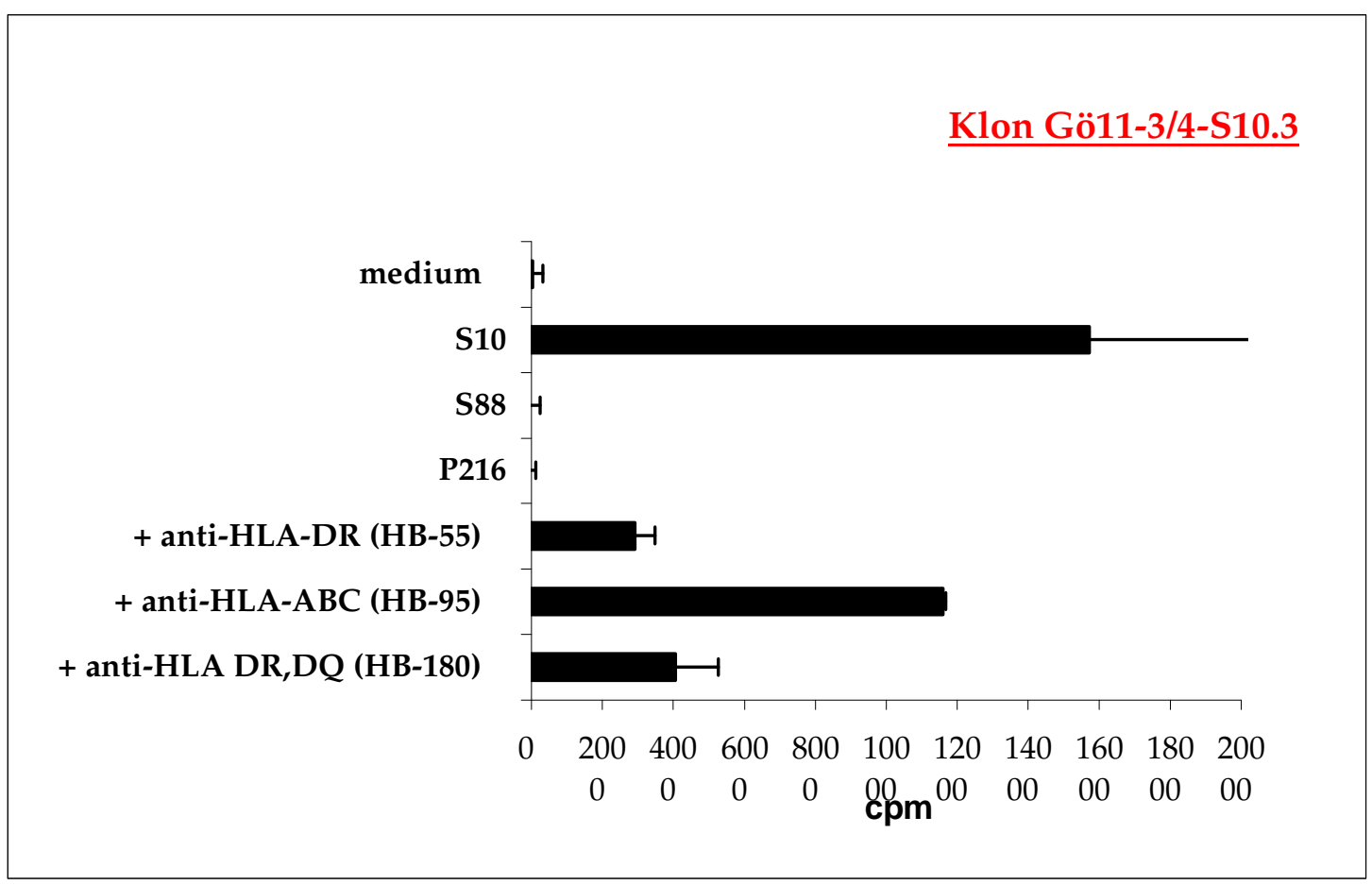

Abb. 4.9: Spezifität und MHC-Restriktionsmuster der T-Zellantworten gegen die Peptide $S_{10}$, $\mathbf{S}_{40}, \mathbf{S}_{88}, \mathbf{P}_{58}, \mathbf{P}_{216}, \mathbf{P}_{235}$ und $\mathbf{P}_{239}$. Einzelne T-Zellklone wurden aus peptidspezifischen T-Zellinien mittels »limiting dilution" kultiviert. Exemplarisch ist die proliferative Antwort von $\mathrm{S}_{10}$-peptidspezifischen T-Zellklon gegenüber korrespondierendem Peptid $\left(\mathrm{S}_{10}\right)$ sowie unspezifischen Kontrollpeptiden gezeigt $\left(\mathrm{S}_{88}, \mathrm{P}_{216}\right)$. Durch Koinkubation der T-Zellklone mit autologen DC, dem spezifischen Peptid und funktionell blockierenden Antikörpern gegen humanes HLA-ABC, -DR und -DQ wurde das HLA-Restriktionsmuster der Peptidepitope untersucht. Der Nachweis einer Proliferation erfolgte mittels $\left[{ }^{3} \mathrm{H}\right]$-Thymidin-Einbau $72 \mathrm{~h}$ nach Stimulation mit den entsprechenden Peptiden und/oder Antikörpern (cpm: counts per minute).

Durchflusszytometrische Analysen mit fluoreszenzmarkierten spezifischen Antikörpern zeigten eine für CD4+ T-Lymphozyten typische Koexpression von CD3 und CD4 (Abb. 4.10) bei allen peptidspezifischen T-Zellklonen. 
A: Klon Gö11-3/4-S10.3
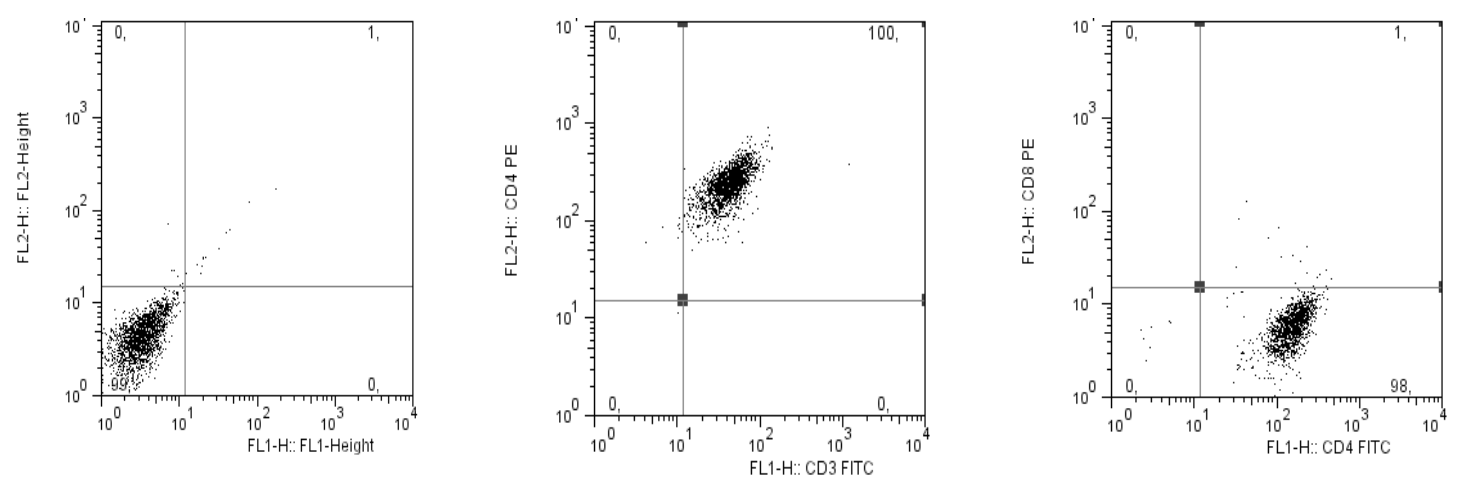

B: Klon Gö14-11/13-P 239.2
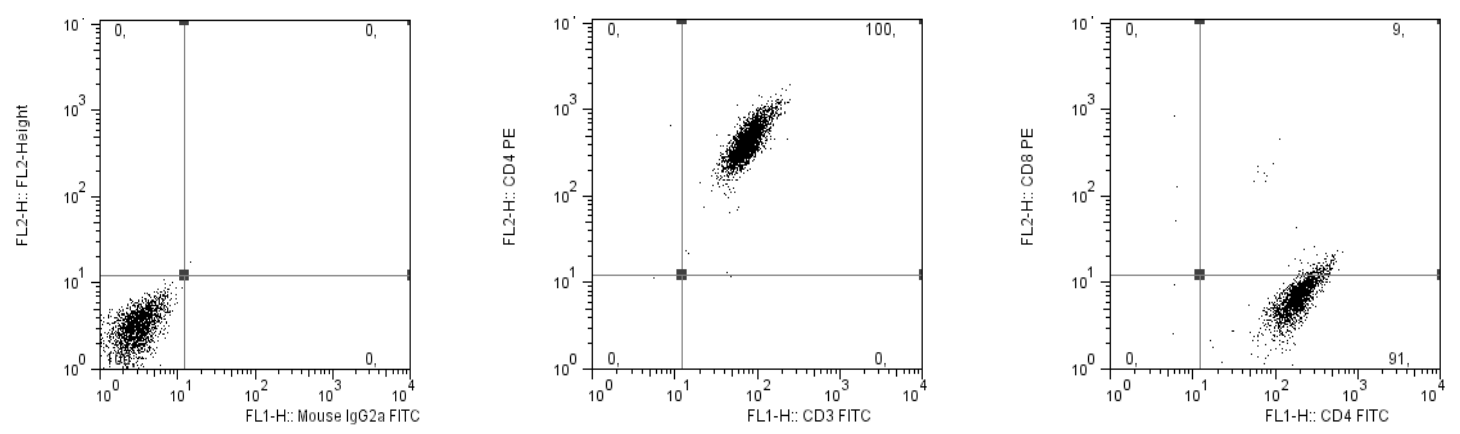

Abb. 4.10: FACS Analysen der peptidspezifischen T-Zellklone. Exemplarisch sind zwei Klone dargestellt (A: Gö11-3/4-S10.3, B: Gö14-11/13-P239.2). Die Detektion erfolgte durch Doppelfärbung mit $\alpha$-humanen CD3-FITC- und CD4-PE-gekoppelten Antikörpern sowie mit $\alpha$-humanen CD4FITC- und CD8-PE-gekoppelten Antikörpern. Als Isotypkontrolle diente ein $\alpha$-maus IgG-FITCgekoppelter Antikörper.

Titrationsversuche mit den entsprechenden Peptiden erfolgten zur Abschätzung der Peptid-HLA-Affinität bzw. der Peptid-HLA/TCR-Avidität. Als semiquantitatives Maß diente hierbei die Peptidkonzentration, bei der die Proliferationsaktivität halbmaximal war. Je niedriger die Peptidkonzentration war, desto hochaffiner war die Bindung der Peptidepitope an die MHC-Moleküle, 
eine wichtige Voraussetzung für die natürliche Präsentation von "genuinen" T-Zellepitopen aus einem intrazellulär prozessierten Proteinantigen. In Abbildung 4.11 ist exemplarisch die Titrationskurve für die Peptide $S_{10}$ und $S_{88}$ dargestellt. Tabelle 4.4 zeigt die ermittelte halbmaximale Proliferationsaktivität aller peptidspezifischen T-Zellklone.

A:

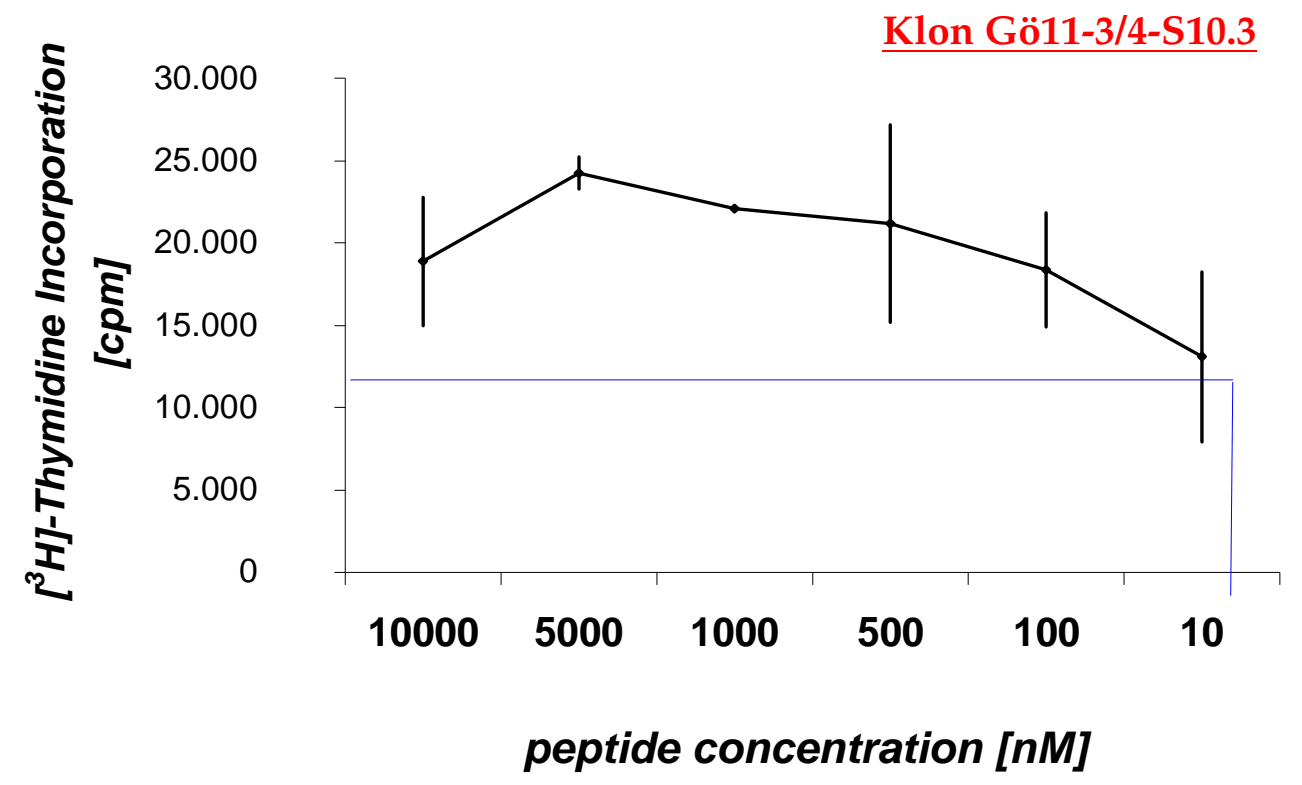


B:

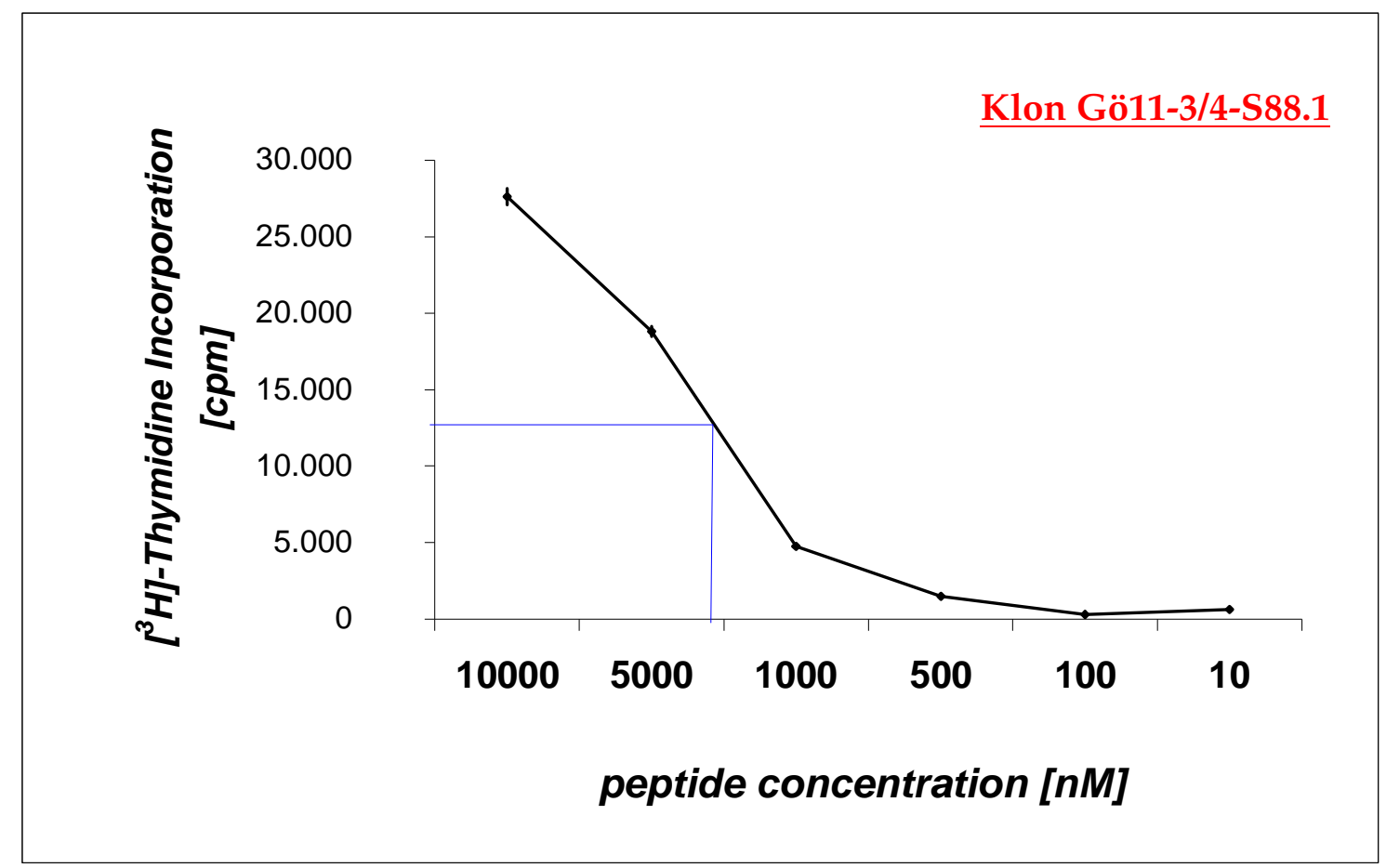

Abb. 4.11: Peptid:MHC/TCR-Avidität verschiedener T-Zellklone. Die Avidität des Peptid:MHC/TCR-Komplexes wurde semiquantitativ durch Kokultivierungen des T-Zellklons mit antigenpräsentierenden Zellen und verschiedenen Konzentrationen des entsprechenden Peptids ermittelt. Als Vergleichsmaß zu anderen T-Zellklonen diente die Konzentration, die zur halbmaximalen Proliferationsaktivität der T-Zellen führte (hier: A: < $10 \mathrm{nM}$; B: $3000 \mathrm{nM}$ ) (cpm: counts per minute, nM: Nanomolar). Der Proliferationsnachweis auf die unterschiedlichen Peptidkonzentrationen erfolgte mittels $\left[{ }^{3} \mathrm{H}\right]$-Thymidin-Einbau $72 \mathrm{~h}$ nach Stimulation

\begin{tabular}{cr} 
Peptid & max $_{\mathbf{1} / \mathbf{2}}$ \\
\hline $\mathrm{S}_{10}$ & $<50 \mathrm{nM}$ \\
$\mathrm{S}_{40}$ & $400-700 \mathrm{nM}$ \\
$\mathrm{S}_{88}$ & $2000-3000 \mathrm{nM}$ \\
$\mathrm{P}_{58}$ & $100-300 \mathrm{nM}$
\end{tabular}




$\begin{array}{lr}\mathrm{P}_{216} & 400-2000 \mathrm{nM} \\ \mathrm{P}_{235} & 1000-2000 \mathrm{nM} \\ \mathrm{P}_{239} & 1000-3000 \mathrm{nM}\end{array}$

Tabelle 4.4: Halbmaximale Proliferationsaktivität der peptidspezifischen T-Zellklone.

Für eine Immuntherapie von Tumoren mit spezifischen T-Helferzellen ist es unerlässlich, dass die peptidspezifischen T-Zellklone das Epitop aus natürlich prozessiertem Proteinantigen erkennen. Die Prozessierung und Präsentation der SVN-Peptidepitope aus natürlichem Antigen wurde durch Kokultivierung peptidspezifischer T-Zellklone mit SVN-Protein-gepulsten DC untersucht. Eine Analyse von PR3-peptidspezifischen-T-Zellklonen auf natürliches Antigen erfolgte durch Kokultivierung von peptidspezifischen T-Zellklonen mit Ad5/F35Virus transduzierten DC. Wie in 4.2 beschrieben, enthält der Virus die kodierende Sequenz für PR3-LAMP-1, welches nach Transduktion in DC exprimiert wird. Lediglich für das SVN-Peptid $S_{10}$ zeigte sich eine spezifische T-Zellproliferation bei Exposition mit rekombinanten SVN-Protein (Abb. 4.12). Dies wurde an drei S10-spezifischen T-Zellklonen von unterschiedlichen Spendern gezeigt. Für die PR3-spezifischen T-Zellklone konnte keine spezifische Proliferation auf das natürliche Antigen nachgewiesen werden. 


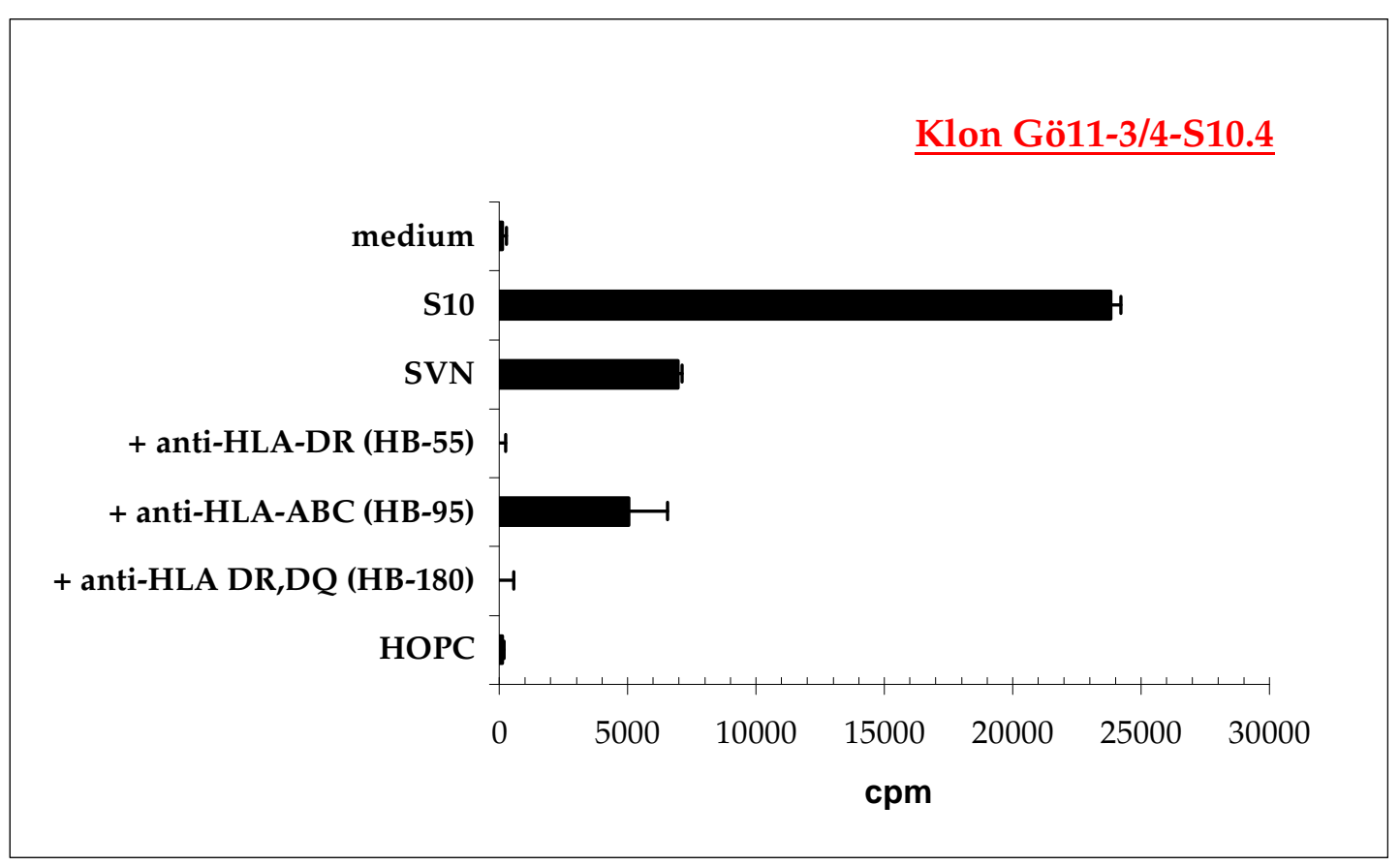

Abb. 4.12: Erkennung von rekombinantem Protein durch $S_{10}$-spezifische T-Zellklone (exemplarisch Klon Gö11-3/4-S $\mathbf{1 0}_{10.4}$ ). Für die restlichen peptid-spezifischen T-Zellklone konnte keine Proteinerkennung nachgewiesen werden. Die SVN-peptid-spezifischen Klone wurden mit Protein-gepulsten (SVN oder einem irrelevanten Immunglobulin „HOPC“) und Peptid-gepulsten autologen DC kokultiviert; die PR3-peptid-spezifischen Klone mit transduzierten DC ( Ad5/F35PR3-LAMP oder AD5/F35-GFP) und Peptid-gepulsten autologen DC (nicht gezeigt). Entsprechend der bekannten HLA-Restriktion des $\mathrm{S}_{10}$-Epitops (Abb. 4.9) konnten die proliferativen T-Zellreaktionen auf das hSVN-Protein durch einen humanen HLA-DR-Antikörper inhibiert werden. Der Proliferationsnachweis erfolgte mittels [ $\left.{ }^{3} \mathrm{H}\right]$-Thymidin-Einbau $72 \mathrm{~h}$ nach Stimulation (cpm: counts per minute).

Tumorantigene von apoptotischen oder nekrotischen Tumorzellen werden in vivo von APC internalisiert, MHC-II-abhängig prozessiert und an CD4+ T-Zellen präsentiert. Zur T-Zellerkennung des genuinen $\mathrm{S}_{10}$-Epitops wurden demzufolge DC mit Tumorzelllysaten von verschiedenen SVN-positiven Tumorzelllinien gepulst. Für das $\mathrm{S}_{10}$-Epitop ließ sich von den Tumorzelllinien Karpas-422, Jurkat und HL-60 eine direkte in vitro-Erkennung von Lysat-gepulsten DC nachweisen 
(Abb. 4.13). Dies konnte an mindestens drei $\mathrm{S}_{10}$-spezifischen T-Zellklonen von unterschiedlichen Spendern gezeigt werden.

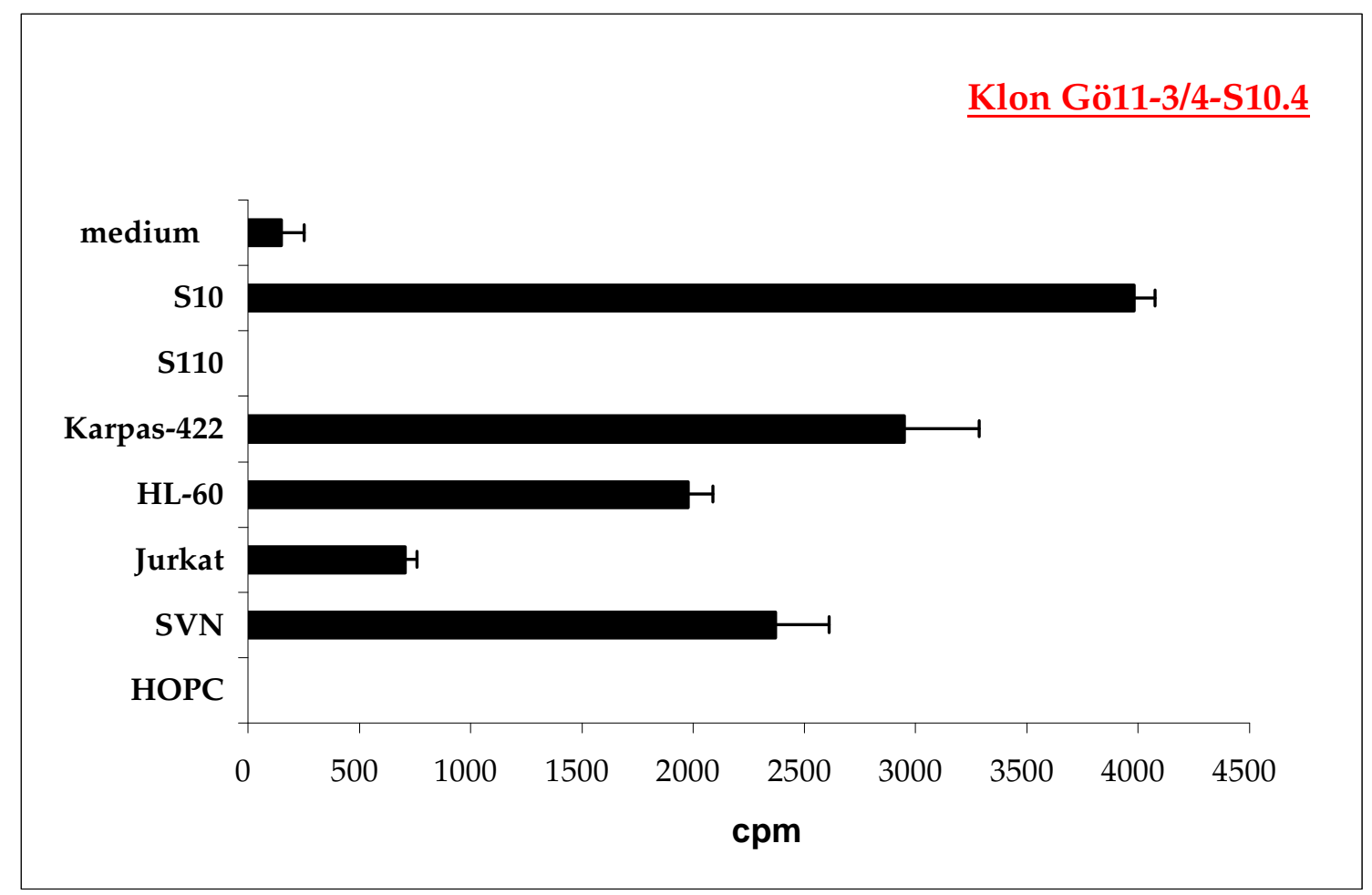

Abb. 4.13: Erkennung von tumorzelllysat-gepulsten DC von verschiedenen SVN-positiven Tumorzelllinien durch $\mathbf{S}_{10}$-spezifische T-Zellklone, exemplarisch dargestellt für den Klon Gö113/4-S10.4. Gezeigt sind lediglich die Tumorzellen, die eine proliferative Antwort aufwiesen. Der Nachweis einer Zellproliferation erfolgte mittels [ $\left.{ }^{3} \mathrm{H}\right]$-Thymidin-Einbau $72 \mathrm{~h}$ nach Stimulation mit autologen DC und entsprechenden Tumorzelllysaten $\left(\mathrm{S}_{10}\right.$ : spezifisches Peptid; $\mathrm{S}_{110}$ : unspezifisches Peptid; Karpas-422, HL-60, Jurkat: verwendete Tumorzelllysate; SVN: rekombinantes Protein; HOPC: unspezifisches Protein; cpm: counts per minute).

Voraussetzung für eine Immuntherapie mit dem identifizierten genuinen Peptidepitop $S_{10}$ ist das Vorhandensein der korrespondierenden CD4+ T-Lymphozyten im Blut von Tumorpatienten. Hierzu wurden PBMC von 
verschiedenen Patienten zum Teil vor Therapie, zum anderen erst nach Beginn einer zytostatischen Therapie, isoliert und mit dem $S_{10}$-Peptid stimuliert. Als antigen-/peptidpräsentierende Zellen fungierten Monozyten und B-Zellen, die in der PBMC-Fraktion enthalten sind. Nach einwöchiger Kultur wurden die Zellen hinsichtlich ihrer peptidspezifischen Proliferation mittels $\left[{ }^{3} \mathrm{H}\right]$-Thymidineinbau analysiert (Abb. 4.14).

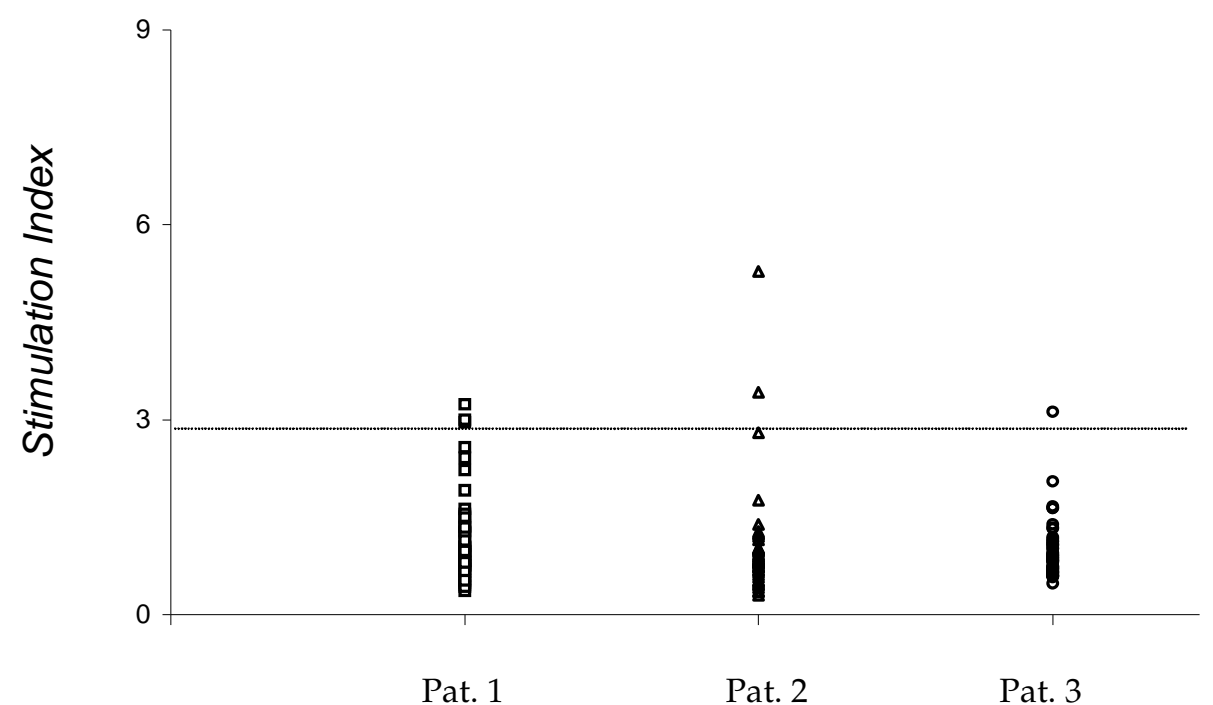

\begin{abstract}
Abb. 4.14: Proliferative T-Zellantwort verschiedener Tumorpatienten auf das $S_{10}$-Peptid. Die PBMC wurden mit dem $\mathrm{S}_{10}$-Peptid in 48 separaten Mikrokulturen (jeweils $2 \times 10^{5}$ Zellen) eine Woche kultiviert. Der proliferative Nachweis mittels $\left[{ }^{3} \mathrm{H}\right]$-Thymidin-Einbau erfolgte $72 \mathrm{~h}$ nach Restimulation mit den entsprechenden Peptiden. Mikrokulturen mit Peptid, die im Vergleich zu Kulturen ohne Peptid größer als dreifache Proliferationsraten aufwiesen, wurden als peptidspezifisch gewertet (Pat.1: Alter 63 Jahre, Erkrankung: MCL (Mantelzelllymphom); Pat. 2: 57 Jahre, c-ALL (akute lymphatische Leukämie); Pat. 3: 82 Jahre, NSCLC ("non small cell lung cancer")).
\end{abstract}

Von 13 getesteten Patienten konnten bei drei Patienten eine proliferative Antwort detektiert werden. 
Die identifizierten Epitope von PR3 wurden zur Untersuchung auf peptidspezifische IFN- $\gamma$ sezernierende CD4+ T-Lymphozyten in Morbus Wegener Patienten eingesetzt. Hierfür wurden PBMC mit dem entsprechenden PR3-Peptid in einer mit IFN- $\boldsymbol{\gamma}$-markierten ELISPOT-Platte inkubiert. $24 \mathrm{~h}$ bzw. $48 \mathrm{~h}$ nach Inkubation wurden die Platten auf IFN- $\gamma$-Spots mittels ELISPOT analysiert. Die Auswertung ergab keinen Unterschied von Spots zwischen den Kontrollen und den peptid-stimulierten PBMC. Auch die Änderung verschiedener Parameter konnte keinen Unterschied zwischen Kontrollen und peptid-stimulierten PBMC aufzeigen.

Neuere Erkenntnisse über die Rolle regulatorischer CD4+ T-Lymphozyten bei der Inhibition antitumoraler Immunreaktionen (Wang et al., 2004; Voo et al., 2005 ; Wang et al., 2005 ; Bluestone and Abbas, 2003; Sakaguchi, 2003; Sutmuller et al., 2001; Liyanage et al., 2002) erforderten die Untersuchung der generierten CD4+ T-Zellklone auf T-regulatorische Marker.

A: : Klon Gö11-3/4-S10.4
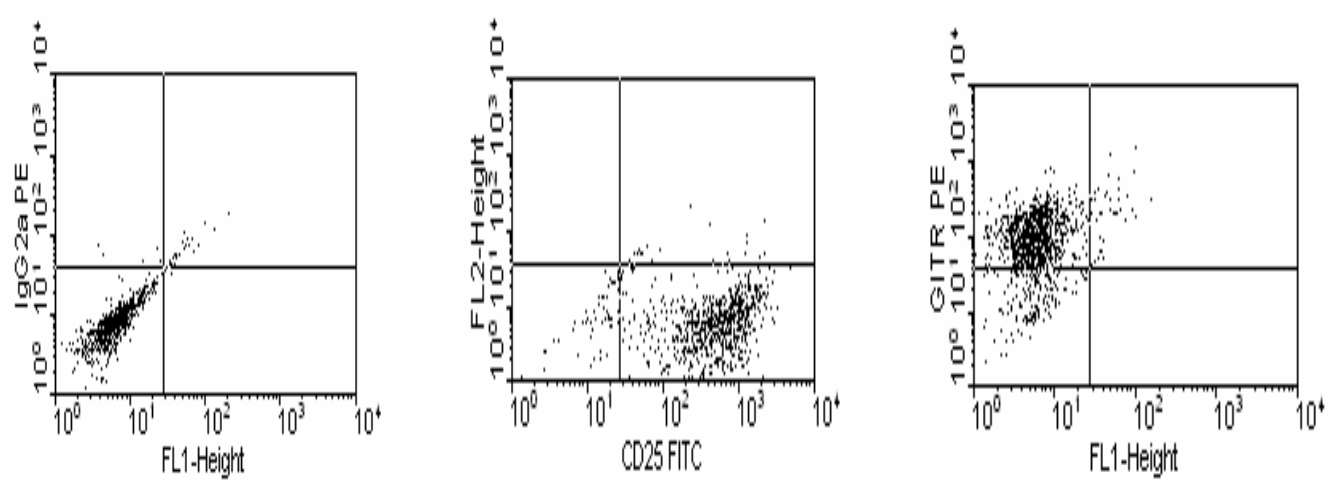


\section{B: Klon Gö14-11/13-P 239.2}
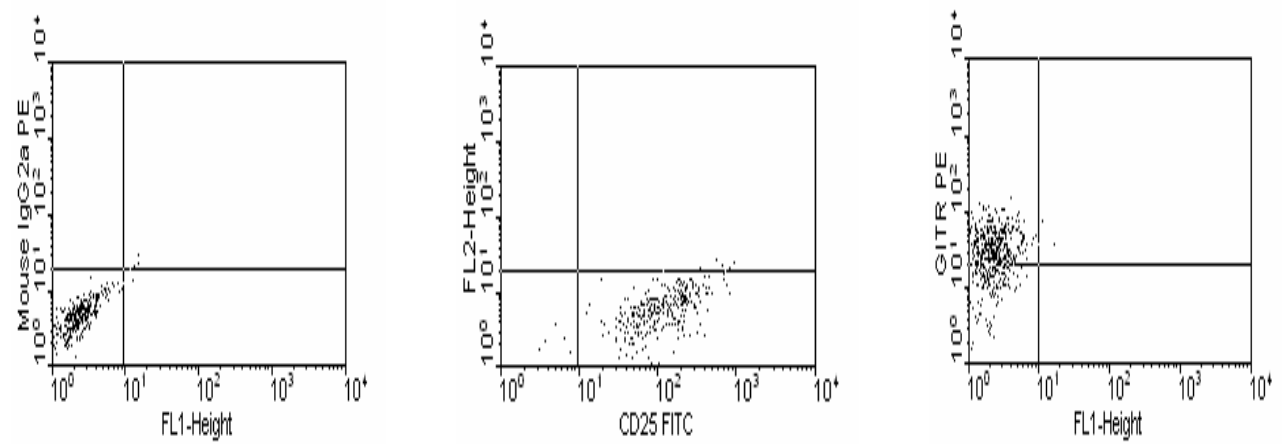

Abb. 4.15: FACS-Analysen der Oberflächenmarker CD25 und GITR. Die Detektion erfolgte mit $\alpha$-humanen CD25-FITC- und GITR-PE-gekoppelten Antikörpern. Als Isotypkontrolle diente ein $\alpha$-muriner IgG2a-PE-gekoppelter Antikörper. Exemplarisch sind die Ergebnisse für zwei Klone dargestellt A: Klon Gö11-3/4-S10.4, B: Klon Gö14-11/13-P239.2.

Für sämtliche Klone ließen sich CD25, GITR (Abb. 4.15) und foxp3 (Abb. 4.16) nachweisen. Während die Expression von CD25 und GITR unspezifische

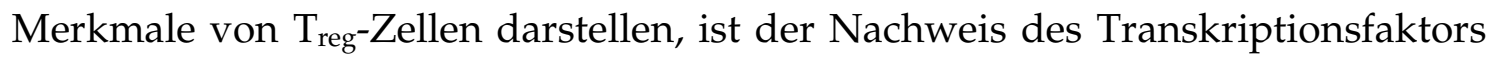
foxp3 ein relativ spezifisches Merkmal für Treg-Lymphozyten (Sakaguchi, 2003).

$\begin{array}{llllllll}M & 1 & 2 & 3 & 1 & 2 & 3 & M\end{array}$

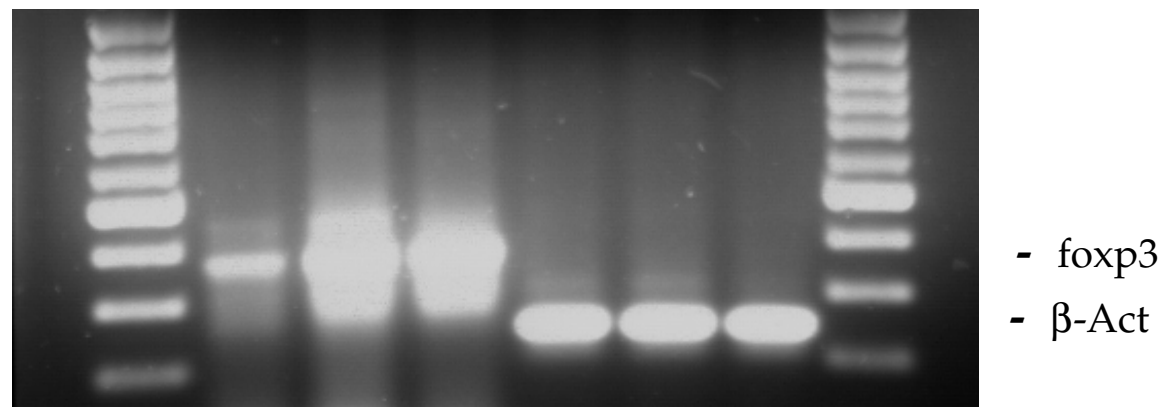

Abb. 4.16: RT-PCR des Transkriptionsfaktors foxp3, exemplarisch für drei Klone gezeigt. Als Kontrolle wurde eine RT-PCR unter Verwendung von $\beta$-Actin-Primern ( $\beta$-Act) durchgeführt

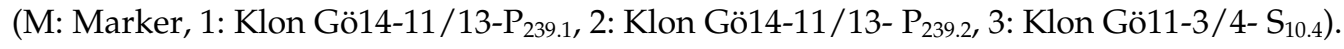


Ein weiteres Charakteristikum von T-regulatorischen Zellen ist die von $\mathrm{T}_{\mathrm{H}}$-Zellen differente Zytokinsekretion. Im Rahmen der vorgestellten Arbeit wurden die T-zelluläre Freisetzung von IL-2, IL-10, TGF- $\beta 1$ und IFN- $\gamma 48$ h nach Stimulierung mit entsprechenden Peptiden untersucht (Abb. 4.17).

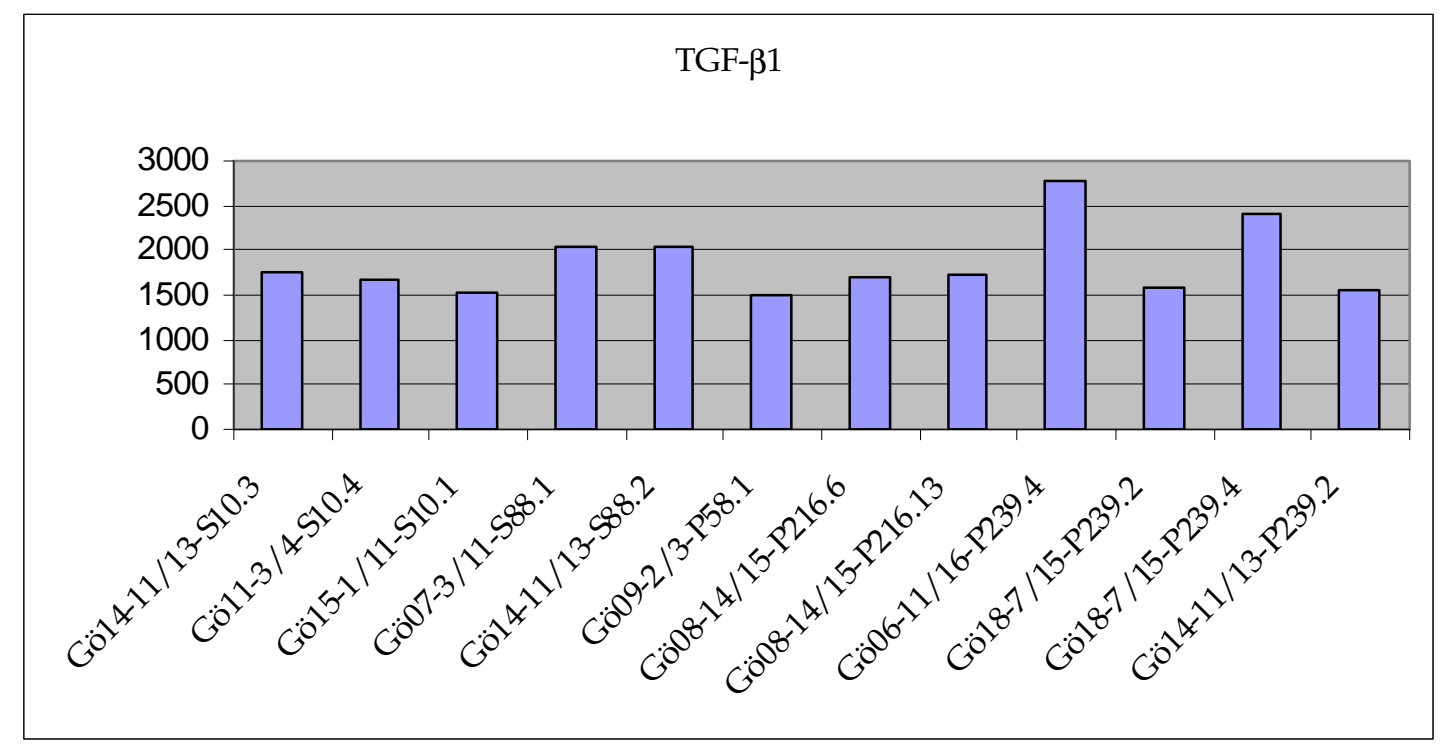

Abb. 4.17: ELISA Zytokinprofil Treg-Zellen. Die Zytokine IL-2, IL-10 und IFN- $\gamma$ konnten nach spezifischer Peptid-Stimulation der T-Zellklone mittels ELISA nicht detektiert werden (nicht gezeigt). Dargestellt ist die TGF-ß1-Ausschüttung peptidspezifischer T-Zellklone (in pg/ml). Der Nachweis erfolgte $48 \mathrm{~h}$ nach Stimulation mit den entsprechenden Peptiden.

Mittels ELISA konnte eine Sekretion von TGF- $\beta 1$ nachgewiesen werden. IL-2, Il-10 und IFN- $\gamma$ konnten dagegen nicht detektiert werden. Es handelte sich somit bei sämtlichen T-Zellklonen um T-regulatorische Zellen. 


\section{Diskussion}

Die Therapie von Tumoren basiert seit Jahrzehnten auf den drei Säulen Operation, Bestrahlung und Chemotherapie. Die Heilungschancen bei Tumorerkrankungen nehmen zwar durch die immer besser werdenden operationstechnischen, radiotherapeutischen und chemotherapeutischen Verfahren und Therapiestrategien sowie Maßnahmen zur Früherkennung zu, dennoch ist eine gezielte und sichere Vernichtung aller Krebszellen in einem Patienten mit diesen konventionellen Behandlungen oft nicht möglich. Alternative Therapieoptionen, $\mathrm{zu}$ denen immuntherapeutische Ansätze zählen, sind notwendig und zunehmend vielversprechend auf dem Weg zu höheren Heilungsraten bei malignen Erkrankungen. Eine immuntherapeutische Strategie beruht auf dem Einsatz monoklonaler Antikörper, die gegen Tumorantigene gerichtet sind. Eine andere Möglichkeit liegt in der Verabreichung sogenannter Immunmodulatoren wie Interferonen und Interleukinen, die die Immunantwort beeinflussen können. Der Ansatz einer zellulären Immuntherapie durch antigenspezifische T-Lymphozyten kann ebenfalls zur Zerstörung der Tumorzellen führen. In diesem Zusammenhang können antigenspezifische T-Zellen durch Vakzinierung mit ganzen Tumorzellen, ausgewählten Tumorproteinen, nackter Antigen-DNA oder mit DC, die durch virale oder nicht-virale Vektoren mit Tumorantigenen transduziert worden sind, aktiviert werden (Berzofsky et al., 2004). Besonders attraktiv für klinische Anwendungen sind Impfungen mit tumorassoziierten Peptidepitopen, da Peptide in aller Regel einfach synthetisierbar, chemisch stabil und frei von mikrobiellen Pathogenen sowie ohne inhärent onkogenes Potential sind (Celis et al.,1995). 
In den vergangenen Jahren erfolgte in einer Vielzahl von klinischen Studien die Peptidvakzinierung mit MHC-Klasse-I-abhängigen Epitopen (Jäger et al., 2000; Melief et al., 1996). Bisher konnten jedoch trotz vielfältiger Optimierungsstrategien keine befriedigenden tumorspezifischen CD8+ T-Zellantworten in Patienten mit malignen Erkrankungen beobachtet werden (Rosenberg, 2004). Aufgrund der bisher sehr limitierten Erfolge von CD8 bzw. MHC-I-orientierten Peptidvakzinen in der Tumorimmuntherapie und der Erkenntnis, dass CD4+ T-Zellen eine fundamentale Bedeutung in der Antitumor-Immunantwort haben, wurden die Bemühungen zur Identifizierung neuer MHC-Klasse-II-restringierter Tumorantigene (TA) erheblich verstärkt (Toes et al., 1999; Zeng, 2001). Die Aktivität der CD4+ T-Zellen wirkt sich dabei durch die Hilfe für CD8+ T-Zellen (Toes et al., 1999; Zeng, 2001), Induktion der IFN-ץ-abhängigen Monozyten-/Makrophagenvermittelten Zytotoxizität (Egeter et al., 2000; Greenberg, 1991; Mumberg et al., 1999) oder durch Aktivierung der B-Zellen zur Antikörperproduktion (Hung et al., 1998) aus. Eine wichtige Voraussetzung für diese potentielle Verbesserung antitumoraler Immuntherapien ist die Kenntnis von MHCKlasse-II-bindenden Peptidepitopen, die eine Aktivierung tumorspezifischer CD4+ T-Helferlymphozyten bewirken. In vitro dienen die Helferzellepitope der Analyse von T-Helferzellantworten, die aus aktiven Immunisierungen mit verschiedenen Antigenformen resultieren. Zudem bietet die Kenntnis von Helferzellepitopen aus TA die Möglichkeit, diese in Form von synthetischen Peptiden direkt oder beladen auf antigenpräsentierende DC als Vakzine zu applizieren. Durch eine parallele Impfung von MHC-I- und MHC-IIrestringierten Peptidepitopen aus demselben TA einer Tumorentität sollen die Voraussetzungen für eine optimale Vernetzung von CD8+ CTL- und CD4+ T-Helferaktivierung über DC, die am Ort des Tumors parallel CTL- und

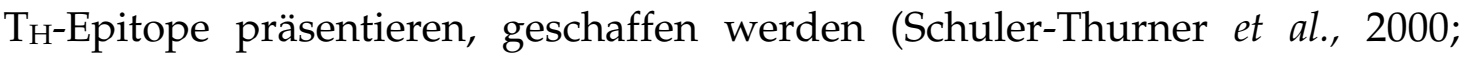
Bennett. et al., 1998; Ridge et al., 1998). Nach wie vor ist aber die Zahl der zur Verfügung stehenden tumorspezifischen T-Helferepitope sehr begrenzt. Diese Arbeit fokussierte sich dementsprechend auf die Identifikation von 
T-Helferzellepitopen in solchen TA, die bereits bekannte Zielantigene von CD8+ CTL-Reaktionen waren.

Ein Verfahren zur Aufdeckung von MHC-II-abhängigen Peptidepitopen in definierten Proteinantigenen basiert auf überlappenden synthetischen Peptiden, die die gesamte Primärsequenz des Antigens abdecken (Tsukui et al., 1998). Die in vitro Stimulation von T-Zellen mit diesen Peptiden ist wegen der Größe der ausgewählten Proteine aber nicht praktikabel. Für das kleinere Survivin (SVN) hätten 32 überlappende Peptide (15mere; Peptidabstand 4 AS) in die Induktion von T-Zellreaktionen eingesetzt werden müssen, für die Proteinase 3 (PR3) sogar 60 überlappende Peptide. Von einer primären Stimulation von $\mathrm{T}_{\mathrm{H}}$-Zellen mit dieser Strategie wurde daher abgesehen.

Ein alternatives Verfahren basiert auf bioinformatischen Computerprogrammen. Die Vollendung des humanen Genomprojektes und die Verfügbarkeit von Algorithmen zur Vorhersage des HLA-Bindungsverhaltens von beliebigen Peptiden erlauben die Identifizierung von neuen T-Zellepitopkandidaten. Proteinantigene können somit auf potentielle MHC-I- und MHC-II-abhängige Kandidatenepitope untersucht werden (Rammensee et al., 1995; Rammensee et al., 1999; Lu and Celis, 2000; Bian et al., 2003). Mit dem Computerprogramm TEPITOPE wurde 1999 die Möglichkeit geschaffen, Peptidliganden für verschiedene HLA-Allele der Klasse II vorherzusagen (Sturnioli et al., 1999). Dieses Programm beruht auf virtuellen Matrizen und berücksichtigt den hohen Polymorphiegrad des HLA-Klasse-II-Systems. Hierdurch können Kandidatenepitope prädiziert werden, die mit hoher Wahrscheinlichkeit an mehrere HLA-DR-Allele binden (Bian and Hammer, 2004). Im Rahmen dieser Arbeit wurden die tumorassoziierten Antigene (TAA) SVN und PR3, von denen MHC-Klasse-I-Epitope bekannt sind, untersucht. Die Prädiktionsbedingungen wurden so gewählt, dass die vorhergesagten Peptidepitope mit hoher Wahrscheinlichkeit an mindestens zwei HLA-DR-Allele banden. Die Epitopdeduktion ergab für SVN 6 und für PR3 11 Kandidatenepitope. 
Bei Beginn des dargelegten Projekts waren erst wenige MHC-II-abhängige Peptidepitope in der Literatur beschrieben (Knutson et al., 2001; Wang, 2001; Schuler-Thurner, 2002; Yu and Restifo, 2002) und in klinischen Vakzinierungsversuchen eingesetzt worden (Slingluff et al., 2001; Brossart et al., 2000). Für die Identifizierung von TA-spezifischen T-Lymphozyten musste daher eine Methode etabliert werden, die mittels Peptiden eine zuverlässige in vitro-Stimulation und immunologische Charakterisierung von TA-spezifischen CD4+ T-Lymphozyten erlaubte. Trotz vielfacher Austestung der Zusammensetzung des Zellkulturmediums (Peptidkonzentration, Serum, Zytokine), der Zellaufbereitung (unselektierte PBMC versus CD4+ T-Lymphozyten), der initialen Stimulationsdauer, des Zellkulturformates (,,bulk“- versus „split well“-Kulturen), sowie der optimalen antigenpräsentierenden Zellen (Monozyten/Makrophagen/B-Lymphozyten aus PBMC oder DC; Peptid gepulst oder direkt der Kokultur zugesetzt) gestaltete sich die Generierung von peptidspezifischen CD4+ T-Zelllinien ausgesprochen schwierig, da diese durch ein Überwachsen der Kulturen mit unspezifischen T-Zellen ihre Antigenspezifität rasch verloren. Erst die Klonierung der T-Zellen mittels „limiting dilution“ unmittelbar nach der initialen Stimulation unter serum- und zytokinfreien Bedingungen ermöglichte die Expansion von peptidspezifischen CD4+ T-Zellen, die anschließend in Folgeversuchen näher charakterisiert wurden.

Ein potentieller Einsatz von Peptidepitopen in der Immuntherapie hängt entscheidend davon ab, dass die peptidspezifischen CD4+ T-Lymphozyten auf das entsprechende Antigen reagieren. Die Erkennung des natürlich prozessierten Proteinantigens in Form von „genuinen“ oder „echten“ Epitopen wird prinzipiell von diversen Faktoren beeinflusst. - Die intrazelluläre Antigenverarbeitung in MHC-II-bindende Peptidepitope spielt eine wichtige Rolle. APC nehmen TA über Endo-, Phago- oder Pinozytose aus abgestorbenen Tumorzellen in intrazelluläre Vesikel (Endosomen) auf (Pieters, 
1997). Diese Endosomen enthalten Proteasen, die bei niedrigem $\mathrm{pH}-$ Wert aktiv sind und mit der Zeit die aufgenommenen Proteine in zahlreiche Peptidfragmente spalten. Im MHC-II-Kompartiment, einem lysosomalverwandten Organell (LRO: lysosomal-related organell), werden die Peptide anschließend mit Hilfe von HLA-DM über bestimmte Verankerungsreste an MHC-II-Moleküle gebunden und an die Zelloberfläche transportiert. Die Gruppe von Verankerungsresten, welche die Bindung an ein bestimmtes MHC-Klasse-II-Molekül erlauben, nennt man Sequenzmotiv. In der vorliegenden Arbeit konnte lediglich für das SVN-Epitop $S_{10}$ eine Proteinerkennung nachgewiesen werden. Bei den anderen identifizierten Peptiden (SVN: $\mathrm{S}_{40}, \mathrm{~S}_{88}$; PR3: $\mathrm{P}_{58}, \mathrm{P}_{216}, \mathrm{P}_{235}$ und $\mathrm{P}_{239}$ ) handelt es sich um „kryptische“ Epitope, da bei diesen keine Proteinerkennung detektierbar war. Während der endosomalen Proteolyse ist es wichtig, dass die vorhandenen Sequenzmotive nicht - wie im Falle von "kryptischen“ Epitopen - abgebaut werden. Im Gegensatz zu MHC-I-restringierten Epitopen können MHC-IIMoleküle unterschiedlich lange (12-28) Peptide aufnehmen (Rammensee, 1995; Rudensky et al., 1991), eine proteolytische Spaltung der Peptidepitope in definierter Länge ist daher nicht erforderlich. Auch sind die exakte Zusammensetzung und die spezifischen Funktionen der an der endosomalen Proteolyse beteiligten Endo- und Exopeptidasen erst ansatzweise verstanden (Pieters, 1997; Watts, 2004). Daraus ergibt sich, dass für MHC-Klasse-IIabhängige Epitope zur Zeit keine verlässlichen Vorhersagen bezüglich der endosomalen Abspaltungsmuster von Peptidfragmenten - und somit keine Vorhersagen von potentiellen $\mathrm{T}_{\mathrm{H}}$-Zellepitopen - aus einzelnen Proteinen möglich sind.

Eine andere Erklärung für das Phänomen „kryptischer“ Epitope ergibt sich aus der niedrigen Avidität der TCR von CD4+ T-Zellen. Die Avidität zwischen Epitop und MHC-Molekül wird durch die Bindungsstärke zwischen Peptidepitop, MHC-Molekül und T-Zellrezeptor (TCR) bestimmt. Der Weitertransport und damit die Dichte entsprechender MHC-Peptid-Komplexe auf der Zelloberfläche beeinflusst zusammen mit zellulären 
Adhäsionsmolekülen die Gesamtbindungsstärke zwischen $\mathrm{T}_{\mathrm{H}}$-Zelle und APC. TA-spezifische T-Zellen könnten dann aufgrund einer geringen Avidität zwar auf extern applizierte synthetische Peptide reagieren, aber nicht auf die natürlich prozessierten auf den APC bzw. Tumorzellen (Dutoit et al., 2001). In Vereinbarung mit der nachgewiesenen Proteinerkennung ergab sich in Peptidtitrationsversuchen eine deutlich höhere Avidität für das Peptid $\mathrm{S}_{10} \mathrm{im}$ Gegensatz zu den niedrigen Aviditäten für die kryptogenen Peptide $S_{40}, S_{88}$, $\mathrm{P}_{58}, \mathrm{P}_{216}, \mathrm{P}_{235}$ und $\mathrm{P}_{239}$.

In Hinblick auf mögliche zukünftige Bestrebungen PR3 oder SVN als Antigen für die Induktion einer therapeutischen Immunreaktion gegen Tumoren zu nutzen, musste geklärt werden, ob sich von dem identifizierten $S_{10}$-Epitope auch CD4+ T-Lymphozyten aus dem Blut von Tumorpatienten stimulieren ließen. Von einigen der getesteten Patienten ließ sich eine spezifische Antwort gegen das $S_{10}$-Peptid nachweisen. Das unterschiedliche Ansprechen auf die Stimulierung könnte mit dem HLA-Typ der Spender zusammenhängen, da die meisten der identifizierten T-Zellepitope sich auf eine limitierte Anzahl von HLA-Molekülen beschränken (Gilboa, 1999). So sollte das durch TEPITOPE ermittelte Peptid $S_{10}$ vornehmlich an HLA-DR 3, 11 und 15 binden. Eine erfolgreiche Vakzinierung mit tumorassoziierten Peptiden wird demnach eine individuell auf den HLA-Typ der Tumorpatienten zugeschnittene Peptidauswahl erfordern.

Besondere Aufmerksamkeit muss darauf gelegt werden, dass auch eine Immunantwort gegen gesundes menschliches Gewebe möglich sein kann. Dies liegt in der Tatsache begründet, dass bei der Immuntherapie das Immunsystem direkt aktiviert wird und die induzierte Immunantwort gegen Antigene gerichtet ist, die auch auf gesunden menschlichen Zellen präsentiert werden. Der Nachweis von SVN in Thymusgewebe (Kobayashi et al., 2002) und eine durch Zytokine vermehrte Expression in CD34+ hämatopoetischen Zellen sowie in Endothelzellen während der Angiogenese (Fukuda and Pelus, 
2002b) zeigt, dass es sich bei SVN nicht um ein tumorspezifisches Antigen handelt. Der Einsatz von SVN in der Vakzinierungstherapie darf deshalb nur mit Vorsicht angegangen werden. Durch die Überexpression von SVN in Tumoren bleibt aber zu hoffen, dass die aktivierten T-Lymphozyten vor allem die Tumorzellen lysieren werden und es nach einer Vakzinierung zu keinen therapielimitierenden Nebenwirkungen an gesunden Organen kommen muss. Die nachgewiesene Expression von SVN in PBMC, iDC (unreife DC) sowie mDC (reife DC) bzw. PR3 in iDC und mDC und das Fehlen einer Antwort bei Stimulation mit SVN- bzw. PR3-spezischen T-Zellklonen weisen daraufhin, dass die Expression dieser TAA in gesunden Zellen nicht für eine Aktivierung ausreicht. Der Grund für die ausbleibende Antwort ist bisher nicht geklärt. Möglicherweise wird eine ausreichende Avidität der induzierten T-Zellen erst durch eine quantitativ höhere Expression von Peptiden auf Tumorzellen erreicht, da nach Peptidbeladung der APC eine spezifische T-Zell-Proliferation nachgewiesen werden konnte. Auch ein Unterschied im Repertoire von T-ZellEpitopen bei nicht-malignen Zellen und Tumorzellen könnte eine Rolle spielen.

Besondere Vorsicht ist bei einem möglichen Einsatz von PR3 in der Tumorvakzinierung geboten, da PR3 nicht nur das Zielantigen leukämiespezifischer CD8+ T-Zellen sondern auch das Zielantigen der humoralen Immunität bei der cANCA-positiven Wegenerschen Granulomatose ist (Goldschmeding et al., 1989; Niles et al., 1989). Der Morbus Wegener stellt eine systemische Vaskulitis dar, die sich bevorzugt am oberen und unteren Respirationstrakt in Form von Rhinitiden, Sinusitiden und pulmonaler Infiltration sowie an den Nieren als Glomerulonephritiden mit progredienter Niereninsuffizienz manifestiert (Wiik, 2000). Bei der Mehrzahl der Patienten mit einer Wegener-Granulomatose lassen sich AntineutrophileAntikörper (cANCA) gegen die Proteinase 3 nachweisen (Wiik, 2000). Die epitopen Bindungsstrukturen für einige der aus Patientenserum isolierten cANCA im PR3-Protein sind bekannt (zur Übersicht: Wiik, 2000). Überdies 
konnte anhand von genetischen Analysen der TCR bei Wegener-Patienten gezeigt werden, dass das normale T-Zellrepertoire in Abhängigkeit von der Erkrankung beeinträchtigt ist (Giscombe et al., 1995). In einer Arbeit konnte mittels TCR-Genanalysen eine klonale Expansion von CD4+ T-Zellen bei Patienten mit dem HLA-DRB1*0401-Allel in Assoziation zum Erkrankungsgeschehen nachgewiesen werden (Grunewald et al., 1998). Die bis heute publizierten T-zellimmunologischen Untersuchungen sind allesamt mit dem Gesamtprotein PR3 als Antigen durchgeführt worden und erlaubten keine abschließenden Aussagen bezüglich der Art - CTL versus Helfer-T-Zellen und pathophysiologischen Relevanz der T-zellulären Komponente bei Wegenerschen Granulomatosen (Brouwer et al., 1994; Ballieux et al.,1995; Griffith et al., 1996). MHC-Klasse-II-Epitope als Ziele einer CD4+ T-Helferreaktion gegen PR3 sind für diese Autoimmunerkrankungen bisher nicht beschrieben. Ein in vitro-Nachweis von IFN- $\gamma$-produzierenden CD4+ T-Zellen aus PBMC von Morbus Wegener Patienten nach Stimulation mit den identifizierten PR3-Peptiden konnte mit Hilfe des ELISPOTS in dieser Arbeit nicht gezeigt werden. Ein Grund dafür könnte sein, dass eingefrorene PBMC für die Stimulation genutzt wurden. Weiterhin ist es auch möglich, dass aktivierte T-Lymphozyten in den PBMC von Morbus Wegener schon vorhanden sind und somit kein Unterschied zwischen den Kontrollen und den peptid-stimulierten CD4+ T-Zellen detektierbar war. - Für einen erfolgversprechenden Einsatz von PR3 in der Tumorimmuntherapie ist die Identifikation genuiner MHC-Klasse-II-Epitope notwendig - im Rahmen der vorgestellten Arbeiten konnten bisher lediglich kryptische MHC-Klasse-IIEpitope in PR3 identifiziert werden.

Bei der Entwicklung von klinisch wirksamen Immuntherapien müssen weiterhin vielfältige Tumorresistenz- sowie immunologische Mechanismen, die Immunreaktionen gegen Tumorzellen supprimieren und $\mathrm{zu}$ Immuntoleranz führen, bedacht werden (Berzofsky et al., 2004; Mapara and Sykes, 2004). Neuere Erkenntnisse über die Rolle von regulatorischen CD4+ 
T-Zellen $\left(\mathrm{T}_{\text {reg }}\right)$ in der Bekämpfung von Tumoren erfordern hierbei eine besondere Berücksichtigung in der Entwicklung von immuntherapeutischen Konzepten (Wang et al., 2004; Wang et al., 2005; Voo et al., 2005). Als „regulatorisch" wirkend werden meist Zellen beschrieben, die verschiedene aktivierende Vorgänge des Immunsystems unterdrücken. Sie werden deshalb auch oftmals als Suppressor-Zellen bezeichnet und nehmen offenbar eine Schlüsselposition in der peripheren Toleranz gegenüber körpereigenen Zellen

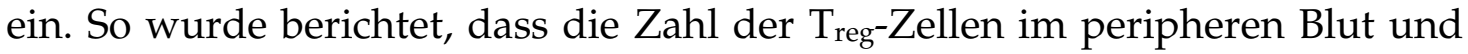
Tumorgewebe verschiedener Patienten erhöht ist (Wolf et al., 2003; Liyanage et al., 2002; Woo et al., 2001; Woo et al., 2002). Im Mausmodell konnte gezeigt werden, dass die Depletion von CD4+CD25+ Zellen die Antwort des Immunsystems gegen den Tumor verbessert (North and Awwad, 1990; Shimizu et al., 1999; Onizuka et al., 1999; Sutmuller et al., 2001; Steitz et al., 2001). In den letzten Jahren sind eine Reihe regulatorischer T-Lymphozyten beschrieben worden. Die Entwicklung dieser $\mathrm{T}_{\text {reg-Zellen ist bis heute noch }}$ nicht vollständig geklärt. Zum Teil können $\mathrm{T}_{\text {reg-Lymphozyten im Thymus }}$ entstehen. Es wird vermutet, dass diese autoreaktiven T-Zellen der negativen Selektion durch eine schwache Avidität zum autoantigenen Peptid entgehen (Lee et al., 1999a). Mit einer sogenannten infektiösen Toleranz werden $\mathrm{T}_{\text {reg- }}$ Zellen beschrieben, die bestimmte regulatorische Eigenschaften besitzen bzw. die Toleranz gegenüber körpereigenen Antigenen auf andere T-Zellen übertragen können (Waldmann and Cobbold, 1998; Jonuleit et al., 2002; Dieckmann et al., 2002). Eine weitere Gruppe von $\mathrm{T}_{\text {reg-Zellen kann durch }}$ inadäquate Antigendarbietung oder unter suboptimalen Kostimulations- und Zytokinbedingungen außerhalb des Thymus entstehen (Bluestone and Abbas, 2003).

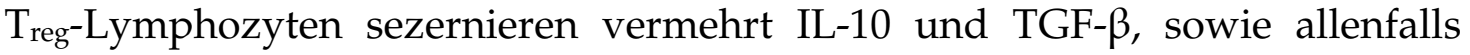
wenig Il-2, Il-4 und IFN-ү. Phänotypisch zeichnen sie sich durch die Expression von CD25, GITR und CTLA4 aus. Während diese Marker unspezifisch sind, stellt die Expression des Transkriptionsfaktors FOXP3 ein 


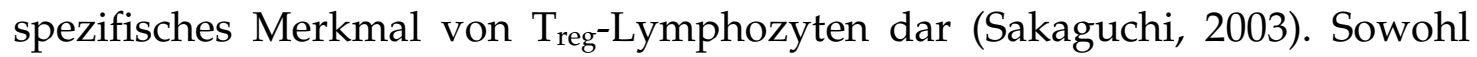

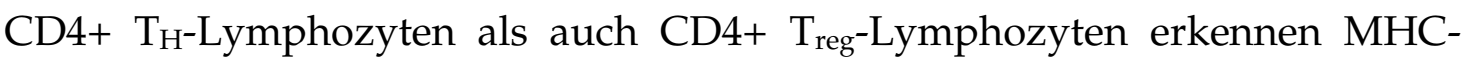
Klasse-II-restringierte Peptidepitope (Sakaguchi et al., 2003; Shevach, 2002).

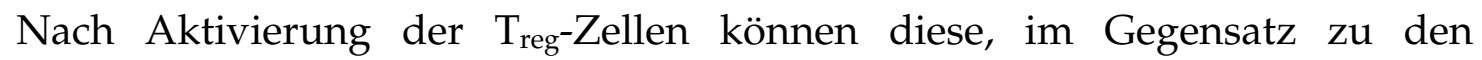
$\mathrm{T}_{\mathrm{H}}$-Zellen, antigen-unspezifisch und nicht-MHC-II-restringiert ihre hemmende Wirkung auf Zielzellen ausüben (Jonuleit et al., 2001; Dieckmann et al., 2001; Thornton and Shevach, 2000). Zudem wurde beschrieben, dass die Stimulation von humanen T-Lymphozyten mit bestimmten MHC-II-abhängigen Peptidepitopen aus den TA LAGE1, EBNA1 und ARTC1 zur bevorzugten

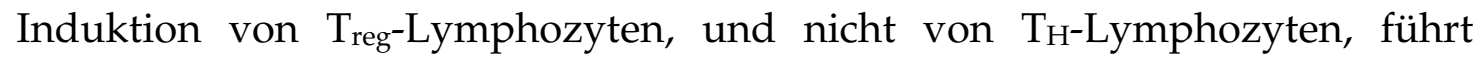
(Wang et al., 2004; Wang et al., 2005; Voo et al., 2005). In vitro konnte gezeigt werden, dass diese TA-spezifischen CD4+ T-Lymphozyten eine hemmende Wirkung auf stimulierte T-Lymphozyten besitzen (Wang et al., 2004; Wang et al., 2005; Voo et al., 2005). Jonuleit und Mitarbeiter haben berichtet, dass durch die wiederholte Stimulation mit allogenen unreifen DC eine Population regulatorischer CD4+ T-Zellen entsteht, die sich durch die Produktion von IL-10 auszeichnet (Jonuleit et al., 2000). Für die Expansion von $T_{\text {reg-Zellen ist in }}$ vivo TGF- $\beta 1$ ein wichtiger Faktor (Peng et al., 2004; Huber et al., 2004). Er dient als Kofaktor für die Expression von FOXP3 (Cobbold et al., 2004); dies führt

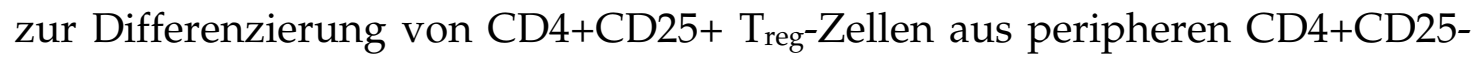
T-Zellen (Chen et al., 2003; Fantini et al., 2004). In naiven T-Lymphozyten inhibiert TGF- $\beta$ die Expression von T-bet, einem wichtigen Transkriptionsfaktor für die Differenzierung zu $\mathrm{T}_{\mathrm{H}} 1-Z$ Zllen (Gorelik et al., 2002; Chen et al., 2003). Weiterhin kann TGF- $\beta$ die IFN- $\gamma$ Sekretion von $\mathrm{T}_{\mathrm{H}} 1$-Effektorzellen inhibieren (Ludviksson et al., 2000; Kitani et al., 2000). In CD8+ CTLs inhibiert TGF- $\beta$ die Transkription der Schlüsselgene für das zytotoxische Programm (Trapani, 2005; Khazaie and von Boehmer, 2006).

Die in dieser Arbeit identifizierten und charakterisierten CD4+ T-Lymphozyten zeichneten sich alle durch das Vorhandensein der typischen

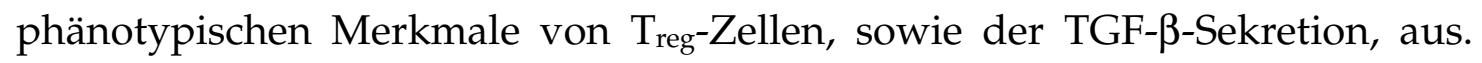


Auch eine Stimulation mit reifen DC (mDC) brachte $\mathrm{T}_{\text {reg-Zellen hervor. In der }}$ Literatur wird häufig über die Notwendigkeit eines sogenannten "danger" Signals diskutiert, das zur Aktivierung des Immunsystems führt (Fuchs and Matzinger, 1996). Vakzinationen, die mit Peptiden, ohne Zugabe von Adjuvantien oder mit wenig stimulierenden Adjuvantien durchgeführt wurden, können T-Zellen nicht effektiv aktivieren und somit Anergie erzeugen (Staveley-O' Carroll et al., 1998; Grohmann et al., 1998). Die zusätzliche Einbeziehung von Adjuvantien bei der Stimulation mit Peptiden könnte somit zu einer präferentiellen Aktivierung von T-Helferzellen führen. In zukünftigen Experimenten ist eine mögliche Verschiebung der beschriebenen T-Zellantworten gegen das identifizierte SVN-Epitope $\mathrm{S}_{10}$ von $\mathrm{T}_{\text {reg- }}$ zugunsten von $\mathrm{T}_{\mathrm{H}}$-Lymphozyten zu untersuchen. 


\section{ZUSAMMENFASSUNG}

Zelluläre Immuntherapien stellen basierend auf gut charakterisierten, tumorspezifischen Antigenen ein vielversprechendes Konzept in der Behandlung maligner Erkrankungen dar. Während für viele Tumorantigene bereits MHC-Klasse-I-Epitope bekannt sind, sind erst wenige Epitope aus MHC-Klasse-II-abhängigen Tumorantigenen beschrieben. Die spezifische Antigenerkennung durch CD4+ T-Lymphozyten erfolgt über ein Peptidepitop, das gebunden an ein MHC-Molekül der Klasse II auf der Oberfläche von spezialisierten antigenpräsentierenden Zellen oder - seltener - auf der Tumorzelloberfläche vorliegt. Im Rahmen der vorgestellten Arbeit wurde ein immunologisches Verfahren etabliert, das eine Identifikation von MHCKlasse-II-assoziierten Peptidepitopen in den tumorassoziierten Antigenen Survivin (SVN) und Proteinase 3 (PR3) ermöglichte. In beiden Tumorproteinen konnten durch computergestützte Vorhersagen zahlreiche Peptidsequenzen mit potentieller Bindung an MHC-II-Moleküle identifiziert werden. In Form von synthetischen Peptiden wurden diejenigen Epitope zur in vitroStimulation von T-Lymphozyten aus peripherem Blut eingesetzt, die mit hoher Bindungswahrscheinlichkeit an mehrere Allele des wichtigsten Isotyps (HLA-DR) banden. Gegen alle (löslichen) untersuchten Peptide wurden in der initialen T-Zellstimulation spezifische Proliferationsreaktionen nachgewiesen. Von den analysierten Peptiden konnten letztendlich 3 von 6 SVN- sowie 4 von 10 PR3-Peptiden T-Zellklone kultiviert werden. Mit Hilfe dieser Klone ließen sich die Bindungsaviditäten zwischen MHC-Molekül, Peptidepitop und T-Zellrezeptor semiquantitativ in Peptidtitrationsversuchen abschätzen. Zudem zeigten alle $\mathrm{T}_{\mathrm{H}}$-Peptidepitope eine HLA-DR-abhängige Präsentation. In Kokultivierungsversuchen mit rekombinantem Proteinen sowie Lysaten von SVN bzw. PR3-exprimierenden Tumorzellen wurde für das Peptid $\mathrm{S}_{10}$ eine 
Epitoperkennung in Prozessierung aus dem natürlichen Proteinantigen nachgewiesen. Spezifische T-Zellantworten gegen dieses genuine T-Zellepitop aus dem Blut von Tumorpatienten konnten ebenso detektiert werden.

In dieser Arbeit wurden alle Experimente in vitro durchgeführt, so dass sich die Ergebnisse nur begrenzt auf das komplexe System des menschlichen Immunsystems übertragen lassen. Weitere Versuche müssen unternommen

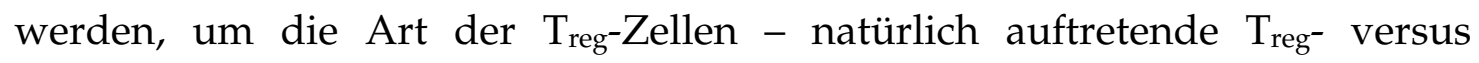

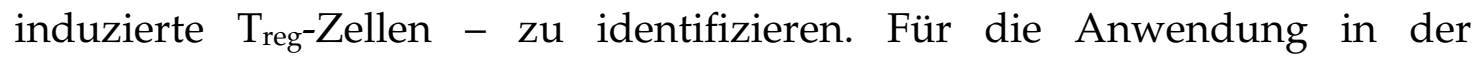
Tumorimmuntherapie ist eine Verschiebung des Gleichgewichtes von $\mathrm{T}_{\text {reg- }}$ zugunsten von $\mathrm{T}_{\mathrm{H}}$-Zellen anzustreben. Hierbei gilt es in zukünftigen Arbeiten herauszufinden, inwieweit sich durch Optimierung des Vakzinierungsintervalls, der wirkungsvollsten Adjuvantien, Dosierungen und Applikationen $\mathrm{T}_{\mathrm{H}}$-Zellen induzieren lassen, die potentiell auch für klinische Anwendungen in aktiven Immunisierungskonzepten gegen Tumoren in Betracht kommen. 


\section{Literaturverzeichnis}

Adida, C., Crotty, PL, McGrath, J., Berrebi, D., Diebold, J., Altieri DC (1998). Developmentally regulated expression of the novel cancer anti-apoptosis gene survivin in human and mouse differentiation. Am. J. Pathol. 52: 43-49.

Adida, C., Haioun, C., Gaulard, P., Lepage, E., Morel, P., Briere, J., Dombret, H., Reyes, F., Diebold. J., Gisselbrecht, C., Salles, G., Altieri, DC, and Molina, TJ (2000a). Prognostic significance of survivin expression in diffuse large B-cell lymphomas. Blood 96: 1921-1925.

Adida, C., Recher, C., Raffoux, E., Daniel, MT, Taksin, AL, Rousselot, P., Sigaux, F., Degos, L., Altieri, DC and Dombret, H. (2000b). Exression and prognostic significance of survivin in de novo acute myeloid leukaemia. Brit. J. Haematol. 111: 196-203

Ahlers, JD, Belyakov, IM, Thomas, EK, Berzofsky, JA (2001). High-affinity T helper epitope induces complementary helper and APC polarization, increased CTL, and protection against viral infection. J. Clin. Invest. 108: 16771685.

Alexandroff, AB, Jackson, AM, Paterson, T., Haley, J.L., Ross, JA, Longo, DL, Murphy, WJ, James, K., Taub, DD (2000). Role for CD40-CD40 ligand interactions in the immune response to solid tumours. Mol. Immunol. 37: 515526. 
Altieri DC (2001). The molecular basis and potential role of survivin in cancer diagnosis and therapy. Trends Mol. Med. 7: 542-547.

Altieri DC (2003). Blocking survivin to kill cancer cells. Methods Mol. Biol. 223: 533-542.

Altomonte, M., Fonsatti, E., Visintin, A., Maio, M. (2003). Targeted therapy of solid malignancies via HLA class II antigens: a new biotherapeutic approach? Oncogene 22: 6564-6569.

Ambrosini, G., Adida, C., Altieri, DC (1997). A novel anti-apoptosis gene, survivin, expressed in cancer and lymphoma. Nat. Med. 3: 917-921.

Ambrosini, G., Adida, C., Sirugo, G., Altieri, DC (1998). Induction of apoptosis and inhibition of cell proliferation by survivin gene targeting. J. Biol. Chem. 273: $11177-11182$.

Andersen, MH, Pedersen, LO, Capeller, B., Brocker, EB, Becker, JC, Thor SP (2001). Spontaneous cytotoxic T-cell responses against survivin-derived MHC class I-restricted T-cell epitopes in situ as well as ex vivo in cancer patients. Cancer Res. 61: 5964-5968.

Andersen, MH, Thor, SP (2002). Survivin-a universal tumor antigen. Histol. Histopathol. 17: 669-675.

Anderson, MS, Venanzi, ES, Klein, L., Chen, Z., Berzins, SP, Turley, SJ, von Boehmer, H., Bronson, R., Dierich, A., Benoist, C., Mathis,D. (2002). Projection of an immunological self shadow within the thymus by the aire protein. Science 298(5597): 1395-1401. 
Anichini, A., Molla, A., Mortarini, R., Tragni, G., Bersani, I., Di Nicola, M., Gianni, AM, Pilotti, S., Dunbar, R., Cerandolo, V., Permiani, G. (1999). An expanded peripheral $\mathrm{T}$ cell population to a cytotoxic $\mathrm{T}$ lymphocyte (CTL)defined, melanocyte-specific antigen in metastatic melanoma patients impacts on generation of peptidespecific CTLs but does not overcome tumor escape from immune surveillance in metastatic lesions. J. Exp. Med. 190: 651-667.

Ballieux, BE, van der Burg, SH, Hagen, EC, van der Woude, FJ, Melief, CJ and Daha, MR (1995). Cell-mediated autoimmunity in patients with Wegener's granulomatosis (WG). Clin. Exp. Immunol. 100(2): 186-193.

Bennett, SR, Carbone, FR, Karamalis, F., Flavell, RA, Miller, JF, Heath, WR (1998). Help for cytotoxic-T-cell responses is mediated by CD40 signalling. Nature 393: 478-480.

Berzofsky, JA, Terabe, M., Oh, S., Belyakov, IM, Ahlers, JD, Janik, JE, Morris, JC (2004). Progress on new vaccine strategies for the immunotherapy and prevention of cancer. J. Clin. Invest. 113: 1515-1525.

Bhandoola, A., Tai, X., Eckhaus, M., Auchincloss, H., Mason, K., Rubin, SA, Carbone, KM, Grossman, Z., Rosenberg, AS, Singer, A. (2002). Peripheral expression of self-MHC-II influences the reactivity and self-tolerance of mature CD4(+) T cells: evidence from a lymphopenic T cell model. Immunity 17(4): $425-436$

Bian, H. and Hammer, J. (2004). Discovery of promiscuous HLA-II-restricted T cell epitopes with TEPITOPE. Methods 34: 468-475.

Bian, H., Reidhaar-Olson, JF and Hammer, J. (2003). The use of bioinformatics for identifying class II-restricted T-cell epitopes. Methods 29: 299-309. 
Bjorkman, PJ, Saper, MA, Samraoui, B., Bennett, WS, Strominger, JL and Wiley, DC (1987). The foreign antigen binding site and $\mathrm{T}$ cell recognition regions of class I histocompatibility antigens. Nature 329: 512-518.

Blattman, JN and Greenberg, PD (2004). Cancer immunotherapy: a treatment for the masses. Science 305: 200-205.

Bluestone, JA and Abbas, AK (2003). Natural versus adaptive regulatory T cells. Nat. Rev. Immunol. 3: 253-257.

Bories, D., Raynal, MC, Solomon, DH, Darzynkiewicz, Z. and Cayre, YE (1989). Down-regulation of a serine protease, myeloblastin, causes growth arrest and differentiation of promyelocytic leukemia cells. Cell 59: 959-968.

Borregaard, N. and Cowland, JB (1997). Granules of the human neutrophilic polymorphonuclear leukocyte. Blood 89: 3503-3521.

Bouneaud, C., Kourilsky, P. and Bousso, P. (2000). Impact of negative selection on the $\mathrm{T}$ cell repertoire reactive to a selfpeptide: a large fraction of $\mathrm{T}$ cell clones escapes clonal deletion. Immunity 13(6): 829-840.

Bradford, MM (1976). A rapid and sensitive method for the quantitation of microgram quantities of protein utilizing the principle of protein-dye binding. Anal. Biochem. 72, 248-254.

Brocker, T. (1997). Survival of mature CD4 T lymphocytes is dependent on major histocompatibility complex class II-expressing dendritic cells. J. Exp. Med. 186(8): 1223-1232. 
Brouwer, E., Stegeman, CA, Huitema, MG, Limburg, PC and Kallenberg, CG (1994). T cell reactivity to proteinase 3 and myeloperoxidase in patients with Wegener's granulomatosis (WG). Clin. Exp. Immunol. 98(3): 448-453.

Brossart, P., Wirths, S., Stuhler, G., Reichardt, VL, Kanz, L. and Brugger, W. (2000). Induction of cytotoxic T-lymphocyte responses in vivo after vaccinations with peptide-pulsed dendritic cells. Blood 96(9): 3102-3108.

Brunner, KT, MacDonald, HR and Cerottini, JC (1980). Antigenic specificity of the cytolytic T lymphocyte (CTL) response to murine sarcoma virus-induced tumors. II. Analysis of the clonal progeny of CTL precursors stimulated in vitro with syngeneic tumor cells. J. Immunol. 124: 1627-1634.

Campanelli, D., Detmers, PA, Nathan, CF and Gabay, JE (1990). Azurocidin and a homologous serine protease from neutrophils. Differential antimicrobial and proteolytic properties. J. Clin. Invest. 85: 904-915.

Carter, BZ, Milella, M., Altieri, DC and Andreeff, M. (2001). Cytokineregulated expression of survivin in myeloid leukemia. Blood 97: 2784-2790.

Celis, E., Sette, A. and Grey, HM (1995). Epitope selection and development of peptide based vaccines to treat cancer. Semin. Cancer Biol. 6: 329-336.

Chambers, CA, Kuhns, MS, Egen, JG and Allison, JP (2001). CTLA-4-mediated inhibition in regulation of $\mathrm{T}$ cell responses: mechanisms and manipulation in tumor immunotherapy. Annu. Rev. Immunol. 19: 565-594.

Chang, JT, Wong, FH, Liao, CT, Chen, IH, Wang, HM and Cheng, AJ (2004). Enzyme immunoassay for serum autoantibody to survivin and its findings in head-and-neck cancer patients. Clin. Chem. 7: 1261-1264. 
Charlton, B. and Lafferty, KJ (1995). The Th1/Th2 balance in autoimmunity. Curr. Opin. Immunol. 7: 793-798.

Chen, CH, Seguin-Devaux, C., Burke, NA, Oriss, TB, Watkins, SC, Clipstone, N. and Ray, A. (2003). Transforming growth factor $\beta$ blocks Tec kinase phosphorylation, $\mathrm{Ca}^{++}$influx, and NFATc translocation causing inhibition of $\mathrm{T}$ cell differentiation. J. Exp. Med. 197: 1689-1699.

Chen, J., Wu, W., Tahir, SK, Kroeger, PE, Rosenberg, SH, Cowsert, LM, Bennett, F., Krajewski, S., Krajewska, M., Welsh, K., Reed, JC and Ng, SC (2000). Down-regulation of survivin by antisense oligonucleotides increases apoptosis, inhibits cytokinesis and anchorage-independent growth. Neoplasia. 2: 235-241.

Chen, W., Jin, W., Hardegen, N., Lei, KJ, Li, L., Marinos, N., McGrady, G. and Wahl, SM (2003). Conversion of peripheral CD4+CD25- naive T cells to CD4+CD25+ regulatory $\mathrm{T}$ cells by TGF- $\beta$ induction of transcription factor Foxp3. J. Exp. Med. 198: 1875-1886.

Cobbold, SP, Castejon, R., Adams, E., Zelenika, D., Graca, L., Humm, S. and Waldmann, H. (2004). Induction of foxp3+ regulatory T cells in the periphery of $\mathrm{T}$ cell receptor transgenic mice tolerized to transplants. J. Immunol. 172: 6003-3010.

Costello, RT, Gastaut, JA and Olive, D. (1999). Tumor escape from immune surveillance Arch. Immunol. Ther. Exp. 47: 83-88.

Davis, ID, Jefford, M., Parente, P. and Cebon, J. (2003). Rational approaches to human cancer immunotherapy. J. Leukoc. Biol. 73: 3-29. 
Dengler, R., Munstermann, U., al-Batran, S., Hausner, I., Faderl, S., Nerl, C., and Emmerich, B. (1995). Immunocytochemical and flow cytometric detection of proteinase 3 (myeloblastin) in normal and leukaemic myeloid cells. Br. J. Haematol. 89: 250-257.

Dieckmann, D., Plottner, H., Berchtold, S., Berger, T. and Schuler, G. (2001). Ex vivo isolation and characterization of CD4(+)CD25(+) T cells with regulatory properties from human blood. J. Exp. Med. 193(11): 1303-1310.

Dieckmann, D., Bruett, CH, Ploettner, H., Lutz, MB and Schuler, G. (2002). Human CD4(+)CD25(+) regulatory, contact-dependent $\mathrm{T}$ cells induce interleukin 10-producing, contact-independent type 1-like regulatory $\mathrm{T}$ cells [corrected]. J. Exp. Med. 196(2): 247-253.

Dutoit, V.; Rubio-Godoy, V.; Dietrich, PY; Quiqueres, AL; Schnuriger, V.; Rimoldi, D.; Lienard, D.; Speiser, D.; Guillaume, P.; Batard, P.; Cerottini, JC; Romero, P. and Valmori, D. (2001). Heterogeneous T-cell response to MAGEA10(254-262): high avidity-specific cytolytic T lymphocytes show superior antitumor activity. Cancer Res. 61(15): 5850-5856.

Egeter, O., Mocikat, R., Ghoreschi, K., Dieckmann, A. and Rocken, M. (2000). Eradication of disseminated lymphomas with CpG-DNA activated T helper type 1 cells from nontransgenic mice. Cancer Res. 60: 1515-1520.

Espinoza-Delgado, I. (2002). Cancer vaccines. Oncologist 7: 20-33.

Falk, K., Rotzschke, O., Stevanovic, S., Jung, G. and Rammensee, HG (1991). Allele-specific motifs revealed by sequencing of self-peptides eluted from MHC molecules. Nature 351: 290-296. 
Fantini, MC, Becker, C., Monteleone, G., Pallone, F., Galle, PR and Neurath, MF (2004). Cutting edge: TGF-beta induces a regulatory phenotype in CD4+ CD25- T cells through Foxp3 induction and down-regulation of Smad7. J. Immunol. 172: 5149-5153.

Fearon, ER and Vogelstein, B. (1990). A genetic model for colorectal tumorigenesis. Cell 61(5): 759-767.

Feili-Hariri, M., Dong, X., Alber, SM, Watkins, SC, Salter, RD and Morel, PA (1999). Immunotherapy of NOD mice with bone marrow-derived dendritic cells. Diabetes 48(12): 2300-2308.

Fenton, RG and Longo, DL (1997). Danger versus tolerance: paradigms for future studies of tumor-specific cytotoxic T lymphocytes. J. Natl. Cancer Inst. 89: $272-275$.

Ferrone, S. and Marincola, FM (1995). Loss of HLA-class I antigens by melanoma cells: molecular mechanisms, functional significance and clinical relevance. Immunol. Today 16: 487-494.

Ford, D. and Burger, D. (1983). Precursor frequency of antigen-specific T cells: effects of sensitization in vivo and in vitro. Cell Immunol. 79: 334-344.

Franzoso, G., Biswas, P., Poli, G., Carlson, LM, Brown, KD, TomitaYamaguchi, M., Fauci, AS and Siebenlist, UK. (1994). A family of serine proteases expressed exclusively in myelo-monocytic cells specifically processes the nuclear factor-kappa B subunit p65 in vitro and may impair human immunodeficiency virus replication in these cells. J. Exp. Med. 180(4): 14451456. 
Fuchs, EJ and Matzinger, P. (1996). Is cancer dangerous to the immune system? Semin. Immunol. 8(5), 271-280.

Fukuda, S. and Pelus, LM (2002a). Elevation of Survivin levels by hematopoietic growth factors occurs in quiescent CD34+ hematopoietic stem and progenitor cells before cell cycle entry. Cell Cycle. 1: 322-326.

Fukuda, S. and Pelus, LM (2002b). Regulation of the inhibitor-of-apoptosis family member survivin in normal cord blood and bone marrow CD34(+) cells by hematopoietic growth factors: implication of survivin expression in normal hematopoiesis. Blood 98: 2091-2100.

Gabrilovich, DI, Chen, HL, Girgis, KR, Cunningham, HT, Meny, GM, Nadaf, S., Kavanaugh, D. Carbone, DP (1996). Production of vascular endothelial growth factor by human tumors inhibits the functional maturation of dendritic cells. Nat. Med. 2: 1096-1103.

Germain, RN (1994). MHC-dependent antigen processing and peptide presentation: providing ligands for T lymphocyte activation. Cell 76: 287-299.

Gianani, R., Jarboe, E., Orlicky, D., Frost, M., Bobak, J., Lehner, R. and Shroyer, KR (2001). Expression of survivin in normal, hyperplastic, and neoplastic colonic mucosa. Hum. Pathol. 32: 119-125.

Gilboa, E. (1999). The makings of a tumor rejection antigen. Immunity 11: 263270.

Gilboa, E. (2001). The risk of autoimmunity associated with tumor immunotherapy. Nat. Immunol. 2: 789-792. 
Giodini, A., Kallio, MJ, Wall, NR, Gorbsky, GJ, Tognin, S., Marchisio, PC, Symons, M. and Altieri, DC (2002). Regulation of microtubule stability and mitotic progression by survivin. Cancer Res. 62: 2462-2467.

Giscombe, R., Grunewald, J., Nityanand, S. and Lefvert, AK (1995). T cell receptor (TCR) V gene usage in patients with systemic necrotizing vasculitis. Clin. Exp. Immunol. 101(2): 213-219.

Giuntoli, RL2, Lu, J., Kobayashi, H., Kennedy, R. and Celis, E. (2002). Direct Costimulation of Tumorreactive CTL by Helper T Cells Potentiate Their Proliferation, Survival, and Effector Function. Clin. Cancer Res. 8: 922-931.

Glennie, MJ and Johnson,PW (2000). Clinical trials of antibody therapy. Immunol. Today 21(8): 403-410.

Goldberg, AL and Rock, KL (1992). Proteolysis, proteasomes and antigen presentation. Nature 357: 375-379.

Goldschmeding, R., van der Schoot, CE, ten Bokkel Huinink, D., Hack, CE, van den Ende, ME, Kallenberg, CG and von dem Borne, AE (1989). Wegener's granulomatosis autoantibodies identify a novel diisopropylfluorophosphatebinding protein in the lysosomes of normal human neutrophils. J. Clin. Invest. 84(5): 1577-1587.

Gorelik, L., Constant, S. and Flavell, RA (2002). Mechanism of transforming growth factor $\beta$-induced inhibition of $\mathrm{T}$ helper type 1 differentiation. J. Exp. Med. 195: 1499-1505.

Gouttefangeas, C. and Rammensee, HG (2000). Problem solving for tumor immunotherapy. Nat. Biotechnol. 18: 491-492. 
Greenberg, PD (1991). Adoptive T cell therapy of tumors: mechanisms operative in the recognition and elimination of tumor cells. Adv. Immunol. 49: 281-355.

Greenfield, EA, Nguyen, KA and Kuchroo, VK (1998). CD28/B7 costimulation: a review. Crit. Rev. Immunol. 18(5): 389-418.

Griffith, ME, Coulthart, A. and Pusey, CD (1996). T cell responses to myeloperoxidase (MPO) and proteinase 3 (PR3) in patients with systemic vasculitis. Clin. Exp. Immunol., 103(2): 253-258.

Grohmann, U., Fioretti, MC, Bianchi, R., Belladonna, ML, Ayroldi, E., Surace, D., Silla, S. and Puccetti, P. (1998). Dendritic cells, interleukin 12, and CD4+ lymphocytes in the initiation of class I-restricted reactivity to a tumor/self peptide. Crit. Rev. Immunol. 18(1-2), 87-98.

Grossman, D., McNiff, JM, Li, F. and Altieri, DC (1999a). Expression and targeting of the apoptosis inhibitor, survivin, in human melanoma. J. Invest. Dermatol. 113: 1076-1081.

Grossman, D., McNiff, JM, Li, F. and Altieri, DC (1999b). Expression of the apoptosis inhibitor, survivin, in nonmelanoma skin cancer and gene targeting in a keratinocyte cell line. Lab. Invest. 79: 1121-1126.

Grunewald, J., Halapi, E., Wahlstrom, J., Giscombe, R., Nityanand, S., Sanjeevi, C. and Lefvert, AK (1998). T-cell expansions with conserved T-cell receptor beta chain motifs in the peripheral blood of HLA-DRB1*0401 positive patients with necrotizing vasculitis. Blood 92(10): 3737-3744.

Hagen, EC, Bailleux, BEPB, Vanes, LA, Daha, MR and van der Woude, FJ (1993). Antineutrophil cytoplasmic autoantibodies - a review of the antigens 
involved, the assays, and the clinical and possible pathogenic consequences. Blood 81: 1996-2002.

Hawiger, D., Inaba, K., Dorsett, Y., Guo, M., Mahnke, K., Rivera, M., Ravetch, JV, Steinman, RM and Nussenzweig, MC (2001). Dendritic cells induce peripheral $\mathrm{T}$ cell unresponsiveness under steady state conditions in vivo. J. Exp. Med. 194(6): 769-779.

Hitt, M., Bett, AJ, Addison, CL, Prevec, L. und Graham, FL (1995). Techniques for human adenovirus vector construction and characterization. Adolph, KW (Hrsg.) Viral Gene Techniques Vol. 7, Academic Press, San Diego: 13-30.

Huber, S., Schramm, C., Lehr, HA, Mann, A., Schmitt, S., Becker, C., Protschka, M., Galle, PR, Neurath, MF and Blessing, M. (2004). Cutting edge: TGF- $\beta$ signaling is required for the in vivo expansion and immunosuppressive capacity of regulatory CD4+CD25+ T cells. J. Immunol. 173: 6526-6531.

Hung, K., Hayashi, R., Lafond-Walker, A., Lowenstein, C., Pardoll, D. and Levitsky, H. (1998). The central role of CD4(+) T cells in the antitumor immune response. J. Exp. Med. 188(12): 2357-2368.

Ikeguchi, M. and Kaibara, N. (2001). Changes in survivin messenger RNA level during cisplatin treatment in gastric cancer. Int. J. Mol. Med. 8: 661-666.

Islam, A., Kageyama, H., Hashizume, K., Kaneko, Y. and Nakagawara, A (2000). Role of survivin, whose gene is mapped to 17q25, in human neuroblastoma and identification of a novel dominant-negative isoform, survivin-beta/2B. Med. Pediatr. Oncol. 35: 550-553.

Jaeger, E., Bernhard, H., Romero, P., Ringhoffer, M., Arand, M., Karbach, J., Ilsemann, C., Hagedorn, M. and Knuth, A. (1996). Generation of cytotoxic T- 
cell responses with synthetic mela31 noma-associated peptides in vivo: implications for tumor vaccines with melanomaassociated antigens. Int. J. Cancer 66: 162-169.

Jäger, E., Jäger, D. and Knuth, A. (2000). Peptide Vaccination in Clinical Oncology. Onkologie 23: 410-415.

Janoff, A. (1985). Elastase in tissue injury. Annu. Rev. Med. 36: 207-216.

Jones, LA, Chin, LT, Longo, DL and Kruisbeek, AM (1990). Peripheral clonal elimination of functional T cells. Science 250(4988): 1726-1729.

Jonuleit, H., Schmitt, E., Kakirman, H., Stassen, M., Knop, J. and Enk, AH (2002). Infectious tolerance: human CD25(+) regulatory $\mathrm{T}$ cells convey suppressor activity to conventional CD4(+) T helper cells. J. Exp. Med. 196(2): 255-260.

Jonuleit, H., Schmitt, E., Schuler, G., Knop, J. and Enk, AH (2000). Induction of interleukin 10-producing, nonproliferating CD4(+) $\mathrm{T}$ cells with regulatory properties by repetitive stimulation with allogeneic immature human dendritic cells. J. Exp. Med. 192(9): 1213-1222.

Jonuleit, H., Schmitt, E., Stassen, M., Tuettenberg, A., Knop, J. and Enk, AH (2001). Identification and functional characterization of human CD4(+)CD25(+) T cells with regulatory properties isolated from peripheral blood. J. Exp. Med. 193(11): 1285-1294.

Jonuleit, H., Schmitt, E., Steinbrink, K. and Enk, AH (2001). Dendritic cells as a tool to induce anergic and regulatory T cells. Trends Immunol 22(7): 394-400. 
Just, J., Moog-Lutz, C., Houzel-Charavel, A., Canteloup, S., Grimfeld, A., Witko-Sarsat, V. and Cayre, YE (1999). Proteinase 3 mRNA expression is induced in monocytes but not in neutrophils of patients with cystic fibrosis. FEBS Lett. 457: 437-440.

Kalams, SA and Walker, BD (1998). The critical need for CD4 help in maintaining effective cytotoxic T lymphocyte responses. J. Exp. Med. 188: 2199-2204.

Khattri, R., Cox, T., Yasayko, SA and Ramsdell, F. (2003). An essential role for Scurfin in CD4+CD25+ T regulatory cells. Nat. Immunol. 4(4): 337-342.

Khazaie, K. and von Boehmer, H. (2006). The impact of CD4+CD25+ Treg on tumor specific CD8+ T cell cytotoxicity and cancer. Semin. Cancer Biol. 16(2): 124-136.

Kim, J., Modlin, RL, Moy, RL, Dubinet, SM, McHugh, T., Nickoloff, BJ and Uyemura, K. (1995). IL-10 production in cutaneous basal and squamous cell carcinomas. A mechanism for evading the local $\mathrm{T}$ cell immune response. J. Immunol. 155: 2240-2247.

Kitani, A., Fuss, IJ, Nakamura, K., Schwartz, OM, Usui, T. and Strober, W. (2000). Treatment of experimental (trinitrobenzene sulfonic acid) colitis by intranasal administration of transforming growth (TGF)- $\beta 1$ plasmid: TGF- $\beta 1$ mediated suppression of $\mathrm{T}$ helper cell type 1 response occurs by interleukin (IL)-10 induction and IL-12 receptor $\beta 2$ chain downregulation. J. Exp. Med. 192: $41-52$.

Knuth, A., Danowski, B., Oettgen, HF and Old, LJ (1984). T-cell-mediated cytotoxicity against autologous malignant melanoma: analysis with interleukin 2-dependent T-cell cultures. Proc. Natl. Acad. Sci. U S A 81: 3511-3515. 
Knuth, A., Wölfel, T., Klehmann, E., Boon, T. and Meyer zum Büschenfelde, KH (1989). Cytolytic Tcell clones against an autologous human melanoma: specificity study and definition of three antigens by immunoselection. Proc. Natl. Acad. Sci. U S A 86: 2804-2808.

Knutson, KL, Schiffman, K. and Disis, ML (2001). Immunization with a HER2/neu helper peptide vaccine generates HER-2/neu CD8 T-cell immunity in cancer patients. J. Clin. Invest. 107: 477-484.

Kobayashi, Y., Yukiue, H., Sasaki, H., Fukai, I., Yokoyama, T., Kiriyama, M., Yamakawa, Y., Maeda, M. and Fujii, Y. (2002). Developmentally regulated expression of survivin in the human thymus. Hum. Immunol. 63: 101-107.

Laemmli, UK (1970). Cleavage of structural proteins during the assembly of the head of bacteriophage T4. Nature 227, 680-685.

Lee, DS, Ahn, C., Ernst, B., Sprent, J. and Surh, CD (1999a). Thymic selection by a single $\mathrm{MHC} /$ peptide ligand: autoreactive $\mathrm{T}$ cells are low-affinity cells. Immunity 10: 83-92.

Lee, KH, Panelli, MC, Kim, CJ, Rike,r AI, Bettinotti, MP, Roden, MM, Fetsch, P., Abati, A., Rosenberg, SA and Marincola, FM (1998). Functional dissociation between local and systemic immune response during anti-melanoma peptide vaccination. J. Immunol. 161: 4183-4194.

Lee, PP, Yee, C., Savage, PA, Fong, L., Brockstedt, D., Weber, JS, Johnson, D., Swetter, S., Thompson, J., Greenberg, PD, Roederer, M. and Davis MM (1999b). Characterization of circulating $\mathrm{T}$ cells specific for tumor-associated antigens in melanoma patients. Nat. Med. 5(6): 677-685. 
Lenschow, DJ, Herold, KC, Rhee, L., Patel, B., Koons, A., Qin, HY, Fuchs, E., Singh, B., Thompson, CB and Bluestone, JA (1996). CD28/B7 regulation of Th1 and Th2 subsets in the development of autoimmune diabetes. Immunity 5(3): 285-293.

Laemmli, UK (1970). Cleavage of structural proteins during the assembly of the head of bacteriophage T4. Nature 227, 680-685.

Li, F., Ambrosini, G., Chu, EY, Plescia, J., Tognin, S., Marchisio, PC and Altieri, DC (1998a). Control of apoptosis and mitotic spindle checkpoint by survivin. Nature 396: 580-584.

Li, K., Adibzadeh, M., Halder, T., Kalbacher, H., Heinzel, S., Muller, C., Zeuthen, J. and Pawelec, G. (1998b). Tumour-specific MHC-class-II-restricted responses after in vitro sensitization to synthetic peptides corresponding to gp100 and Annexin II eluted from melanoma cells. Cancer Immunol. Immunother. 47(1): 32-38.

Liyanage, UK, Moore, TT, Joo, HG, Tanaka, Y., Herrmann, V., Doherty, G., Drebin, JA, Strasberg, SM, Eberlein, TJ, Goedegebuure, PS and Linehan, DC (2002). Prevalence of regulatory T cells is increased in peripheral blood and tumor microenvironment of patients with pancreas or breast adenocarcinoma. J. Immunol. 169: 2756-2761.

Livingston, PO, Shiku, H., Bean, MA, Pinsky, CM, Oettgen, HF and Old, LJ (1979). Cell-mediated cytotoxicity for cultured autologous melanoma cells. Int. J. Cancer 24: 34-44.

Lo, D., Burkly, LC, Flavell, RA, Palmiter, RD and Brinster, RL (1989). Tolerance in transgenic mice expressing class II major histocompatibility complex on pancreatic acinar cells. J. Exp. Med. 170(1): 87-104. 
Lode, HN, Xiang, R., Pertl, U., Forster, E., Schoenberger, SP, Gillies, SD and Reisfeld, RA (2000). Melanoma immunotherapy by targeted IL-2 depends on CD4(+) T-cell help mediated by CD40/CD40L interaction. J. Clin. Invest. 105: 1623-1630.

Lu, J. and Celis, E. (2000). Use of two predictive algorithms of the world wide web for the identification of tumor-reactive T-cell epitopes. Cancer Res. 60: $5223-5227$.

Ludviksson, BR, Seegers, D., Resnick, AS and Strober, W. (2000). The effect of TGF-beta1 on immune response of naïve versus memory CD4+ Th1/Th2 T cells. Eur. J. Immunol. 30: 2101-2111.

Lutz, PG, Moog-Lutz, C., Coumau-Gatbois, E., Kobari, L., Di Gioia, Y., Cayre, YE (2000). Myeloblastin is a granulocyte colony-stimulating factor-responsive gene conferring factor-independent growth to hematopoietic cells. Proc. Natl. Acad. Sci. U S A 97(4): 1601-1606.

Lutz, PG, Houzel-Chavarel, A., Moog-Lutz, C. and Cayre, YE (2001). Myeloblastinis an Myb target gene: mechanisms of regulation in myeloid leukemia cells growth-arrested by retinoic acid. Blood 97: 2449-2456.

Mackensen, A., Herbst, B., Chen, JL, Kohler, G., Noppen, C., Herr, W., Spagnoli, GC, Cerundolo, V. and Lindemann, A. (2000). Phase I study in melanoma patients of a vaccine with peptide-pulsed dendritic cells generated in vitro from CD34(+) hematopoietic progenitor cells. Int. J. Cancer 86: 385-392.

Mahotka, C., Wenzel, M., Springer, E., Gabbert, HE and Gerharz, CD (1999). Survivin-deltaEx3 and survivin-2B: two novel splice variants of the apoptosis 
inhibitor survivin with different antiapoptotic properties. Cancer Res. 59: 60976102.

Mapara, MY and Sykes, M. (2004). Tolerance and cancer: mechanisms of tumor evasion and strategies for breaking tolerance. J. Clin. Oncol. 22: 1136-1151.

Marchand, M., van Baren, N., Weynants, P., Brichard, V., Dreno, B., Tessier, MH, Rankin, E., Parmiani, G., Arienti, F., Humblet, Y., Bourlond, A., Vanwijck, R., Lienard, D., Beauduin, M., Dietrich, PY, Russo, V., Kerger, J., Masucci, G., Jäger, E., De Greve, J., Atzpodien, J., Brasseur, F., Coulie, PG, van der Bruggen, P. and Boon, T. (1999). Tumor regressions observed in patients with metastatic melanoma treated with an antigenic peptide encoded by gene MAGE-3 and presented by HLA-A1. Int. J. Cancer 80: 219-230.

Matzinger, P. (1994). Tolerance, danger, and the extended family. Annu. Rev. Immunol. 12: 991-1045.

Melief, CJ, Offringa, R., Toes, RE and Kast, WM (1996). Peptide-based cancer vaccines. Curr. Opin. Immunol. 8: 651-657.

Menges, M., Rossner, S., Voigtlander, C., Schindler, H., Kukutsch, NA, Bogdan, C., Erb, K., Schuler, G. and Lutz, MB (2002). Repetitive injections of dendritic cells matured with tumor necrosis factor alpha induce antigenspecific protection of mice from autoimmunity. J. Exp. Med. 195(1): 15-21.

Molldrem, JJ, Dermime, S., Parker, K., Jiang, YZ, Mavroudis, D., Hensel, N., Fukushima, P. and Barrett, AJ. (1996). Targeted T-cell therapy for human leukemia: cytotoxic $\mathrm{T}$ lymphocytes specific for a peptide derived from proteinase 3 preferentially lyse human myeloid leukemia cells. Blood 88(7): 2450-2457. 
Molldrem, JJ, Lee, PP, Wang, C., Felio, K., Kantarjian, HM, Champlin, RE and Davis, MM (2000). Evidence that specific T lymphocytes may participate in the elimination of chronic myelogenous leukemia. Nat. Med. 6(9): 1018-1023.

Monaco, JJ (1992). A molecular model of MHC class-I-restricted antigen processing. Immunol. Today 13: 173-179.

Mukherji, B. and MacAlister, TJ (1983). Clonal analysis of cytotoxic T cell response against human melanoma. J. Exp. Med. 158: 240-245.

Mumberg, D., Monach, PA, Wanderling, S., Philip, M., Toledano, AY, Schreiber, RD and Schreiber, H. (1999). CD4(+) T cells eliminate MHC class IInegative cancer cells in vivo by indirect effects of IFN-gamma. Proc. Natl. Acad. Sci. U S A 96(15): 8633-8638.

Nestle, FO, Alijagic, S., Gilliet, M., Sun, Y., Grabbe, S., Dummer, R., Burg, G. and Schadendorf, D. (1998). Vaccination of melanoma patients with peptideor tumor lysate-pulsed dendritic cells [see comments]. Nat. Med. 4: 328-332.

Niles, JL, McCluskey, RT, Ahmad, MF and Arnaout, MA (1989). Wegener's granulomatosis autoantigen is a novel neutrophil serine proteinase. Blood 74(6): 1888-1893.

Novellino, L., Castelli, C. and Parmiani, G. (2005). A listing of human tumor antigens recognized by T-cells: March 2004 update. Cancer Immunol. Immunother. 54: 187-207.

North, RJ and Awwad, M. (1990). Elimination of cycling CD4+ suppressor $\mathrm{T}$ cells with an anti-mitotic drug releases non-cycling CD8+ $\mathrm{T}$ cells to cause regression of an advanced lymphoma. Immunology 71(1): 90-95. 
O'Garra, A., Steinman, L. and Gijbels, K. (1997). CD4+ T-cell subsets in autoimmunity. Curr. Opin. Immunol. 9: 872-883.

Old, LJ (1996). Immunotherapy for cancer. Sci. Am. 275(3): 136-143.

Olie, RA, Simoes-Wust, AP, Baumann, B., Leech, SH, Fabbro, D., Stahel, RA and Zangemeister-Wittke, U. (2000). A novel antisense oligonucleotide targeting survivin expression induces apoptosis and sensitizes lung cancer cells to chemotherapy. Cancer Res. 60: 2805-2809.

Onizuka, S., Tawara, I., Shimizu, J., Sakaguchi, S., Fujita, T. and Nakayama, E. (1999). Tumor rejection by in vivo administration of anti-CD25 (interleukin-2 receptor alpha) monoclonal antibody. Cancer Res. 59(13): 3128-3133.

Ossendorp, F., Mengede, E., Camps, M., Filius, R. and Melief, CJ (1998). Specific $\mathrm{T}$ helper cell requirement for optimal induction of cytotoxic $\mathrm{T}$ lymphocytes against major histocompatibility complex class II negative tumors. J. Exp. Med. 187(5): 693-702.

Owen, CA and Campbell, EJ (1999). The cell biology of leukocyte-mediated proteolysis. J. Leukoc. Biol. 65: 137-150.

Panelli, MC., Bettinotti, MP, Lally, K., Ohnmacht, GA, Li, Y., Robbins, P., Riker, A., Rosenberg, SA and Marincola, FM (2000a). A tumor-infiltrating lymphocyte from a melanoma metastasis with decreased expression of melanoma differentiation antigens recognizes MAGE-12. J. Immunol. 164(8): 4382-4392.

Panelli, MC, Wunderlich, J., Jeffries, J., Wang, E., Mixon, A., Rosenberg, SA and Marincola, FM (2000 b). Phase 1 study in patients with metastatic melanoma of immunization with dendritic cells presenting epitopes derived 
from the melanomaassociated antigens MART-1 and gp100. J. Immunother. 23(4): 487-498.

Peng, Y., Laouor, MO, Li, EA, Green, A. and Flavell, RA (2004). TGF- $\beta$ regulates in vivo expansion of Foxp3-expressing CD4+CD25+ regulatory $\mathrm{T}$ cells responsible for protection against diabetes. Proc. Natl. Acad. Sci. USA 101: $4572-4577$.

Piali, L., Fichtel, A., Terpe, HJ, Imhof, BA and Gisler, RH (1995). Endothelial vascular cell adhesion molecule I expression is suppressed by melanoma and carcinoma. J. Exp. Med. 181: 811-816.

Pieper, R., Christian, RE, Gonzales, MI, Nishimura, MI, Gupta, G., Settlage, RE, Shabanowitz, J., Rosenberg, SA, Hunt, DF and Topalian, SL (1999). Biochemical identification of a mutated human melanoma antigen recognized by CD4(+) T cells. J. Exp. Med. 189: 757-766.

Pieters, J. (1997). MHC class II restricted antigen presentation. Curr. Opin. Immunol. 9: 89-96.

Powrie, F. and Maloy, KJ (2003). Immunology. Regulating the regulators. Science 299(5609): 1030-1031.

Qin, Z. and Blankenstein, T. (2000). CD4+ T cell--mediated tumor rejection involves inhibition of angiogenesis that is dependent on IFN gamma receptor expression by nonhematopoietic cells. Immunity 12: 677-686.

Radoja, S. and Frey, AB (2000). Cancer-induced defective cytotoxic T lymphocyte effector function: another mechanism how antigenic tumors escape immune-mediated killing. Mol. Med. 6: 465-479. 
Rammensee, HG (1995). Chemistry of peptides associated with MHC class I and class II molecules. Curr. Opin. Immunol. 7: 85-96.

Rammensee, HG, Friede, T. and Stevanoviic, S. (1995). MHC ligands and peptide motifs: first listing. Immunogenetics 41: 178-228.

Rammensee, HG, Bachmann, J., Emmerich, NP, Bachor, OA and Stevanovic, S. (1999). SYFPEITHI: database for MHC ligands and peptide motifs. Immunogenetics 50: 213-219.

Rao, J., Zhang, F., Donnelly, RJ, Spector, NL and Studzinski, GP. (1998). Truncation of Sp1 transcription factor by myeloblastin in undifferentiated HL60 cells. J. Cell Physiol. 175(2): 121-128.

Rao, NV, Rao, GV, Marshall, BC and Hoidal, JR (1996). Biosynthesis and processing of proteinase 3 in U937 cells - processing pathways are distinct from those of cathepsin G. J. Biol. Chem. 271: 2972-2978.

Rayman, P., Uzzo, RG, Kolenko, V., Bloom, T., Cathcart, MK, Molto, L., Novick, AC, Bukowski, RM, Hamilton, T. and Finke, JH (2000). Tumorinduced dysfunction in interleukin-2 production and interleukin-2 receptor signaling: a mechanism of immune escape. Cancer J. 6: 81-87.

Renkvist, N., Castelli, C., Robbins, PF and Parmiani, G. (2001). A listing of human tumor antigens recognized by $\mathrm{T}$ cells. Cancer Immunol. Immunother. 50: 3-15.

Restifo, NP (2000). Not so Fas: Re-evaluating the mechanisms of immune privilege and tumor escape. Nat. Med. 6: 493-495. 
Ridge, JP, Di Rosa, F. and Matzinger, P. (1998). A conditioned dendritic cell can be a temporal bridge between a CD4+ T-helper and a T-killer cell. Nature 393: 474-478.

Rocha, B. and von Boehmer, H. (1991). Peripheral selection of the T cell repertoire. Science 251(4998): 1225-1228.

Roncarolo, MG, Levings, MK and Traversari, C. (2001). Differentiation of T regulatory cells by immature dendritic cells. J. Exp. Med. 193(2): F5-9.

Rosenberg, SA (1999). A new era for cancer immunotherapy based on the genes that encode cancer antigens. Immunity 10: 281-287.

Rosenberg, SA (2001). Progress in human tumour immunology and immunotherapy. Nature 411: 380-384.

Rosenberg, SA (2004). Shedding light on immunotherapy for cancer. N. Engl. J. Med. 350: 1461-1463.

Rosenberg, SA, Yang, JC and Restifo, NP (2004). Cancer immunotherapy: moving beyond current vaccines. Nat. Med. 10: 909-915.

Rosenberg, SA, Yang, JC, Schwartzentruber, DJ, Hwu, P., Marincola, FM, Topalian, SL, Restifo, NP, Dudley, ME, Schwarz, SL, Spiess, PJ, Wunderlich, JR, Parkhurst, MR, Kawakami, Y., Seipp, CA, Einhorn, JH and White, DE (1998). Immunologic and therapeutic evaluation of a synthetic peptide vaccine for the treatment of patients with metastatic melanoma. Nat. Med. 4: 321-327.

Rohayem, J., Diestelkoetter, P., Weigle, B., Oehmichen, A., Schmitz, M.,Mehlhorn, J., Conrad, K. and Rieber, EP (2000). Antibody response to the 
tumor-associated inhibitor of apoptosis protein survivin in cancer patients. Cancer Research 60: 1815-1817.

Rouse, BT, Rollinghoff, M. and Warner, NL (1972). Anti-theta serum-induced supression of the cellular transfer of tumour-specific immunity to a syngeneic plasma cell tumour. Nat. New Biol. 238: 116-117.

Rudensky, AY, Preston-Hurlburt, P., Hong, SC, Barlow, A. and Janeway, CA Jr. (1991). Sequence analysis of peptides bound to MHC class II molecules. Nature 353: 622-627.

Ruff, AL, Guarnieri, FG, Staveley-O'Carroll, K., Siliciano, RF, August, JT (1997). The enhanced immune response to the HIV gp160/LAMP chimeric gene product targeted to the lysosome membrane protein trafficking pathway. J. Biol. Chem. 272(13): 8671-8678.

Sakaguchi, S. (2003). The origin of FOXP3-expressing CD4+ regulatory T cells: thymus or periphery. J. Clin. Invest. 112: 1310-1312.

Sakaguchi, S., Hori, S., Fukui, Y., Sasazuki, T., Sakaguchi, N. and Takahashi, T. (2003). Thymic generation and selection of CD25+CD4+ regulatory $\mathrm{T}$ cells: implications of their broad repertoire and high self-reactivity for the maintenance of immunological self-tolerance. Novartis. Found. Symp. 252: 616.

Salomon, B., Lenschow, DJ, Rhee, L., Ashourian, N., Singh, B., Sharpe, A. and Bluestone, JA (2000). B7/CD28 costimulation is essential for the homeostasis of the CD4+CD25+ immunoregulatory $\mathrm{T}$ cells that control autoimmune diabetes. Immunity 12(4): 431-440. 
Schmitz, M., Diestelkoetter, P., Weigle, B., Schmachtenberg, F., Stevanovic, S., Ockert, D., Rammensee, HG and Rieber, EP. (2000). Generation of survivinspecific CD8+ T effector cells by dendritic cells pulsed with protein or selected peptides. Cancer Res. 60: 4845-4849.

Schoenberger, SP, Toes, RE, van der Voort, EI, Offringa, R. and Melief, CJ (1998). T-cell help for cytotoxic T lymphocytes is mediated by CD40-CD40L interactions. Nature 393: 480-483.

Schubert, LA, Jeffery, E., Zhang, Y., Ramsdell, F. and Ziegler, SF (2001). Scurfin (FOXP3) acts as a repressor of transcription and regulates $\mathrm{T}$ cell activation. J. Biol. Chem. 276(40): 37672-37679.

Schuler-Thurner, B., Schultz, ES, Berger, TG, Weinlich, G., Ebner, S., Woerl, P., Bender, A., Feuerstein, B., Fritsch, PO, Romani, N. and Schuler, G. (2002). Rapid Induction of Tumor-specific Type $1 \mathrm{~T}$ Helper Cells in Metastatic Melanoma Patients by Vaccination with Mature, Cryopreserved, Peptideloaded Monocyte-derived Dendritic Cells. J. Exp. Med. 195: 1279-1288.

Schultze, JL and Vonderheide, RH (2001). From cancer genomics to cancer immunotherapy: toward second-generation tumor antigens. Trends Immunol. 22: 516-523.

Seliger, B., Maeurer, MJ and Ferrone, S. (1997). TAP off-tumors on. Immunol. Today 18: 292-299.

Seliger, B., Maeurer, MJ and Ferrone, S. (2000). Antigen-processing machinery breakdown and tumor growth. Immunol. Today 21: 455-464.

Shevach, EM (2002). CD4+CD25+ suppressor T cells: more questions than answers. Nat. Rev. Immunol. 2: 389-400. 
Shimizu, J., Yamazaki, S. and Sakaguchi, S. (1999). Induction of tumor immunity by removing CD25+CD4+ T cells: a common basis between tumor immunity and autoimmunity. J. Immunol. 163(10): 5211-5218.

Slingluff, CL Jr., Yamshchikov, G., Neese, P., Galavotti, H., Eastham, S., Engelhard, VH, Kittlesen, D., Deacon, D., Hibbitts, S., Grosh, WW, Petroni, G., Cohen, R., Wiernasz, C., Patterson, JW, Conway, BP and Ross, WG (2001). Phase I trial of a melanoma vaccine with gp100(280-288) peptide and tetanus helper peptide in adjuvant: immunologic and clinical outcomes. Clin. Cancer Res. 7(10): 3012-3024.

Spector, NL, Hardy, L., Ryan, C., Miller, WH Jr, Humes, JL, Nadler, LM and Luedke, E. (1995). 28-kDa mammalian heat shock protein, a novel substrate of a growth regulatory protease involved in differentiation of human leukemia cells. J. Biol. Chem. 270(3): 1003-1006.

Spector, T. (1978). Refinement of the coomassie blue method of protein quantitation. A simple and linear spectrophotometric assay for less than or equal to 0.5 to 50 microgram of protein. Anal. Biochem. 86, 142-146.

Staveley-O'Carroll, K., Sotomayor, E., Montgomery, J., Borrello, I., Hwang, L., Fein, S., Pardoll, D. and Levitsky, H. (1998). Induction of antigen-specific T cell anergy: An early event in the course of tumor progression. Proc. Natl. Acad. Sci. U S A, 95(3), 1178-1183.

Stefanova, I., Dorfman, JR and Germain, RN (2002). Self-recognition promotes the foreign antigen sensitivity of naive T lymphocytes. Nature 420(6914): 429434 . 
Steinman, RM and Nussenzweig, MC (2002). Avoiding horror autotoxicus: the importance of dendritic cells in peripheral T cell tolerance. Proc. Natl. Acad. Sci. U S A 99(1): 351-358.

Steinman, RM (2003). The control of immunity and tolerance by dendritic cell. Pathol. Biol. (Paris) 51(2): 59-60.

Steitz, J., Bruck, J., Lenz, J., Knop, J. and Tuting, T. (2001). Depletion of CD25(+) CD4(+) $\mathrm{T}$ cells and treatment with tyrosinase-related protein 2-transduced dendritic cells enhance the interferon alpha-induced, CD8(+) T-celldependent immune defense of B16 melanoma. Cancer Res. 61(24): 8643-8646.

Sturniolo, T., Bono, E., Ding, J., Raddrizzani, L., Tuereci, O., Sahin, U., Braxenthaler, M., Gallazzi, F., Protti, MP, Sinigaglia, F. and Hammer, J. (1999). Generation of tissue-specific and promiscuous HLA ligand databases using DNA microarrays and virtual HLA class II matrices. Nat. Biotechnol. 17: 555561.

Sutmuller, RP, van Duivenvoorde, LM, van Elsas, A., Schumacher, TN, Wildenberg, ME, Allison, JP, Toes, RE, Offringa, R. and Melief, CJ (2001). Synergism of cytotoxic $\mathrm{T}$ lymphocyte-associated antigen 4 blockade and depletion of $\mathrm{CD} 25(+)$ regulatory $\mathrm{T}$ cells in antitumor therapy reveals alternative pathways for suppression of autoreactive cytotoxic T lymphocyte responses. J. Exp. Med. 194(6): 823-832.

Swana, HS, Grossman, D., Anthony, JN, Weiss, RM and Altieri, DC (1999). Tumor content of the antiapoptosis molecule survivin and recurrence of bladder cancer. N. Engl. J. Med. 341: 452-453.

Tamm, I., Wang, Y., Sausville, E., Scudiero, DA, Vigna, N., Oltersdorf, T. and Reed, JC (1998). IAP-family protein survivin inhibits caspase activity and 
apoptosis induced by Fas (CD95), Bax, caspases, and anticancer drugs. Cancer Res. 58: 5315-5320.

Tanaka, C., Uzawa, K., Shibahara, T., Yokoe, H., Noma, H. and Tanzawa, H. (2003). Expression of an inhibitor of apoptosis, survivin, in oral carcinogenesis. J. Dent. Res. 82: 607-611.

Tanaka, K., Iwamoto, S., Gon, G., Nohara, T., Iwamoto, M. and Tanigawa, N. (2000). Expression of survivin and its relationship to loss of apoptosis in breast carcinomas. Clin. Cancer Res. 6: 127-134.

Thornton, AM and Shevach, EM (2000). Suppressor effector function of CD4+CD25+ immunoregulatory $\mathrm{T}$ cells is antigen nonspecific. J. Immunol. 164(1): 183-190.

Toes, RE, Ossendorp, F., Offringa, R. and Melief, CJ (1999). CD4 T cells and their role in antitumor immune responses. J. Exp. Med. 189(5): 753-756.

Tran, J., Master, Z., Yu, JL, Rak, J., Dumont, DJ and Kerbel, RS (2002). A role for survivin in chemoresistance of endothelial cells mediated by VEGF. Proc. Natl. Acad. Sci. U S A 99: 4349-4354.

Trapani, JA (2005). The dual adverse effects of TGF- $\beta$ secretion on tumor progression. Canc. Cell 8(5): 349-350.

Tsukui, T., Hildesheim, A., Schiffman, MH, Lucci, J. III, Contois, D., Lawler, P., Rush, BB, Lorincz, AT, Corrigan, A., Burk, RD, Qu, W., Marshall, MA, Mann, D., Carrington, M., Clerici, M., Shearer, GM, Carbone, DP, Scott, DR, Houghten, RA and Berzofsky, JA (1996). Interleukin 2 production in vitro by peripheral lymphocytes in response to human papillomavirus-derived peptides: correlation with cervical pathology. Cancer Res. 56: 3967-3974. 
Tsung, K., Dolan, JP, Tsung, YL and Norton, JA (2002). Macrophages as effector cells in interleukin 12-induced $\mathrm{T}$ cell-dependent tumor rejection. Cancer Res. 62: 5069-5075.

van der Bruggen, P., Traversari, C., Chomez, P., Lurquin, C., De Plaen, E., Van den Eynde, B., Knuth, A. and Boon, T. (1991). A gene encoding an antigen recognized by cytolytic $\mathrm{T}$ lymphocytes on a human melanoma. Science 254(5038): 1643-1647.

van Elsas, A., Sutmuller, RP, Hurwitz, AA, Ziskin, J., Villasenor, J., Medema, JP, Overwijk, WW, Restifo, NP, Melief, CJ, Offringa, R. and Allison, JP (2001). Elucidating the autoimmune and antitumor effector mechanisms of a treatment based on cytotoxic T lymphocyte antigen-4 blockade in combination with a B16 melanoma vaccine: comparison of prophylaxis and therapy. J. Exp. Med. 194(4): 4814-489.

Viret, C., Wong FS and Janeway, CA Jr. (1999). Designing and maintaining the mature TCR repertoire: the continuum of self-peptide:self-MHC complex recognition. Immunity 10(5): 559-568.

Voo, KS, Peng, G., Guo, Z., Fu, T., Li, Y., Frappier, L. and Wang, RF (2005). Functional characterization of EBV-encoded nuclear antigen 1-specific CD4+ helper and regulatory $\mathrm{T}$ cells elicited by in vitro peptide stimulation. Cancer Res. 65: 1577-1586.

Waldmann, H. and Cobbold, S. (1998). How do monoclonal antibodies induce tolerance? A role for infectious tolerance? Annu. Rev. Immunol. 16: 619-644. 
Wang, HY, Lee, DA, Peng, G., Guo, Z., Li, Y., Kiniwa, Y., Shevach, EM and Wang, RF (2004). Tumorspecific human CD4+ regulatory $\mathrm{T}$ cells and their ligands: implications for immunotherapy. Immunity 20: 107-118.

Wang, HY, Peng, G., Guo, Z., Shevach, EM and Wang, RF (2005). Recognition of a new ARTC1 peptide ligand uniquely expressed in tumor cells by antigenspecific CD4+ regulatory T cells. J. Immunol. 174: 2661-2670.

Wang, RF (2001). The role of MHC class II-restricted tumor antigens and CD4+ T cells in antitumor immunity. Trends Immunol. 22(5): 269-276.

Wang, RF, Wang, X., Atwood, AC, Topalian, SL and Rosenberg, SA (1999a). Cloning genes encoding MHC class II-restricted antigens: mutated CDC27 as a tumor antigen. Science 284: 1351-1354.

Wang, RF, Wang, X. and Rosenberg, SA (1999b). Identification of a novel major histocompatibility complex class II-restricted tumor antigen resulting from a chromosomal rearrangement recognized by CD4(+) T cells. J. Exp. Med. 189: 1659-1668.

Watts, C. (2004). The exogenous pathway for antigen presentation on major histocompatibility complex class II and CD1 molecules. Nat. Immunol. 5: 685692.

Wiik, A. (2000). What you should know about PR3-ANCA. An introduction. Arthritis Res. 2(4): 252-254.

Witko-Sarsat, V., Lesavre, P., Lopez, S., Bessou, G., Hieblot, C., Prum, B., Noel, LA, Guillevin, L., Ravaud, P., Sermet-Gaudelus, I., Timsit, J., Grünfeld, JP and Halbwachs-Mercarelli, L. (1999). A large subset of neutrophils expressing 
membrane proteinase 3 is a risk factor for vasculitis and rheumatoid arthritis. J. Am. Soc. Nephrol. 10: 1224-1233.

Woo, EY, Chu, CS, Goletz, TJ, Schlienger, K., Yeh, H., Coukos, G., Rubin, SC, Kaiser, LR and June, CH (2001). Regulatory CD4(+)CD25(+) T cells in tumors from patients with early-stage nonsmall cell lung cancer and late-stage ovarian cancer. Cancer Res. 61(12): 4766-4772.

Woo, EY, Yeh, H., Chu, CS, Schlienger, K., Carroll, RG, Riley, JL, Kaiser, LR and June, CH. (2002). Cutting edge: Regulatory T cells from lung cancer patients directly inhibit autologous $T$ cell proliferation. J. Immunol. 168(9): 4272-4276.

Wölfel, T. and Huber, C. (2001). Therapeutic vaccination against T-cell-defined tumor antigens. Onkologie 24: 9.

Wolf, AM, Wolf, D., Steurer, M., Gastl, G., Gunsilius, E. and GrubeckLoebenstein, B. (2003). Increase of Regulatory T Cells in the Peripheral Blood of Cancer Patients. Clin. Cancer Res. 9(2): 606-612.

Wu, LC, Tuot, DS, Lyons, DS, Garcia, KC and Davis, MM (2002). Two-step binding mechanism for T-cell receptor recognition of peptide MHC. Nature 418(6897): 552-6.

Wulfing, C., Sumen, C., Sjaastad, MD, Wu, LC, Dustin, ML and Davis, MM (2002). Costimulation and endogenous MHC ligands contribute to $\mathrm{T}$ cell recognition. Nat. Immunol. 3(1): 42-7.

Yamazaki, S., Iyoda, T., Tarbell, K., Olson, K., Velinzon, K., Inaba, K., and Steinman, RM (2003). Direct expansion of functional CD25+ CD4+ regulatory T cells by antigen-processing dendritic cells. J. Exp. Med. 198(2): 235-47. 
Yu, Z. and Restifo, NP (2002). Cancer vaccines: progress reveals new complexities. J. Clin. Invest. 110: 289-294.

Zajac, AJ, Murali-Krishna, K., Blattman, JN and Ahmed, R. (1998). Therapeutic vaccination against chronic viral infection: the importance of cooperation between CD4+ and CD8+ T cells. Curr. Opin. Immunol. 10: 444-449.

Zeng, G. (2001). MHC class II-restricted tumor antigens recognized by CD4+ T cells: new strategies for cancer vaccine design. J. Immunother. 24: 195-204.

Zhang, T., Otevrel, T., Gao, Z., Gao, Z., Ehrlich, SM, Fields, JZ and Boman, BM (2001). Evidence that APC regulates survivin expression: a possible mechanism contributing to the stem cell origin of colon cancer. Cancer Res. 61: 8664-8667.

Zinkernagel, RM and Doherty, PC (1979). MHC-restricted cytotoxic T cells: studies on the biological role of polymorphic major transplantation antigens determining T-cell restrictionspecificity, function, and responsiveness. Adv. Immunol. 27: 51-177. 


\subsection{Vektorkarten}
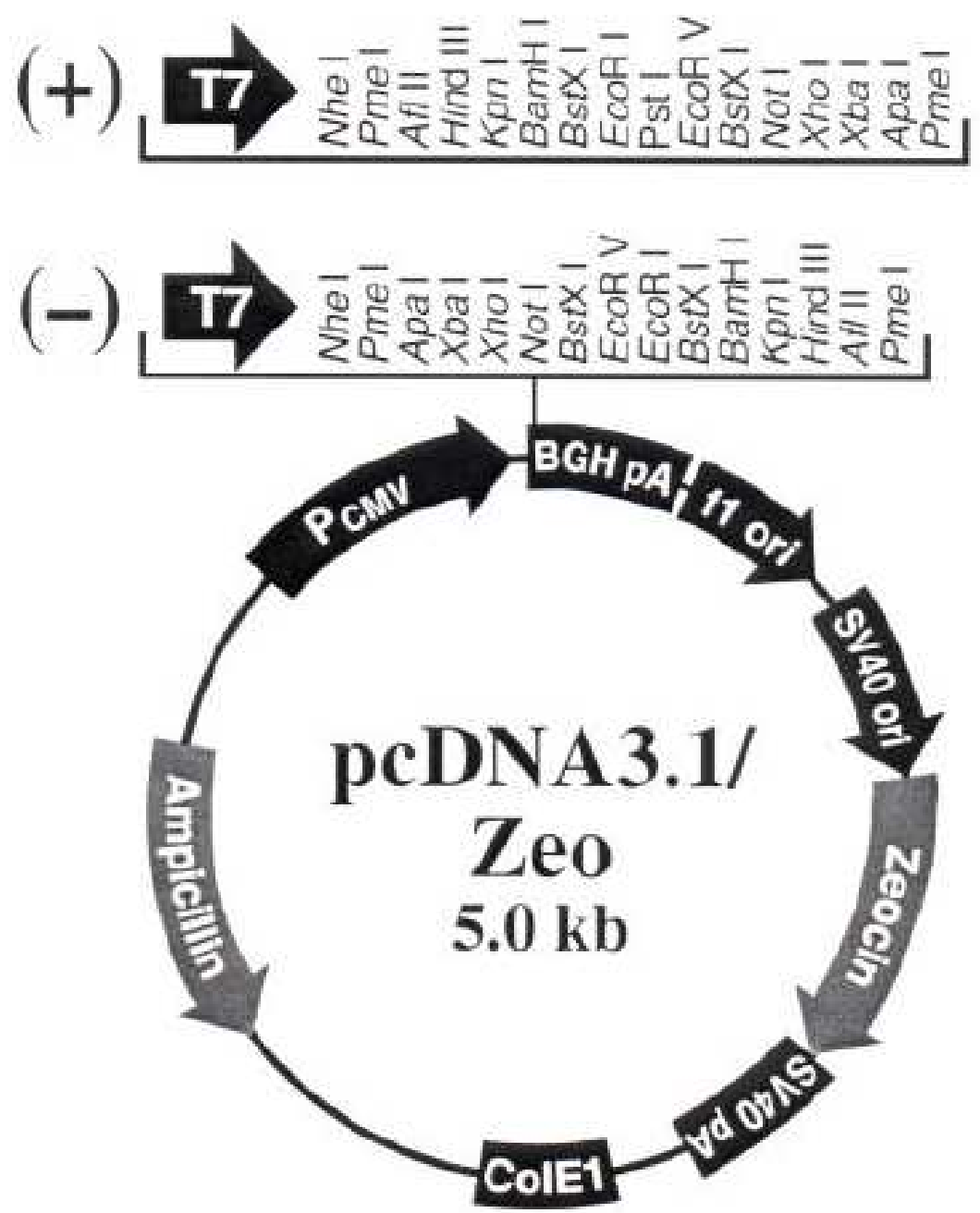

Abb. 7.1: Plasmidkarte und MCS (,,multiple cloning site“) von pcDNA3.1. 


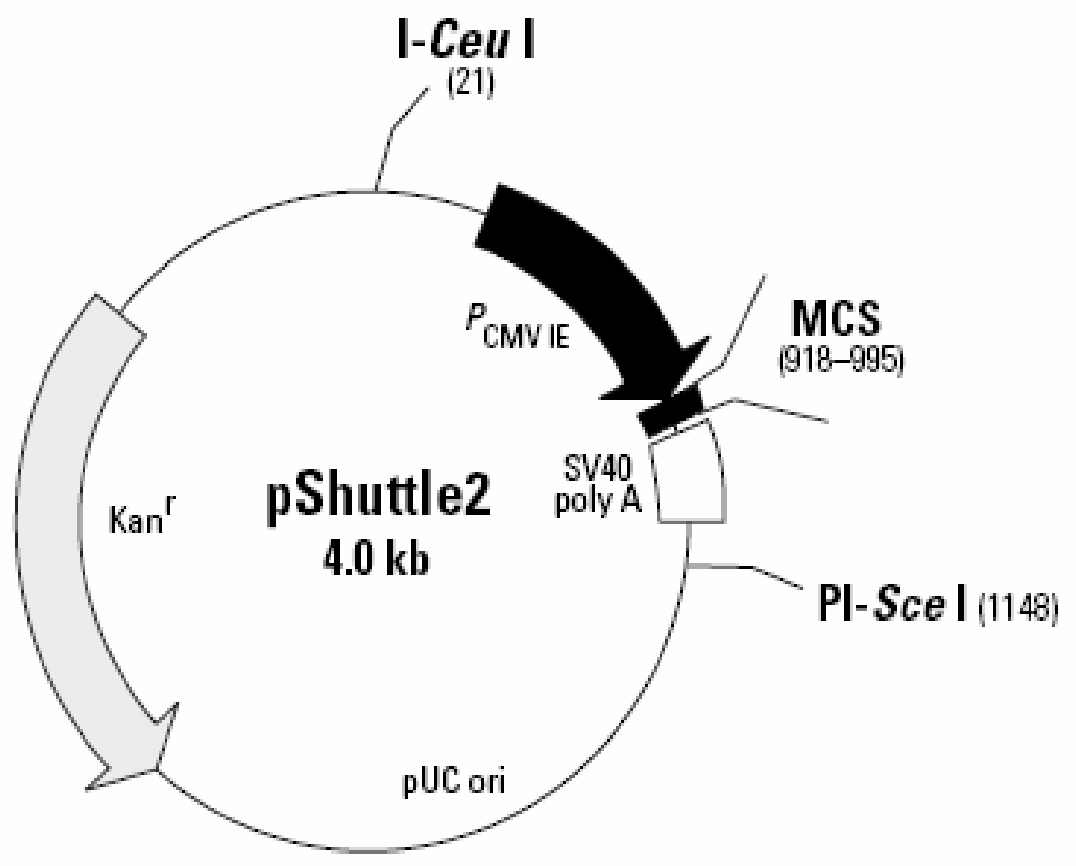

\section{pShuttle2 MCS}

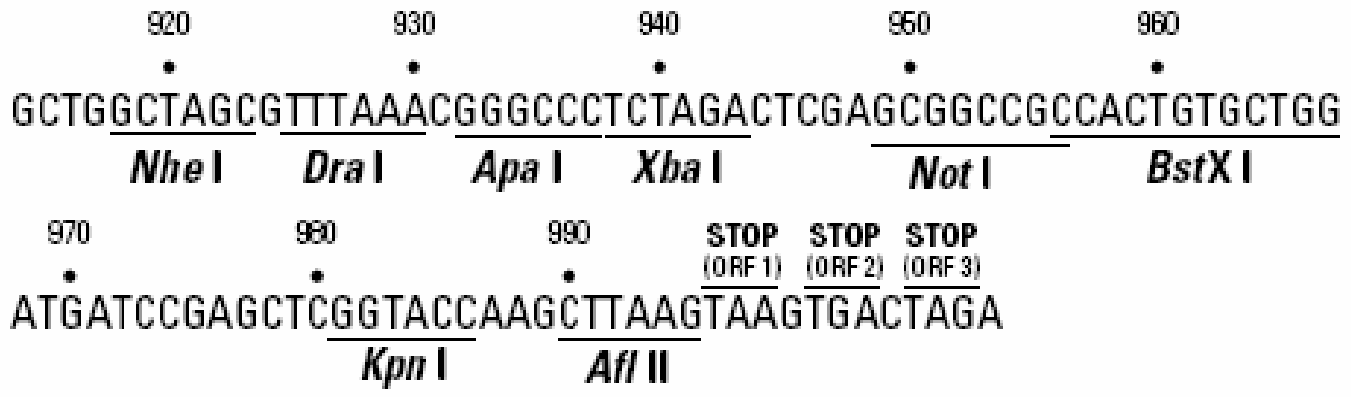

Abb. 7.2: Plasmidkarte und MCS („,multiple cloning site“) von pShuttle. 


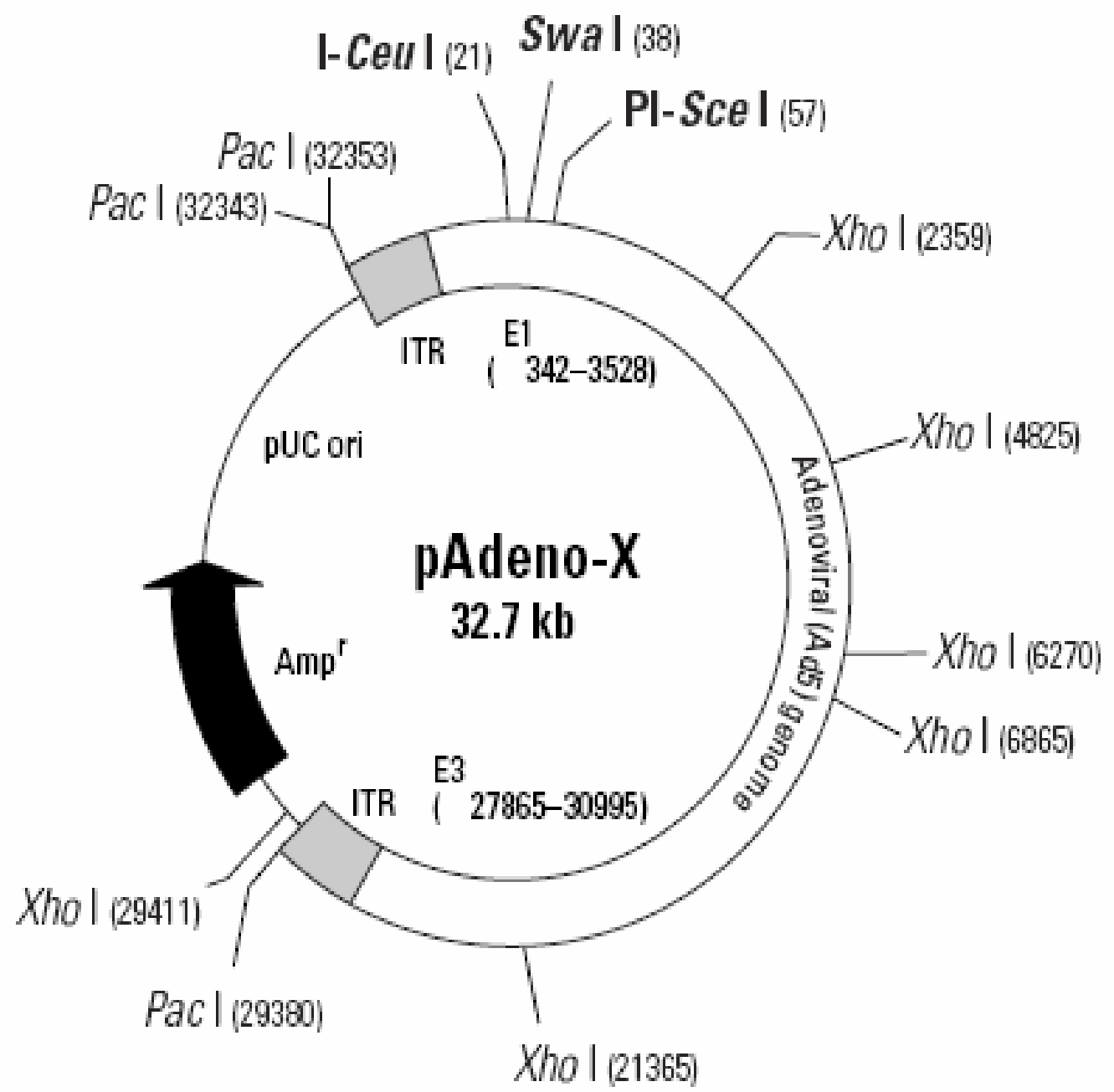

Abb. 7.3: Plasmidkarte von Adeno-X. 

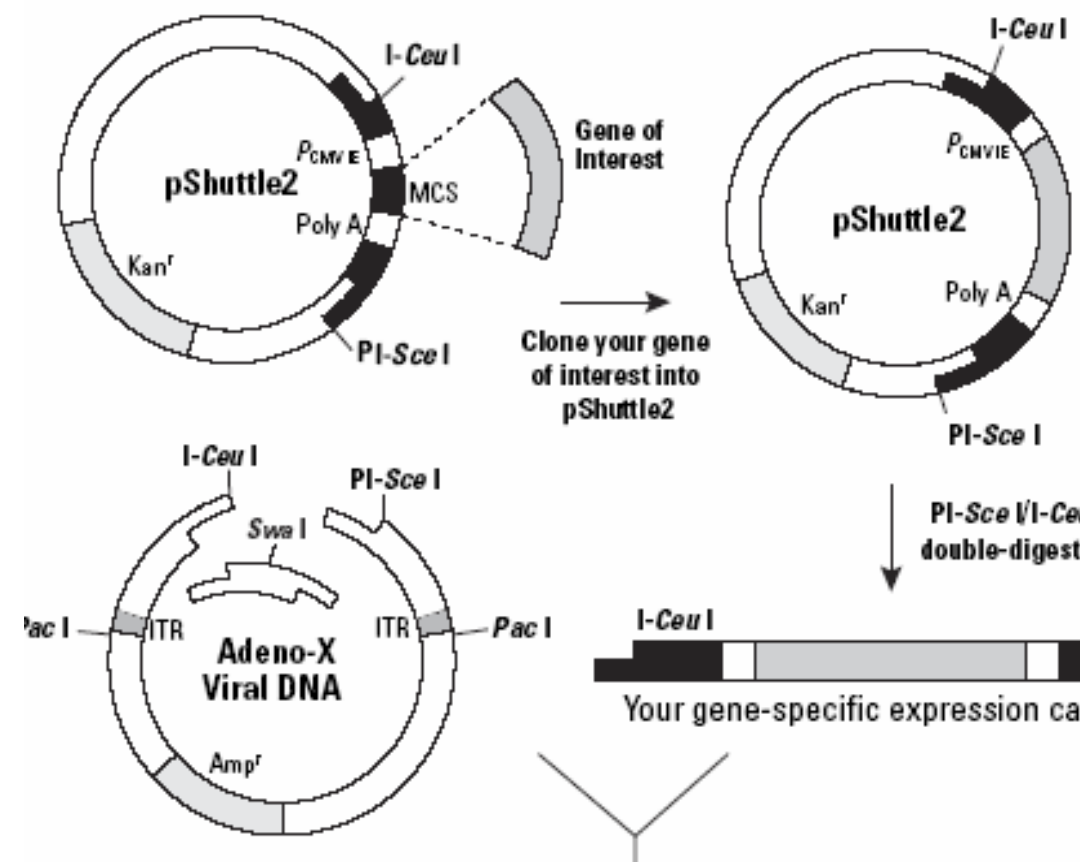

pShuttle2

PI-Sce I

I-Sce VI-Ceu I

double-digestion

2-3 days

In vitro ligation

Swal* digestion

Your gene-specific expression cassette

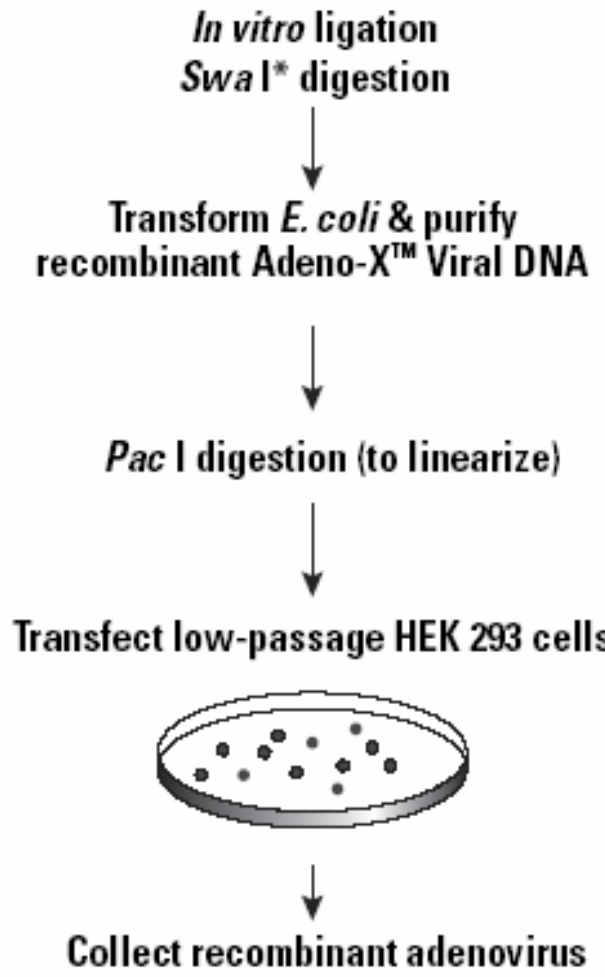

10-14 days

Abb. 7.4: Schematische Darstellung der rekombinanten Adenovirusproduktion mit dem Adeno- $X^{\mathrm{TM}}$ System der Fa. Clontech. 


\section{$\underline{7.2 \text { Abbildungsverzeichnis }}$}

Abb. 1: CD4+ T-Zellen als Regulatoren der Anti-Tumor-Immunität.

Abb. 4.1: Nachweis von SVN-mRNA mittels RT-PCR.

Abb. 4.2: Nachweis von PR3-mRNA mittels RT-PCR.

Abb. 4.3: Exemplarische Darstellung eines Western Blot durchgeführt mit einem monoklonalen SVN-Antikörper.

Abb. 4.4: : Exemplarische Darstellung eines Western Blot durchgeführt mit einem monoklonalen PR3-Antikörper.

Abb. 4.5 Wesentliche Schritte für die Herstellung eines Adenovirus (Ad5/F35).

Abb. 4.5A: Nachweis der Ligation und Klonierung des chimären Gens in pcDNA3.1.

Abb. 4.5B: Nachweis der Ligation und Klonierung des chimären Gens in pShuttle.

Abb. 4.5C: Restriktionsanalyse der viralen Vektor-DNA (Ad5/F35).

Abb. 4.6: Nachweis der PR3-LAMP-1-Expression nach Transduktion des Virus in verschiedene Zielzellen mittels Western Blot.

Abb. 4.7: Adenovirale Transduktion von humanen DC mit Ad5/F35 GFP. 
Abb. 4.8: Exemplarische Darstellung der proliferativen T-Zellantwort auf verschiedene Peptide.

Abb. 4.9: Spezifität und MHC-Restriktionsmuster der T-Zellantworten gegen die Peptide $S_{10}, S_{40}, S_{88}, P_{58}, P_{216}, P_{235}$ und $P_{239}$.

Abb. 4.10: FACS Analysen der peptidspezifischen T-Zellklone.

Abb. 4.11: Peptid:MHC/TCR-Avidität verschiedener T-Zellklone.

Abb. 4.12: Erkennung von rekombinantem Protein durch $\mathrm{S}_{10}$-spezifische T-Zellklone (exemplarisch Klon Gö11-3/4-S 10.4 ).

Abb. 4.13: Erkennung von tumorzelllysat-gepulsten DC von verschiedenen SVN-positiven Tumorzelllinien durch $\mathrm{S}_{10}$-spezifische T-Zellklone.

Abb. 4.14: Proliferative T-Zellantwort verschiedener Tumorpatienten auf das $\mathrm{S}_{10}$-Peptid.

Abb. 4.15: FACS-Analysen der Oberflächenmarker CD25 und GITR.

Abb. 4.16: RT-PCR des Transkriptionsfaktors FoxP3.

Abb. 4.17: ELISA Zytokinprofil $\mathrm{T}_{\text {reg-Zellen. }}$

Abb. 7.1: Plasmidkarte und MCS (",multiple cloning site“) von pcDNA3.1.

Abb. 7.2: Plasmidkarte und MCS („multiple cloning site“) von pShuttle.

Abb. 7.3: Plasmidkarte von Adeno-X. 
Abb. 7.4: Schematische Darstellung der rekombinanten Adenovirusproduktion mit dem Adeno- $X^{\mathrm{TM}}$ System der Fa. Clontech.

Tabelle 4. 1a: Expression von SVN bzw. PR3 in Tumorzelllinien.

Tabelle 4. 1b: Expression von SVN bzw. PR3 in PBMC und DC.

Tabelle 4.2: Titer der Viruspräparation.

Tabelle 4.3: Bezeichnungen, AS-Positionen und AS-Sequenzen der synthetischen SVN- bzw. PR3-Peptide.

Tabelle 4.4: Halbmaximale Proliferationsaktivität der peptidspezifischen T-Zellklone. 


\section{Danksagungen:}

Besonders herzlich bedanken möchte ich mich bei Herrn PD Dr. med. Roland Schroers. Unter seiner optimalen wissenschaftlichen Leitung durfte ich in den letzten drei Jahren meine Doktorarbeit am Uniklinkum Göttingen anfertigen. Während dieser Zeit hatte ich stets seine vollste Unterstützung.

Mein Dank gilt auch Herrn Prof. Dr. Rüdiger Hardeland vom Lehrstuhl für Stoffwechselphysiologie der Georg-August Universität Göttingen für die Übernahme und Hilfe bei meiner Doktorarbeit. Seine Bereitschaft, diese Arbeit zu betreuen, hat mir die Möglichkeit gegeben diese Arbeit außerhalb des Fachbereichs durchzuführen.

Herrn Prof. Dr. med Kurt von Figura, Lehrstuhl für Biochemie II der Georg-August Universität Göttingen, danke ich für die Übernahme der Zweitbegutachtung.

Herrn Professor Dr. med Lorenz Trümper danke ich für die Möglichkeit, diese Arbeit in der Abteilung Hämatologie und Onkologie anzufertigen. 
Ein ganz besonderer Dank gilt den Kollegen meiner Arbeitsgruppe. Herrn York Hildebrandt danke ich für die hervorragende Einarbeitung in dieses Thema und die jederzeit tatkräftige Hilfe bei den Versuchen. Ein großes Danke schön auch an Frau Sabrina Becker, die immer ein fröhliches und konstruktives Arbeitsklima im Labor geschaffen hat, in dem es viel Spaß gemacht hat zu arbeiten.

Ein herzliches Danke schön auch an Frau Silke Straßenburg aus der Abteilung Neuropathologie, die mir sehr bei den ELISAs geholfen hat und Tobias Wommelsdorf für die Unterstützung bei den ELISPOTs. Ebenso möchte ich mich bei allen übrigen Mitarbeitern der Abteilung Hämatologie und Onkologie für ihre Unterstützung und das freundliche Arbeitsklima bedanken.

Meinen Studienkollegen und Freunden danke ich für die schöne Zeit und dass sie für den nötigen Abstand zur Relativierung der wissenschaftlichen Hochs und Tiefs sorgten. Die Stunden mit euch sind unvergessen.

Mein größter Dank gilt meinen Eltern und Geschwistern, die mich immer bestärkt haben, in dem was ich tun wollte und die mich immer mit allen Mitteln unterstützt haben. Ohne Eure Hilfe wäre dies so nicht möglich gewesen. Es war und ist ein gutes Gefühl, mich auf Euer Vertrauen verlassen zu können. 


\section{Eidesstattliche Erklärung:}

Hiermit versichere ich, die vorliegende Arbeit selbstständig angefertigt und vorher nicht an anderer Stelle eingereicht zu haben. Es wurden keine anderen als die hier aufgeführten Hilfsmittel verwendet.

Göttingen, den 26. Mai 2006 


\section{Publikationen}

Schroers, R., Hildebrandt, Y., Hasenkamp, J., Glass, B., Lieber, A., Wulf, G., and Piesche, M. (2004). Gene transfer into human T lymphocytes and natural killer cells by Ad5/F35 chimeric adenoviral vectors. Exp. Hematol. 32(6): 536-546.

Prinz, M., Garbe, F., Schmidt, H., Mildner, A., Gutcher, I., Wolter, K., Piesche, M., Schroers, R., Weiss, E., Kirschning, CJ, Rochford, CD, Brück, W., and Becher, B. (2006). Innate immunity mediated by TLR9 modulates pathogenicity in an animal model of multiple sclerosis. J. Clin. Invest. 116(2): 456-464.

Piesche, M., Hildebrandt, Y., Becker, S., Schmitz M., Wulf, G., Trümper, L., and Schroers, R. Survivin-Specific CD4+ T-Cell Responses Induced by MHC Class II-Restricted Epitopes. submitted

Wolff, S., Stoeter, M., Piesche, M., Henne-Bruns, D., Banting, G., and Knippschild, U. Casein kinase 1 delta $(\mathrm{CK} 1 \delta)$ interacts with the SNARE associated protein snapin. submitted 


\section{Wissenschaftliche Präsentationen}

Juli 2004: Vortrag und zweiter Chairman auf dem EACR in Innsbruck, Österreich: „Gene transfer into human T lymphocytes and natural killer cells by Ad5/F35 chimeric adenoviral vectors."

Oktober 2005: Posterpräsentation auf der DGHO in Hannover, Deutschland: "Survivin-specific CD4+ T-helper responses induced by MHC class II-restricted epitopes." 


\section{Lebenslauf}

\section{Allgemeine Angaben:}

Name:

Geburtsdatum/-ort:

Staatsangehörigkeit:

Familienstand:

Anschrift:

\section{Schulausbildung:}

$1982-1986$

$1986-1992$

$1992-1996$

\section{Zivildienst:}

$1996-1997$

\section{Studium:}

$1997-2002$

$2001-2002$

14. November 2002 $2003-2006$

06. Juli 2006
Matthias Georg Piesche

26. Mai 1976 in Bautzen

deutsch

ledig

Erlenweg 7

37077 Göttingen

matthiaspiesche@compuserve.de

Katholische Grundschule Eichelstraße, Bensberg

Johannes Gutenberg Realschule, Bensberg

Gymnasium Herkenrath, Herkenrath

mobile Krankenpflege beim Arbeiter-Samariter-Bund, Bergisch Gladbach

Biologie an der Rheinischen Friedrich-WilhelmsUniversität, Bonn

Diplomarbeit in der Arbeitsgruppe von PD Dr. Uwe Knippschild, Abteilung Tumorvirologie am HeinrichPette-Institut für Experimentelle Virologie und Immunologie an der Universität Hamburg

„Charakterisierung der Wechselwirkungen der Stressinduzierten Proteinkinase Casein Kinase 1 delta $(\mathrm{CK} 1 \delta)$ mit zellulären Proteinen."

Diplom in Biologie

Doktorarbeit in der Arbeitsgruppe von PD Dr. med. Roland Schroers, Abteilung Hämatologie und Onkologie am Uniklinikum Göttingen, Georg-August-Universität Göttingen

„Identifikation und immunologische Charakterisierung von MHC-Klasse-II-Peptidepitopen in humanen Leukämie- und Lymphom-assoziierten Antigenen."

Rigorosum im Fachbereich Biologie an der Georg-AugustUniversität Göttingen 